IDENTIFICATION AND CHARACTERIZATION OF M CELLS IN THE MAMMALIAN CONJUNCTIVA

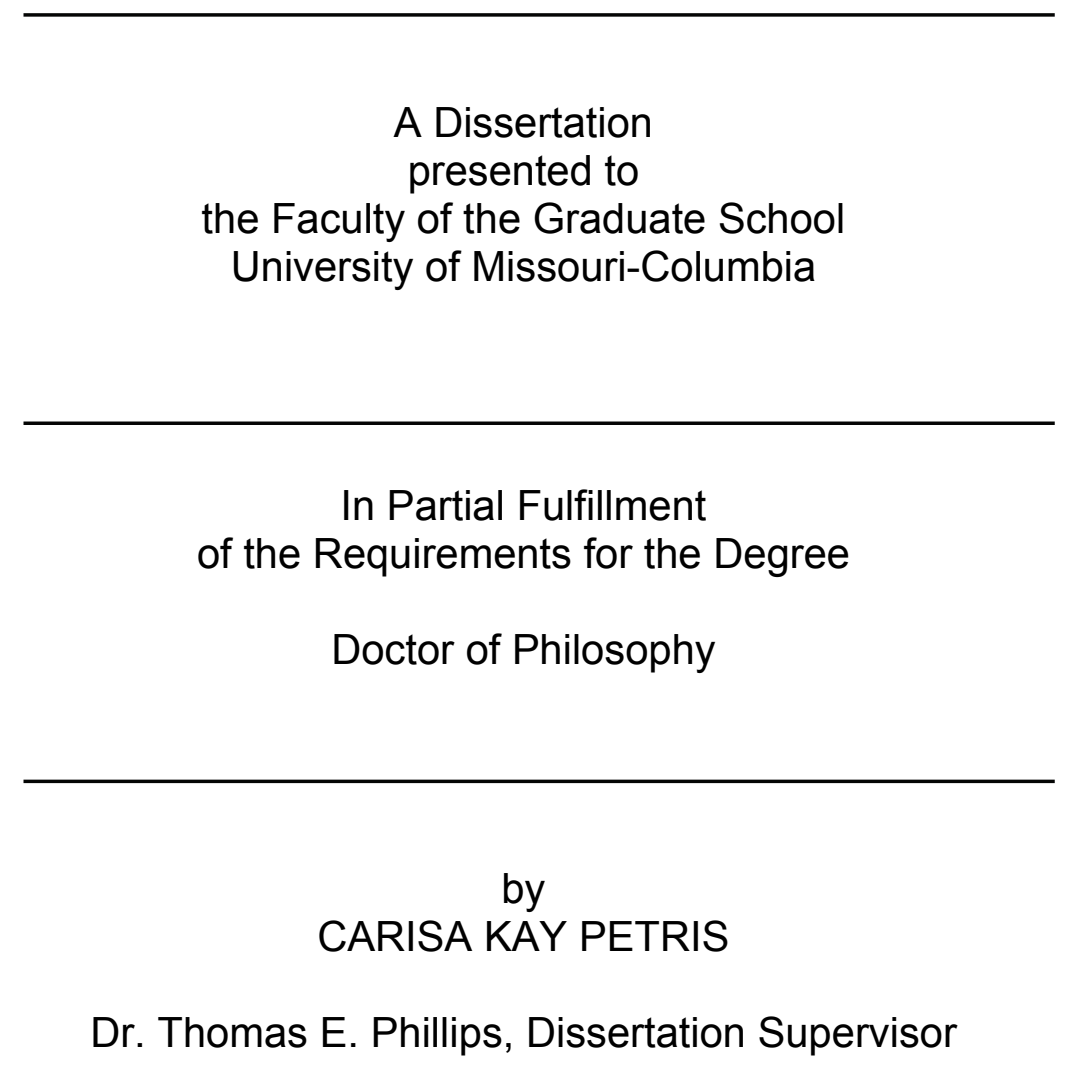

AUGUST 2007 
The undersigned, appointed by the dean of the Graduate School, have examined the dissertation entitled

\section{IDENTIFICATION AND CHARACTERIZATION OF M CELLS IN THE MAMMALIAN CONJUNCTIVA}

presented by Carisa Kay Petris, a candidate for the degree of doctor of philosophy, and hereby certify that, in their opinion, it is worthy of acceptance.

Professor Thomas Phillips

Professor Joel Maruniak

Professor Cecil Moore

Professor Steven Nothwehr

Professor Per Stromhaug

Professor Miriam Golomb 
To my grandma, whom I hope to be like in every way.

To my mother, the most nurturing and loving mom ever.

To my father, who is more clever than MacGyver, thanks for always reminding me that "a mind is a terrible thing to waste."

To my sister, for whom I always try to set a good example.

And finally, to the love of my life, my hubby Mick. 


\section{ACKNOWLEDGEMENTS}

I would like to thank the following people who, in their own individual way, helped me throughout my studies.

First and foremost, I would like to thank my advisor, Dr. Tom Phillips. Thank you for introducing me to the beauty of science behind the microscope. My experiences in your histology class and in the lab as a graduate student have shaped the way I think about science and will likely influence my future in medicine. I am truly grateful to have trained under your guidance. Thank you for your patience and support throughout my Ph.D.

I would like to thank Dr. Miriam Golomb, whose expertise in Haemophilus influenzae made her an important collaborator during my final studies. I really appreciated both your professional and personal support.

To Dr. Cecil Moore, a specialist in veterinary ocular surgery, whose collaboration at the beginning of my studies was essential for the project. Thank you for teaching me the intricacies of performing an ocular exenteration and for your encouragement throughout my studies.

Thank you to Dr. Hongshan Liu who was a great lab mate; you were greatly missed after leaving the lab. Thank you for all of your support in the lab and for your assistance with surgeries on experiment days.

To past members of the Phillips lab: Dr. Hongshan Liu, C.J. Hayes, Ryan Hunsel, Kelly Malan Eimer, Kay Rodgers, and Dr. Charlette Cain. Thank you for your friendship and all the good times we shared in the lab. 
To members of my committee, Drs. Thomas Phillips, Miriam Golomb, Steven Nothwehr, Joel Maruniak, Cecil Moore, and Per Stromhaug, thank you for your advice throughout my Ph.D. studies.

I would like to thank members of the EM core, Cheryl Jensen, Randy Tindall, and Lou Ross. Thank you for your training and for all of the laughs. I would have never known how much fun electron microscopy and ultrathin cryosectioning could be without your help.

I would also like to thank the members of the Molecular Cytology Core Facility, Shiv, Cameron, and Brady, who share my love for microscopy. Thank you for always being so accommodating to my crazy schedule when I needed to use the core late at night or on the weekends.

Thank you also to staff in Biological Sciences who were always so helpful and cheerful to work with, including Nila Emerich, Tyeece Little, Johnette Blair, Alan Marshall and Matt Nevels.

Thank you to my good friends Crystal, Amy, and Sidney for always being there for me and keeping me in touch with reality.

To my mom and dad, thanks for the genes, and for your understanding when long hours in the lab kept me from family functions. Thank you for your support of all of my endeavors and for fostering my early interest in science. I know that all of my successes in life are as a result of your encouragement to always do my best. And to my little sister, Anna, thanks for being a great sister and supportive friend. I love you guys! 
And finally to my husband, Mick, who has gone through the Ph.D. process himself - I'm sorry you had to go through it again! Your support and insight have been tremendous. Thank you for your love, encouragement, and friendship.

These studies were supported by funding from the National Eye Institute Grant EY13779. 


\section{TABLE OF CONTENTS}

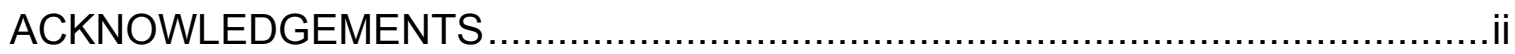

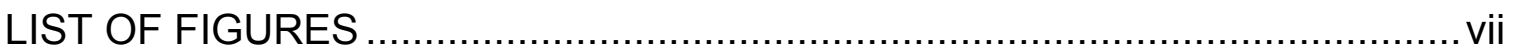

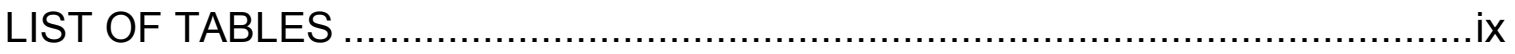

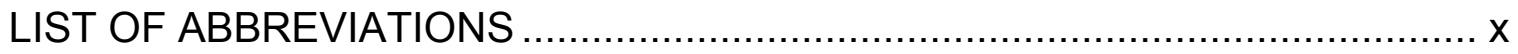

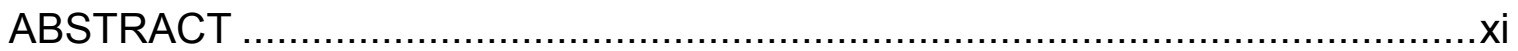

Chapters

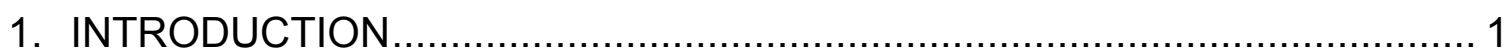

1.1. Mucosa-associated lymphoid tissue

1.2. The ocular surface

1.3. Conjunctiva-associated lymphoid tissue

1.4. $\mathrm{M}$ cells

2. LECTIN AND ANTIBODY STAINING IN VITRO

2.1. Abstract

2.2. Introduction

2.3. Methods and Materials

2.4. Results

2.5. Figures

2.6. Discussion

3. MAL-I UPTAKE STUDIES IN VIVO

3.1. Abstract

3.2. Introduction

3.3. Methods and Materials

3.4. Results

3.5. Figures

3.6. Discussion

4. HAEMOPHILUS INFLUENZAE UPTAKE IN VIVO

4.1. Abstract

4.2. Introduction

4.3. Methods and Materials 
4.4. Results

4.5. Figures

4.6. Discussion

5. SUMMARY AND FUTURE DIRECTIONS ............................................. 115

5.1. Summary

5.2. Future Directions

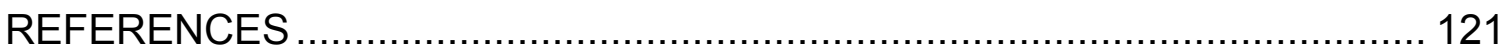

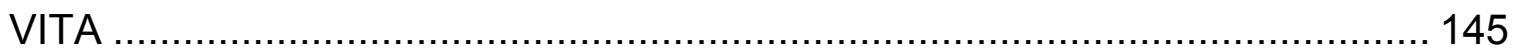




\section{LIST OF FIGURES}

Figure

Page

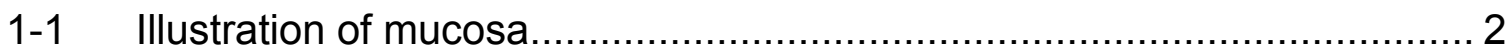

1-2 Illustration of mucosa in regions of organized lymphoid tissue ............... 4

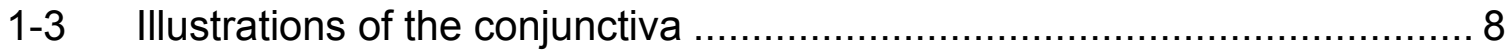

1-4 Diagram of and the epithelial surface and tear film .......................... 12

1-5 Illustration of $\mathrm{M}$ cell mediated transcytosis ................................... 23

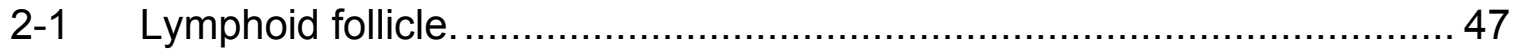

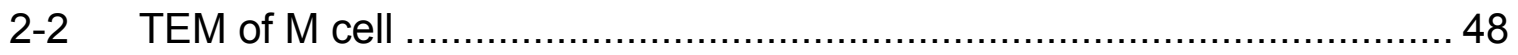

2-3 MAL-I staining of conjunctival FAE and non-FAE ............................ 49

2-4 MAL-II staining of conjunctival FAE and non-FAE ........................... 50

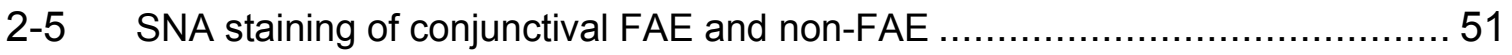

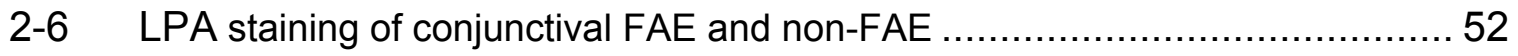

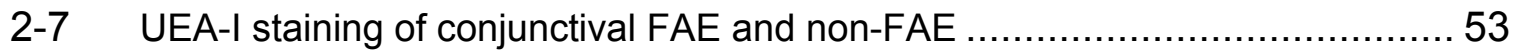

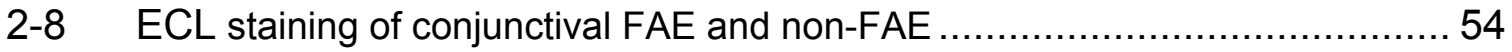

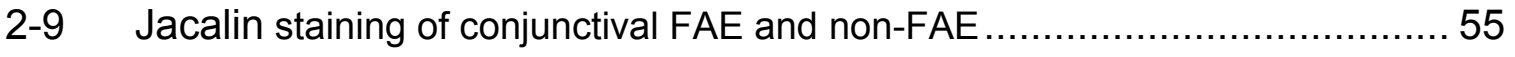

2-10 VVA staining of conjunctival FAE and non-FAE ............................. 56

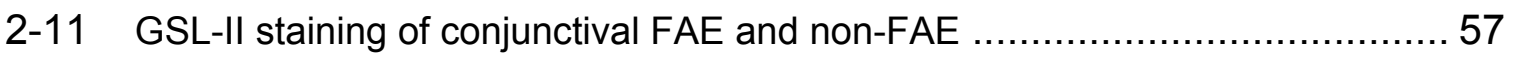

2-12 DSL staining of conjunctival FAE and non-FAE .............................. 58

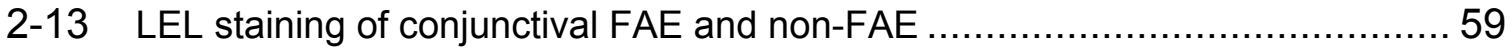

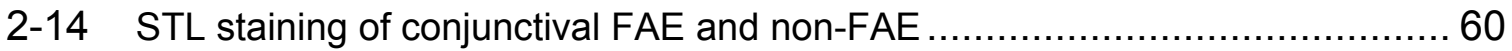

2-15 MAL-I and MAL-II selective labeling of the apical surface of Guinea pig conjunctival FAE.

2-16 Neuraminidase pre-treatment abolished MAL-I binding to the apical surface of conjunctival FAE sections 
3-1 Conjunctival whole mount staining after a $60 \mathrm{~min}$ in vivo exposure to MAL-

I-fluorescein.

3-2 Conjunctival whole mount staining after a $60 \mathrm{~min}$ in vivo exposure to MALI-fluorescein.

3-3 Preferential adherence of MAL-I to the apical surface of certain conjunctival FAE cells.

3-4 Pseudo-colored BSE image of MAL-I labeled cells. .............................. 79

3-5 MAL-I internalization by conjunctival FAE cells. ................................. 80

3-6 MAL-I transcytosis by a subset of FAE cells....................................... 81

4-1 Visualization of bacteria using Zeiss LSM Image Browser................... 103

4-2 Three alternative displays of a single projected $z$-stack of an FAE region following in vivo incubation with FITC-labeled OM12............................ 104

4-3 Projection views of $3 \times 3$ concatenated montage stacks ..................... 105

4-4 Cross-sectional projection views of FAE and non-FAE tissues ............ 106

4-5 Bacterial counts at increasing depth within the FAE ........................ 107

4-6 Preferential adherence of OM12 bacteria to the apical surface of conjunctival FAE cells expressing a(2-3) sialic acid on their surface ..... 108

4-7 Conjunctival $\mathrm{M}$ cell containing a vesicular bound bacterium $61 \mathrm{~min}$ after instillation of OM12 into the inferior conjunctival sac 109 


\section{LIST OF TABLES}

Table

1-1 Species in which M cells have been identified..................................... 24

1-2 Bacteria transcytosed by $\mathrm{M}$ cells ...................................................... 30

1-3 Viruses, Prions, \& Protozoa transcytosed by M cells …....................... 26

1-4 M cell-specific lectins and other markers ........................................... 34

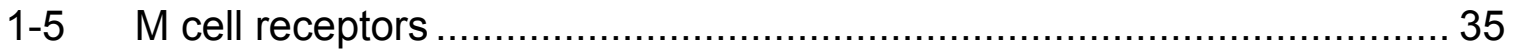

2-1 Lectin panel epitopes and binding specificity to apical membranes of conjunctival epithelial cells............................................................. 46

4-1 Bacterial binding and uptake into fornix FAE and palpebral control regions. 


\section{LIST OF ABBREVIATIONS}

\begin{tabular}{ll} 
APC & Antigen-presenting cell \\
FAE & Follicle-associated epithelium \\
CALT & Conjunctiva-associated lymphoid tissue \\
D-MALT & Diffuse mucosa-associated lymphoid tissue \\
DC & Dendritic cell \\
HEV & High endothelial venule \\
HWB & HEPES wash buffer \\
IEL & Intraepithelial lymphocytes \\
Ig & Immunoglobulin \\
LM & Light microscopy \\
M cell & Membranous or microfold cell \\
MAL-I & Maackia amurensis leukoagglutinin \\
MALT & Mucosa-associated lymphoid tissue \\
NTHi & Nontypeable Haemophilus influenzae \\
O-MALT & Organized mucosa-associated lymphoid tissue \\
PF & Paraformaldehyde \\
PP & Peyer's patches \\
PRR & Pattern recognition receptor \\
SEM & Scanning electron microscopy \\
SlgA & Secretory immunoglobulin A \\
TEM & Transmission electron microscopy \\
TH & Thelper lymphocyte \\
TLR & Toll-like receptor \\
\hline
\end{tabular}




\section{ABSTRACT}

The antigen-sampling $M$ cell is a morphologically and functionally distinct epithelial cell, which is intimately associated with organized lymphoid tissue along mucosal surfaces. At these locations, $M$ cells play a key protective role through inducing adaptive immune responses at mucosal surfaces; however, some opportunistic pathogens exploit the antigen-sampling activity of $\mathrm{M}$ cells to breach the mucosal surface. Two characteristic hallmarks of M cells include a unique morphology and the ability to transcytose material from the mucosal surface to underlying immune cells. M cells have been identified at many mucosal surfaces including the oropharynx, bronchi, and gastrointestinal tract, but the presence of $\mathrm{M}$ cells in the follicle associated epithelium (FAE) of ocular mucosa has been debated. This dissertation examines the hypothesis that the Guinea pig conjunctival FAE contains a unique cell type with the morphological and functional characteristics associated with antigen sampling $M$ cells in other mucosa-associate lymphoid tissue (MALT).

A cell in the conjunctival FAE of the Guinea pig that has the morphological phenotype of $\mathrm{M}$ cells, including an attenuated cytoplasmic bridge filled with numerous membrane-bound vesicles and basolateral membrane pockets encompassing lymphocytes and antigen presenting cells (APCs) was identified using light and transmission electron microscopy (TEM). Scanning electron microscopy (SEM) revealed that these cells had sparse pleomorphic microvilli and microfolds that are characteristic of M cells. When FAE was stained with a 
panel of lectins, the apical surface of a subset of epithelial cells was selectively labeled with the sialyllactose-binding lectin Maackia amurensis leukoagglutinin (MAL-I), providing further support that these cells are distinct from neighboring FAE cells. Next, MAL-I was used to determine whether these cells possessed the quintessential property of $\mathrm{M}$ cell function, transcytosis of macromolecules, and it was found that these cells selectively bound and translocated MAL-I to underlying intraepithelial immune cells in vivo (Meagher et al., 2005). Further evidence defining these cells as conjunctival $M$ cells was their specific translocation of a sialyllactose-binding strain of nontypeable Haemophilus influenzae (NTHi) (Petris et al., 2007). This is the first research to demonstrate M-cell mediated uptake of bacteria across conjunctival epithelium. Similar results were obtained in our lab using latex beads in rabbit FAE (Liu et al., 2005).

Together these results identify and characterize a morphologically distinct and functional $\mathrm{M}$ cell in the mammalian conjunctiva. These findings provide important new insights into ocular mucosal immunity, and identify a potential therapeutic target for modulating the entry of pathogens and delivery of ocular mucosal vaccines. 


\section{Chapter 1. Introduction}

\subsection{Mucosa-associated lymphoid tissue}

Mucosa. Mucosal membranes (or mucosae) are moist surfaces of the body that communicate with the external environment and consist of an epithelium which usually contains mucin-secreting cells, a lamina propria of loose connective tissue, and often a thin layer of smooth muscle (Figure 1-1). Examples of mucosal membranes include the lining of the gastrointestinal tract, respiratory tract, genitourinary tract, and the conjunctiva of the eye.

Mucosal immune protection. The mucosal immune system protects mucosal tissues from environmental antigens and pathogens by innate and adaptive defense mechanisms involving lymphoid tissues and accessory cells in these areas. Mucosa-associated lymphoid tissue (MALT), is the term used to describe the lymphoid tissues along various mucosal surfaces which possess a relatively consistent morphology and share a common function in protecting mucosal surfaces (Bienenstock et al., 1978). MALT comes in two forms: one made of organized lymphoid tissue (organized-MALT) and the other a diffuse arrangement of lymphoid cells located either in the epithelium or within the lamina propria (diffuse-MALT).

Diffuse-MALT. Diffuse-MALT (D-MALT) is composed of T lymphocytes and immunoglobulin-secreting plasma cells scattered diffusely in the epithelium, lamina propria, and interstitium (Figure 1-1). D-MALT is the site of effector 
functions of the mucosal immune system and provides protection by active immune responses, including secretion of soluble immunoglobulins into the lumen and/or by direct action of effector immune cells.

\section{Mucosal surface}

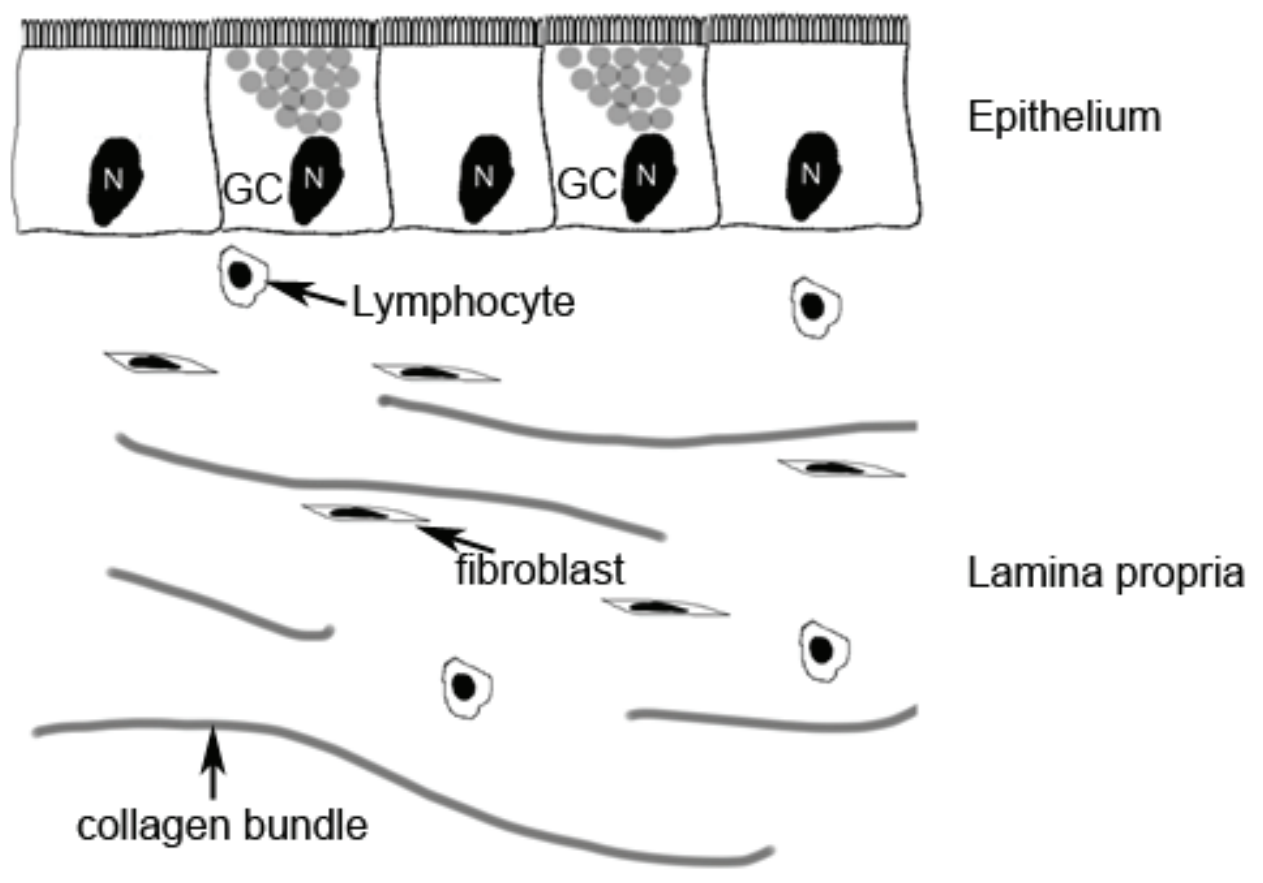

Figure 1-1. Illustration of mucosa. The majority of mucosae are depicted as above. The mucosal epithelium separates the external environment from the underlying lamina propria and often contains the specialized mucus-secreting goblet cell (GC). The lamina propria is a loose connective tissue layer and is depicted here with many of its common constituents. Often a smooth muscle layer is present below the lamina propria which is not shown in this image. This mucosa has effector cells of the mucosal immune system (lymphocytes) and referred to as diffuse mucosa-associated lymphoid tissue. 
Organized-MALT. Organized-MALT (O-MALT) consists of organized lymphoid tissue, in the form of lymphoid follicles (described below), which are in close association with a specialized epithelium (Figure 1-2). O-MALT functions as the inductive arm of the mucosal immune system since it has the innate ability to detect and sample external antigens and pathogens. With the aid of underlying organized lymphoid tissue, antigens and pathogens are processed in such a way that induces an adaptive immune response for future protection which is carried out by diffuse-MALT.

Lymphoid follicles. Lymphoid follicles, a component of O-MALT, consists of a scaffolding of follicular dendritic cells that supports a cluster of naive B lymphocytes with immunoglobulin $M(\lg M)$ and $\lg D$ expressed on their surface. The parafollicular areas surrounding the follicle consist of $T$ helper $\left(T_{H}\right)$ cells. The follicles are also flanked by high endothelial venules (HEVs), which serve as entry sites for migrating lymphoid cells. Above the follicle is a unique epithelium, known as the follicle-associated epithelium (FAE), which tends to lack goblet cells and is distinguished by the presence of specialized antigen-sampling membranous or $M$ cells. $M$ cells are involved in detection and transport of antigens and pathogens, across the epithelial barrier, to organized lymphoid tissue and are integral to the inductive immune function of this tissue. The exact mechanism by which $\mathrm{M}$ cells interact with underlying immune cells is still unknown (Neutra et al., 2001). 


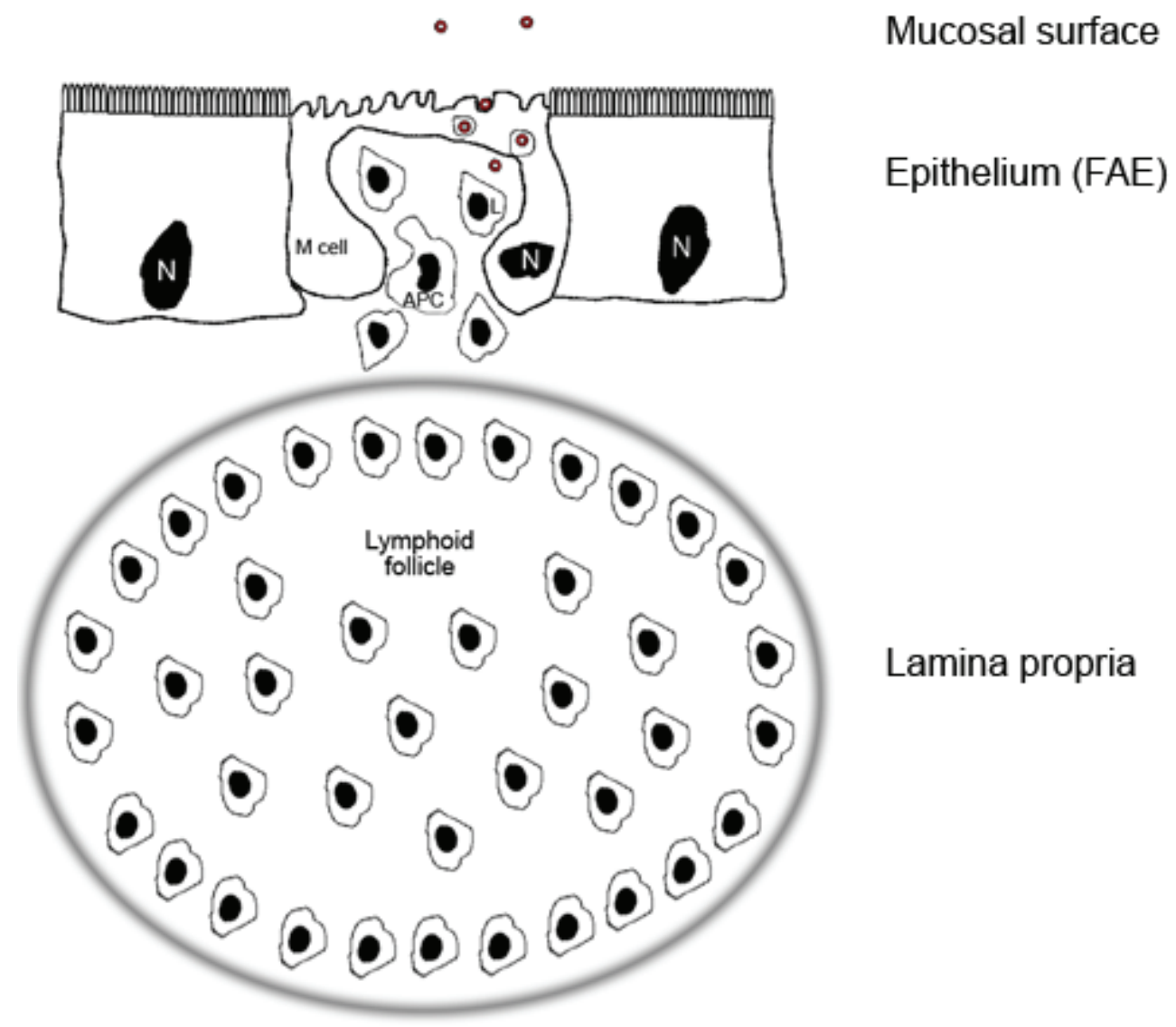

Figure 1-2. Illustration of mucosa in regions of organized lymphoid tissue. Certain regions of the mucosae contain organized lymphoid tissue in the lamina propria, represented here as a solitary lymphoid follicle. The mucosal epithelium separates the external environment from the underlying lymphoid tissue and often contains the specialized antigen-sampling $M$ cell. This region of mucosa has is part of the inductive limb of the mucosal immune system and is referred to as organized mucosa-associated lymphoid tissue. 
In the small intestine, regions of aggregated lymphoid follicles are called Peyer's patches. O-MALT in the Peyer's patches differs slightly from O-MALT in other locations (including the conjunctiva), in that the FAE is separated from the follicle by a subepithelial "dome" region which is rich in T and B lymphocytes and dendritic cells.

MALT in various locations. MALT has been most extensively studied in the intestinal tract where it is termed gut-associated lymphoid tissue (GALT) (Cooper et al., 1966; Bockman et al., 1977), in the bronchi it is referred to as bronchus-associated lymphoid tissue (BALT) (Bienenstock et al., 1973), in the nasal mucosa, nasal-associated lymphoid tissue (NALT) (Spit et al., 1989a), and in the conjunctiva as conjunctival-associated lymphoid tissue (CALT) (Chandler et al., 1980; Knop et al., 2000; Giuliano et al., 2002). More recently MALT has been described in the salivary glands as duct-associated lymphoid tissue (DALT) (Nair et al., 1986), and larynx as larynx-associated lymphoid tissue (LALT) (Kracke et al., 1997), and in the lacrimal drainage system (LDALT) (Knop et al., 2001) of the eye.

Common mucosal immune system. The general concept of a common mucosal immune system stems from the observation that following immunization at one mucosal location, immune cells migrate to other mucosal sites where they provide protection against the immunizing antigen. Many studies have demonstrated the commonality of the mucosal immune system following oral immunization by the detection of specific IgA antibody sections in saliva, tears, 
female reproductive tract and mammary secretions (Mestecky et al., 1978;

McDermott et al., 1979; Weisz-Carrington et al., 1979; McDermott et al., 1980;

Montgomery et al., 1984; Mestecky, 1987).

\subsection{The ocular surface}

$\underline{\text { Anatomy }}$

The ocular surface consists of the cornea and the conjunctiva. The conjunctiva has inferior and superior halves that are mirror images of each other, and which line the inner surfaces of the eyelids (palpebral conjunctiva) and reflect back at the fornices (forniceal conjunctiva) to cover the anterior surface of the orbit (bulbar conjunctiva) (Figure 1-3).

Palpebral conjunctiva. While the conjunctiva is often divided into the palpebral, fornix, and bulbar regions, the palpebral region may be further divided into the marginal, tarsal and orbital zones (see Figure 1-3). The marginal zone is a mucocutaneous transition zone between skin and conjunctiva proper which begins at the subtarsal fold and continues on the back of the lid for $\sim 2 \mathrm{~mm}$. Two lacrimal puncta open nasally on to the marginal portion of the conjunctiva, one superiorly and one inferiorly near the medial canthus. This results in a continuous epithelial connection from the conjunctiva to the lacrimal drainage system that leads to the nose. This is the route by which disease may spread from the conjunctival sac to the nose and vice versa. The tarsal conjunctiva is a thin, wellvascularized region that readily adheres to the tarsus, a fibrous connective tissue 
plate. Its vascularity gives it a reddish color and it is examined for paleness in suspected cases of anemia. Lastly, the orbital zone lies between the superior and inferior borders of the tarsal plate and the fornix. It loosely adheres to underlying nonstriated muscle and its surface forms horizontal folds which are deepest when eyes are wide-open and shallowest when eyes are shut.

Conjunctival fornix. The forniceal conjunctiva is a cul-de-sac which adheres to underlying loose fibrous tissue (and contains conjunctival glands of Krause and nonstriated muscle of Muller). For descriptive purposes, the fornix is often divided into superior, inferior, lateral and medial regions.

Bulbar Conjunctiva. The bulbar region, which covers the bulb of the eye until it meets the limbus, loosely adheres to the sclera by subconjunctival connective tissue. The bulbar conjunctiva is thin and translucent so that the sclera is easily seen through it; hence the phrase "the white of the eyes." The point at which the bulbar conjunctiva joins the cornea is referred to as the limbus.

Conjunctival sac. The conjunctiva inserts on the globe at the cornealscleral limbus with the eyelids closed, and extends from the globe to the eyelid margins (Figure 1-3). 


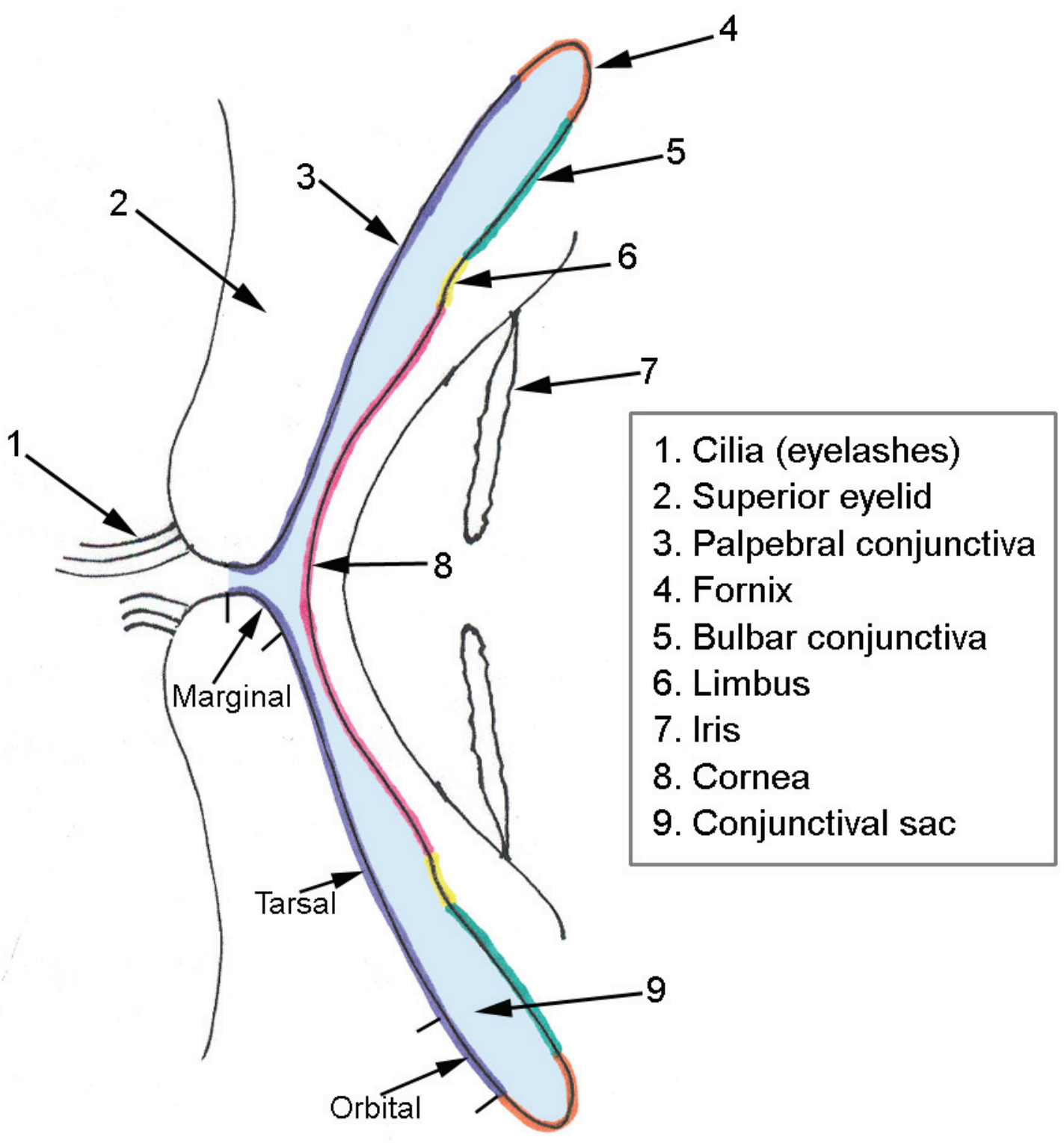

Figure 1-3. Illustration of the superior and inferior conjunctiva. Image is color-coded as follows: conjunctival sac is light blue; palpebral conjunctival is purple; fornix is orange; bulbar conjunctiva is green; limbus is yellow; and cornea is pink. 


\section{Protection of the ocular surface}

The ocular surface has multiple factors which prevent infection of the outer eye (reviewed in McClellan, 1997). The continuous epithelium of the conjunctiva and cornea serves as a physical barrier against infection. The act of blinking also protects the ocular surface through mechanical flushing of foreign material and cellular debris toward the lacrimal puncta. The tear film imparts protection to the ocular surface in several different ways which are attributed to its antimicrobial proteins (discussed below). Normal bacterial flora may confer protection to the ocular surface through inhibitory effects on pathogenic bacteria species. Finally, the underlying lamina propria, which is richly vascularized, provides antibodies, complement, and leukocytes needed for immune responses. These anatomical, mechanical, immunological, and microbiological phenomena work synergistically to prevent infection of the ocular surface.

\section{$\underline{\text { Tear film }}$}

The tear film is classically described a triple-layered structure consisting of lipid, aqueous, and mucinous layers (Figure 1-4), which creates a smooth refractive surface necessary for normal vision, lubricates the eyelids, transports metabolic products, and clears and protects the ocular surface from noxious stimuli and pathogens (reviewed in Korb et al., 2002). The tear film is thought to be $1.6-7.3 \mu \mathrm{m}$ thick but problems with measuring the tear film have resulted in conflicting results. 
Lipid layer. The outermost layer of the tear film is the lipid layer, which is derived from three glands located in the eyelid. The Meibomian (tarsal) glands which are embedded with collagenous connective tissue under the palpebral (or tarsal) conjunctiva produce the majority of lipid; the other glands include the Zeiss' and Moll's glands which are associated with the eyelashes (Jones, 1973; Bron et al., 1985). The oily, lipid layer slows the evaporation of tears (Mishima et al., 1961) and provides additional protection against droplet infection by causing water droplets to run off the tear film surface (Steuhl, 1989).

Aqueous layer. The middle aqueous layer is derived from the lacrimal glands, which are situated above and anterolateral to the globe of the eye in most mammalian species and secrete on to the conjunctival sac at the upper fornix. In man, accessory glands involved in secretion of the aqueous layer include the glands of Krause and Wolfring. The aqueous layer contains many ions and antimicrobial proteins, such as secretory immunoglobulin $A(\operatorname{sg} A)$, lysozyme, lactoferrin, $\beta$-lysin, and $\beta$-defensins (reviewed in McClellan, 1997; Mclntosh et al., 2005), as well as over 80 other newly identified proteins (Sack et al., 2005). Lysozyme is a bacteriolytic enzyme that has the same site of action as penicillin in the bacterial cell wall (Chipman et al., 1969) and constitutes $40 \%$ of the protein in the tear film. Secretory IgA is produced locally by plasma cells located under the ocular mucosa, and its protective activities include prevention of bacterial attachment, reduction of antigen absorption, and neutralization of toxins and viruses at the ocular surface (reviewed in Russell et al., 2005). Lactoferrin comprises about $25 \%$ of protein in tear fluid (Kijlstra et al., 1983). It 
binds to iron, thereby limiting the availability of this essential nutrient to microorganisms (Arnold et al., 1982). Lactoferrin also enhances NK cell function (Shau et al., 1992; Varadhachary et al., 2004) and prevents formation of active complement components by inhibiting formation of C3 convertase (Kievits et al., 1985); these activities are likely through protein-protein interactions and not as a result of the iron-binding capacity of lactoferrin. $\beta$-lysin is another anti-bacterial protein thought to exist in tears which can lyse bacterial cell walls (Ford et al., 1976). Lastly, $\beta$-defensins are antimicrobial peptides that are eukaryotic analogues of antibiotics. It has recently been demonstrated that many members of the $\beta$-defensin family are made by the ocular surface epithelial cells (Mclntosh et al., 2005).

Mucous layer. Finally, the innermost, mucous layer of the tear film is primarily derived from goblet cells, specialized conjunctival epithelial cells, which produce high-molecular-weight glycoproteins. The crypts of Henle are comprised of infoldings of the conjunctiva consisting of groups of goblet cells. The mucous layer creates a smooth refractive corneal surface by filling in surface irregularities and hinders access of foreign substances to the epithelium. 


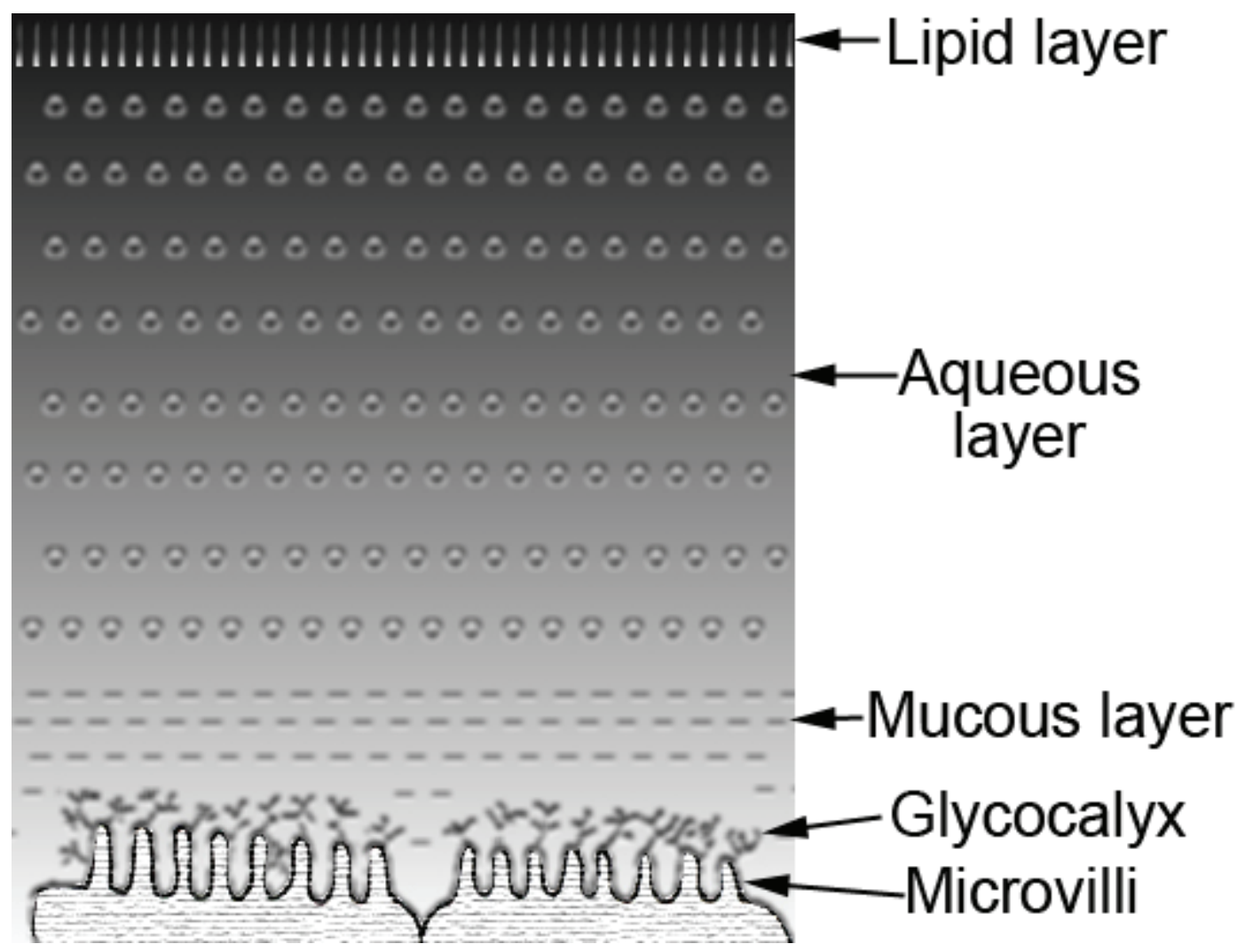

Figure 1-4. Diagram of and the epithelial surface and tear film. The tear film is the protective layer above epithelial cells of the ocular surface, depicted here with microvilli and a glycocalyx. The lipid, aqueous, and mucous layers are present. 


\section{Normal flora of the ocular surface}

Although there has been debate, it is now generally accepted that, under normal conditions, bacteria may be cultured from the conjunctival sac; however, bacterial numbers are often low and no microorganisms are cultured in up to $70 \%$ of healthy subjects. The conjunctiva is most commonly colonized with normal flora of the upper respiratory tract and skin, primarily coagulase-negative staphylococci, Corynebacterium spp (Jensen et al., 1985), and Propionibacterium spp (Perkins et al., 1975; Fleiszig et al., 1992). Other less commonly isolated bacteria include Staphylococcus aureus, Micrococcus spp, Bacillus spp, Bacteroides spp and certain pseudomonads (Perkins et al., 1975; Fleiszig et al., 1992; Thiel et al., 1994). Gram-negative bacteria that are cultured from the eyelid margins and conjunctival sacs of healthy subjects include Haemophilus influenzae, Moraxella spp, and Neisseria meningitidis; Enterobacteriaceae rarely colonizes the normal conjunctival sac, but does so more commonly in the elderly (reviewed in McClellan, 1997).

\section{Conjunctival Epithelium}

The conjunctiva consists of two layers, the epithelium and the lamina propria. The human and Guinea pig conjunctival epithelium is classified as stratified cuboidal/columnar; the ultrastructure tends to be columnar in the palpebral and fornix areas, cuboidal in the bulbar regions, and squamous over lymphoid follicles and at the lid margin (Takskusaki, 1969; Latkovic, 1979b; Latkovic, 1979a). 
Apical surface specializations. The apical surface of the conjunctival epithelial cells has a regular carpeting of microvilli which are longest on the columnar cells of the fornix $(\sim 300 \mathrm{~nm})$ and shorter on those of the bulbar epithelium (Nichols et al., 1983). The regularity of microvilli across the conjunctival surface is disrupted in the FAE by M cells. Studies of the Guinea pig conjunctiva demonstrate that $\mathrm{M}$ cells possess a more irregular apical border composed of fewer microvilli that branch and vary in length (Meagher et al., 2005). The conjunctival epithelium also has an even coating of glycocalyx which radiates outward from each microvillus to a length of $300 \mathrm{~nm}$ (Nichols et al., 1983).

Goblet cells and the mucous layer. The goblet cell-derived mucous layer of the tear film forms a smooth and continuous sheet from the conjunctiva to the cornea (Nichols et al., 1985) and is thought to be tethered to the ocular surface by the glycocalyx (Holly et al., 1977). The distribution of goblet cells in the conjunctiva varies among species (Setzer et al., 1987). In the Guinea pig, goblet cells are found throughout the conjunctival epithelium except near the lid margin, limbus, and within the FAE (Nichols et al., 1983). The relative concentration of goblet cells is greatest at the fornix region of Guinea pig (Setzer et al., 1987; Nichols, 1996).

\section{Lamina propria}

The second major layer of the conjunctiva is the subepithelial, loose connective tissue layer called the lamina propria or substantia propria. The 
lamina propria is a well-vascularized, loose connective tissue predominantly populated by T cells, plasma cells, macrophages, and fibroblasts (Nichols, 1996; Knop et al., 2000), as well as Langerhans cells (Gillette et al., 1982), neutrophils (Allansmith et al., 1978), mast cells, eosinophils (Stock et al., 1989), and NK cells (reviewed in Hingorani et al., 1997). A detailed account of the lymphocyte subtypes found in the lamina propria is discussed in Section 1.3.

Most of the human conjunctival lamina propria contains diffusely scattered lymphoid cells (Allansmith et al., 1978; Knop et al., 1996) with distinct areas of organized lymphoid follicles. While each of the three regions of the conjunctiva (bulbar, palpebral, and forniceal) may contain lymphoid follicles, they are found most often in the fornices of the Guinea pig (Dwyer et al., 1983; Meagher et al., 2005) and the palpebral conjunctiva in the human (Knop et al., 2000). The number of lymphoid follicles increases in humans from birth until age 10 where over 30 follicles may be found per conjunctival sac (Osterlind, 1944). This is followed by a slow decline with increasing age (Osterlind, 1944) with approximately $60 \%$ of individuals having an average of 10 follicles per conjunctival sac in their mid-70's (Knop et al., 2000).

Unlike the conjunctiva of rat and mouse which do not normally contain lymphoid follicles and have very little diffuse lymphoid tissue (McMaster et al., 1967; Chodosh et al., 1998a), the healthy Guinea pig conjunctiva contains abundant lymphoid tissue and is overall very similar in structure to the human conjunctiva (Setzer et al., 1987; Nichols, 1996). For these reasons, the Guinea 
pig is an appropriate comparative model to study ocular mucosal immune responses.

\subsection{Conjunctiva-associated lymphoid tissue (CALT)}

\section{Cellular components and tissue characteristics of CALT}

Conjunctiva-associated lymphoid tissue consisting of solitary or clustered lymphoid follicles has been described in many species: humans, Guinea pigs, rabbits, ferrets, cats, dogs, pigs, sheep, cows, rhesus monkeys, baboons, owl monkeys, bush baby monkeys, rabbits (Axelrod et al., 1979; Chodosh et al., 1998b), turkeys (Fix et al., 1989), and goats (Asti et al., 2000). The FAE in these species typically lack goblet cells but, thus far, studies have only unequivocally demonstrated M cells in the FAE of Guinea pigs (Meagher et al., 2005) and rabbits (Liu et al., 2005). Earlier studies in the Phillips lab also found morphologic evidence of $\mathrm{M}$ cells in the dog conjunctiva. A bacterium was observed in an epithelial cell within the FAE which suggested that M cells may be mediating the uptake of bacteria in the conjunctiva. Unlike our more recent studies, this study was limited to morphologic observations since the TEM approach precluded a quantitative analysis comparing uptake in FAE and nonFAE regions (Giuliano et al., 2002).

CALT FAE, like FAE at other MALT locations, is not involved in the transcytosis of immunoglobulins into the lumen since it does not express the polymeric Ig receptor (Knop et al., 2000). Rather, it is thought that M cells of the 
ocular mucosa may function similarly to those in the Peyer's patches of mice, rabbits, and humans which have been shown to translocate slgA immune complexes from the luminal surface (Roy et al., 1987; Weltzin et al., 1989) in order to induce mucosal immune responses in O-MALT (Neutra et al., 2001). High endothelial venules, which facilitate lymphocyte trafficking, are present surrounding lymphoid follicles in the CALT. Vascular adhesion protein-1 (VAP-1) is one of the vascular addressin/adhesion molecules found on HEVs and is involved with lymphocyte homing to the human CALT (Haynes et al., 1999).

Studies which suggest that CALT is part of the common mucosal immune system demonstrate that lacrimal gland-derived slgA is produced in tears after vaccination of the gut or respiratory tract (Taylor et al., 1985), as well as nasal, oral, and gastric immunization (Mestecky et al., 1978; Nichols et al., 1978; Montgomery et al., 1984; Peppard et al., 1988; Carr et al., 1996; reviewed in Sullivan, 1999). One study which demonstrates that the conjunctiva is an inductive site of the common mucosal immune system was performed by Hall and Pribnow (Hall et al., 1981). In this study, protein antigens were exposed to the rabbit conjunctiva, and antibodies against the protein antigen were subsequently detected in the conjunctiva and other tissues of the body.

Diffuse-MALT is found extending from the lacrimal gland across the conjunctiva to the lacrimal drainage system, whereas organized-MALT is located in distinct packets of lymphoid follicles along the whole lacrimal drainage system (LDALT) (Knop et al., 2002b). Knop \& Knop have demonstrated that the CALT 
and LDALT work together as a functional MALT to protect the ocular surface and can be considered a unified "eye-associated lymphoid tissue" (EALT).

The non-follicular, diffuse-CALT (D-CALT) consists of a variety of lymphoid cells and is prevalent throughout the lacrimal glands, the conjunctiva, and the lacrimal drainage system and consists of a variety of lymphoid cells. The intraepithelial lymphocytes (IELs) of the D-CALT are mostly CD8 ${ }^{+}$ suppressor/cytotoxic T cells, while the lamina propria is populated by equal numbers of $C D 4^{+} T_{H}$ cells and $C D 8^{+}$suppressor/cytotoxic $T$ cells (Sacks et al., 1986). The plasma cells in the D-CALT mostly express IgA, while a minority expresses IgM (Knop et al., 2001). The overlying epithelium strongly expresses the IgA and IgM transporter molecule, polymeric Ig receptor, which is sometimes referred to by its extracellular portion, secretory component (SC) (Knop et al., 2001).

\section{Mucosal immunological responses}

The CALT must maintain the integrity of the ocular surface by destroying invading pathogens while promoting tolerance pathways of the adaptive immune system. Organized lymphoid follicles are the site for antigen transfer into the tissue for antigen presentation and lymphocyte activation and proliferation (Neutra et al., 2001). Many researchers postulated that transfer of antigens into the ocular mucosa would occur via M cells if they did exist in the conjunctiva but, prior to the current studies, no demonstration of functional $\mathrm{M}$ cells had succeeded (Chodosh et al., 1998b; Dua et al., 1994; Gebert \& Pabst, 1999; 
Giuliano et al., 2002; Knop \& Knop, 2000; Latkovic, 1989). Once an antigen enters the lymphoid tissue, the immune cells initiate an active immune response or induce tolerance to the antigen. M cells may play a role in determining the appropriate immune response since they control the amount of antigen to be transported to the underlying lymphoid tissue (reviewed in Neutra et al., 2001). For example, pathogenic antigens and bacteria which strongly adhere to the surface of the $\mathrm{M}$ cell will be translocated in much greater quantities than nonpathogenic materials taken up by fluid-phase transport (Neutra et al., 1987). Antigen presenting cells, like dendritic cells, can process these translocated materials and present them to $\mathrm{T}$ cells. During antigen presentation, costimulation is required for T cell activation otherwise, anergy of the reactive $\mathrm{T}$ cells results; anergy, as well as, deletion and production of immunosuppressive regulatory $\mathrm{T}$ cells results in non-reactivity, i.e. immune tolerance. The cytokines present during costimulation can influence the activation of $\mathrm{T}_{\mathrm{H}}$ cells which then subsequently produce different cytokine profiles and different immune reactions. For example, costimulation in the presence of IL-4 results in a $T_{H} 2$-predominant reaction which supports the differentiation of antibody-producing plasma cells that can produce anti-inflammatory IgA. Deregulation of this pathway can occur and the default IgA response may be switched to an allergic IgE response (Calder et al., 2004). When costimulation occurs in the presence of IL-12, $T_{H} 1$ predominant reactions are generated. $T_{H} 1$ cells produce the inflammatory cytokines IFN- $\gamma$ which creates an inflammatory immune response that may be harmful to the ocular surface (Iwasaki et al., 1999; Knop et al., 2007). 
Active immune response. An active immune response may occur in different ways. While little is known about the fate of transported materials by $M$ cells, there are many proposed possibilities. In one scenario, immature dendritic cells endocytose the antigen and travel to the local draining lymph node or to the adjacent interfolliclular T cell zone where it presents the antigen and activates naive $T$ cells (Brandtzaeg et al., 1999). Activated $T_{H}$ cells migrate to the parafollicular zone of a primary follicle and activate a naive B cell presenting the same antigen. The activated B cell migrates to the center of the follicle and begins to proliferate and differentiate and a germinal center is formed. Thus, the primary lymphoid follicle is transformed into a secondary lymphoid follicle. Memory B cells and antibody secreting plasma cells are generated and migrate to local and distant lymphoid tissues. Plasma cell migration is the result of active immunity and protects mucosal surfaces through the amplified secretion of immunoglobulins. Alternatively, an active immune response may occur when dendritic cells present newly endocytosed antigens to memory $B$ cells and $T_{H}$ cells in the intraepithelial pocket (Brandtzaeg et al., 1999). Stimulated memory B cells will then migrate to follicles and begin proliferating and differentiating, mounting a more rapid response which leads to immunoglobulin production.

One of the main functions of the diffuse-CALT (D-CALT) is the production of dimeric IgA by plasma cells and the transcytosis by the epithelial polymeric $\lg$ receptor to create a protective layer of secretory $\lg \mathrm{A}(\mathrm{s} \lg \mathrm{A})$ on the ocular surface (Knop et al., 2002a). The lacrimal gland was viewed as the predominant source of tear slgA (Sullivan et al., 1984), but recently the conjunctiva and lacrimal 
drainage system have been shown to make a major contribution to ocular surface defense by the production of slgA. The D-CALT has also been implicated in the protection of the ocular surface due to the resident $\mathrm{CD} 8^{+}$ suppressor/cytotoxic T cells (Sacks et al., 1986; Hingorani et al., 1997). Intraepithelial $\mathrm{CD}^{+} \mathrm{T}$ cells and lamina propria $\mathrm{T}_{\mathrm{H}}$ cells of the D-CALT express the $\alpha_{E} \beta_{7}$ integrin, human mucosa lymphocyte antigen (HML-1), which directs these lymphocytes to mucosal tissues (Dua et al., 1994; Knop et al., 2001). This is further evidence that CALT is part of the common mucosal immune system.

\section{$1.4 \mathrm{M}$ cells}

\section{Introduction}

The delicate mucosal linings of the ocular surface and the respiratory, gastrointestinal, and urogenital tracts $\left(400 \mathrm{~m}^{2}\right.$ surface area) are continually exposed to antigens and pathogens from the environment and rely on the innate and adaptive immune responses of the mucosal immune system for protection against infection and inflammation. Organized lymphoid tissue is a component of the mucosal immune system which is found at various, discrete locations throughout the mucosae. The epithelium above lymphoid follicles in these regions, called follicle-associated epithelium (FAE), is unique in that it contains the specialized antigen-sampling $\mathrm{M}$ cell, which is involved in inducing the 
adaptive immune system by delivery of antigens to underlying antigen presenting cells and lymphoid tissue.

The term microfold or M cell was coined in 1974 following observations of a cell in the human Peyer's patches with a unique apical morphology. Instead of closely packed, evenly distributed, homogenous microvilli, the $M$ cell had irregular ridges or microfolds which were noted to converge, branch, doubleback, and sometimes end abruptly (Owen et al., 1974a). M cells in other species were subsequently found to have microvilli on their apical surface, and this term was revised to signify "membranous" cells due to the very thin, membrane-like cytoplasmic arm which the $\mathrm{M}$ cell creates between the apical surface and intraepithelial lymphocytes (see Figure 1-5) (Owen, 1977). M cells have been identified in many species (see Table 1-1) and are recognized as an integral part of MALT in the tonsils (Gebert, 1995), bronchus (Gebert et al., 1992), nasal cavities (Giannasca et al., 1997) appendix (Bockman, 1983), colon (Morfitt et al., 1989; Fujimura et al., 1992), cecum (Gebert et al., 1993; Gebert et al., 1995a), and rectum (Liebler et al., 1991). This dissertation, now, provides the first evidence of $\mathrm{M}$ cells in the conjunctiva (Meagher et al., 2005; Petris et al., 2007). 


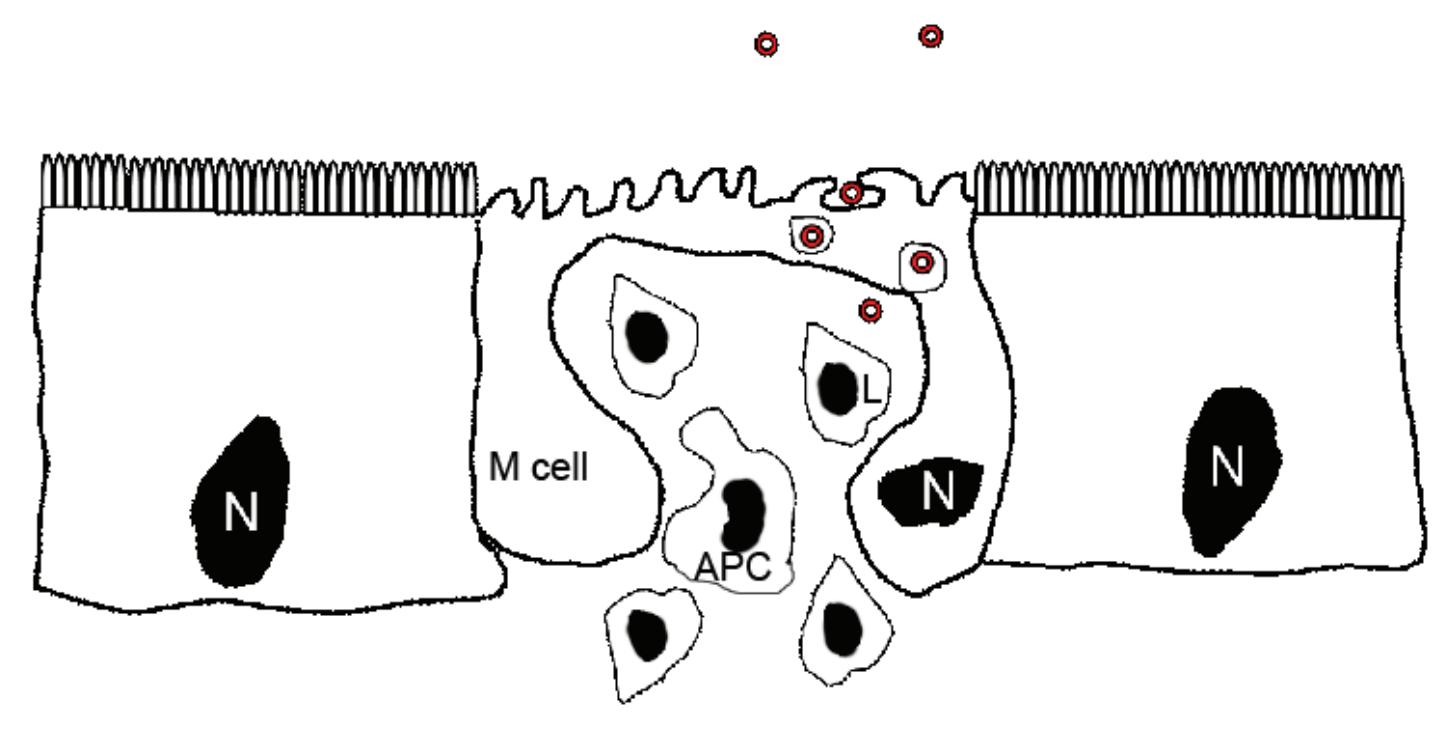

Figure 1-5. Illustration of $M$ cell mediated transcytosis. The $M$ cell in the drawing is depicted as an epithelial cell with irregular microvilli and microplicae, in contrast to the regular microvilli seen on neighboring cells. This epithelium in the image over the lymphoid follicle is referred to as follicle-associated epithelium. Also, a deeply invaginated basolateral membrane forming a pocket with intraepithelial lymphocytes (L) and antigen presenting cells (APC) is depicted. Red circles represent sampled particles which have been transcytosed to the basolateral membrane pocket. $\mathrm{N}=$ nuclei. 


\begin{tabular}{ll}
\hline \multicolumn{2}{l}{$\begin{array}{l}\text { Table 1-1. Species in which M cells have been identified } \\
\text { Species }\end{array}$} \\
\hline References \\
\hline Chickens & (Owen et al., 1974a; Bockman et al., 1975; Owen, 1978) \\
Rabbits & (Bockman et al., 1973; Befus et al., 1980) \\
Pigs & (Bockman et al., 1973; Owen, 1978; Liu et al., 2005) \\
Calves & (Landsverk, 1979; Torres-Medina, 1981) \\
Mice & (Bockman et al., 1973; Owen, 1977) \\
Monkeys & (Owen, 1978) \\
Hamsters & (Owen, 1978) \\
Dogs & (Owen, 1978) \\
White belly opossum & (Coutinho et al., 1993) \\
Sheep & (Landsverk et al., 1991) \\
Horse & (Lowden et al., 1995) \\
\hline
\end{tabular}

\section{Characteristics of follicle-associated epithelium}

The FAE is found above organized lymphoid tissues along mucosal surfaces at various locations. It differs from surrounding epithelium by the presence of $\mathrm{M}$ cells in most locations. A paucity of mucin producing goblet cells in these regions also results in a thinner mucus layer at the FAE (Owen et al., 1974a). It is thought that the thinner mucous layer and an attenuated glycocalyx on $\mathrm{M}$ cells allow closer association of larger antigens with $\mathrm{M}$ cells relative to nonFAE cells. One study compared the accessibility of differently sized adherent probes to the glycocalyx of M cells in the Peyer's patches relative to neighboring enterocytes. Both cell types bound equally well to a small $6.4 \mathrm{~nm}$ diameter probe whereas a $28.8 \mathrm{~nm}$ probe bound only to $\mathrm{M}$ cells. This study demonstrated that there is greater accessibility to M cells than to enterocytes (Frey et al., 1996; 
Mantis et al., 2000). This closer interaction with antigens presumably enhances the specialized function of $\mathrm{M}$ cells to translocate antigens from the mucosal surface to the underlying lymphoid tissue and supports the possibility of specific targeting of $\mathrm{M}$ cells for vaccine delivery.

\section{M cell morphological characteristics}

The classic morphology of $\mathrm{M}$ cells consists of a deeply invaginated basolateral membrane, which forms an intraepithelial pocket, also called a "lymphoid pocket," containing immigrant mononuclear immune cells, including B cells, CD4 ${ }^{+} T_{H}$ cells, macrophages and dendritic cells (Ermak et al., 1990; Ermak et al., 1994; Farstad et al., 1994; Iwasaki et al., 2001; Yamanaka et al., 2001). The $M$ cell creates a thin, apical cytoplasmic bridge separating the apical surface of the cell from the basolateral membrane pocket, which shortens the distance for endocytosed material to cross the epithelial barrier to as little a 1-2 $\mu \mathrm{m}$ (Neutra et al., 1996a). The presence of the apical, cytoplasmic bridge and basolateral membrane pocket is dependent on the number of intraepithelial lymphoid cells. These morphologic findings are not present in immature $\mathrm{M}$ cells at the periphery of Peyer's patch domes which are detected using ultrastructural (Bye et al., 1984) and histochemical criteria (Pappo, 1989).

\section{M cell apical surface morphology}

$M$ cells in a variety of locations and species have been consistently shown to have an apical membrane that is morphologically distinct from adjacent 
epithelial cells. In the small intestine, M cells usually display a flattened apical surface with short microvilli in mice (Bye et al., 1984) or microplicae in humans (Owen et al., 1974a), relative to surrounding epithelial cells. In contrast, M cells at other mucosal locations have microvilli that are taller than those of surrounding epithelial cells, including the rabbit cecum (Jepson et al., 1993a), calf colon (Liebler et al., 1991), pig Peyer's patches (Torres-Medina, 1981), rabbit palatine tonsil (Gebert, 1995) and rabbit conjunctiva (Liu et al., 2005). Despite these variations in M cell apical morphology at different locations, each shares the common property of being distinct from the surrounding epithelia.

\section{M cell glycocalyx}

The carbohydrate layer at the apical surface of epithelial cells, known as the glycocalyx, consists of oligosaccharide moieties of proteoglycans, glycoproteins, and glycolipids anchored in the lipid bilayer of the cell membrane. $\mathrm{M}$ cells possess a glycocalyx with a greater variety of glycoconjugates and more accessibility compared with neighboring non-FAE cells (Frey et al., 1996). This promotes adherence of many bacterial and viral adhesins and foreign particulate material and is consistent with the $\mathrm{M}$ cell's ability to sample luminal antigens and pathogens (Sharon, 1987). Differences in glycosylation patterns of M cell glycocalyx may account for variability in the binding specificities among $\mathrm{M}$ cells to antigens and certain pathogens (Frey et al., 1996; Silvey et al., 2001; Petris et al., 2007). This variation in glycocalyx even occurs amongst $M$ cells within a single FAE; this may maximize the variety of antigens able to bind at this location 
(Giannasca et al., 1994b). Different glycosylation patterns also exist at anatomically distinct mucosal locations (Jepson et al., 1995; Gebert, 1996a) and vary from species to species (Sharma et al., 1996) which likely reflects variations in microenvironment and antigens present at various mucosal locations. Lectins, which bind selectively to sugars or glycoconjugates, have been exploited to preferentially label $\mathrm{M}$ cell apical surface, but due to the wide variations in glycocalyx, there is no universal anti-carbohydrate M-cell marker.

\section{Unique functional characteristics of $M$ cells}

A quintessential function of $\mathrm{M}$ cells is transcytosis of sampled luminal contents to lymphoid cells and APCs within the basolateral pocket. Consistent with active transcytosis, $\mathrm{M}$ cells are typically filled with tubulo-vesicular endosomes (Neutra et al., 1987) and have a limited terminal web (Owen, 1977). $M$ cells have the ability to transport macromolecules, particles, and infective agents by a variety of endocytotic mechanisms, including phagocytosis (Neutra et al., 1995) and pinocytosis (Owen, 1977). The variable microvilli and microfolds on the surface of $\mathrm{M}$ cells are interspersed with plasma membrane sub-domains that participate in clathrin-mediated endocytosis of adsorbed macromolecules for delivery to a poorly defined endosomal/prelysosomal/lysosomal compartment and subsequent release into the underlying lymphoid pocket (Neutra et al., 1987). There is evidence that larger vesicles contain an acidic environment (Allan et al., 1993). Cathepsin E, an endosomal protease, has also been identified in rabbit M cells (Finzi et al., 1993). Despite 
these findings, M cells generally lack lysosomes (Owen et al., 1986a), and most endocytosed materials are delivered directly across the epithelium by transepithelial vesicular transport (Owen et al., 1986a), similar to that of polarized epithelial cells (Neutra et al., 1996b). Additionally, major histocompatibility complex (MHC) class II has been documented in subpopulations of $\mathrm{M}$ cells of some species (Allan et al., 1993), although it is not known if M cells play a major role in antigen presentation.

\section{Defining an M cell}

Experiments aimed at detecting $M$ cells for the first time in new mucosal locations have emphasized the importance of functional assays, since a single marker for $\mathrm{M}$ cells does not exist (Gebert et al., 1999). Morphologic characteristics and glycocalyx composition, when taken alone, are not sufficient to define an $M$ cell since these features vary between mucosal locations and species. Demonstration of transepithelial transport, a quintessential function of $M$ cells, is therefore a necessary step in defining $M$ cells.

\section{M cells of the conjunctiva}

The first arguments for the existence of $\mathrm{M}$ cells in the conjunctiva were based on the morphologic observation that lymphoid follicles in the Guinea pig conjunctiva make intimate contact with the epithelial layer, and that some cells with M-cell-like morphological characteristics were interspersed among cuboid cells in the epithelium (Latkovic, 1989). Nevertheless, this early study failed to 
demonstrate histochemical markers or functional activity of these putative $\mathrm{M}$ cells.

\section{$\underline{M \text { cell transcytosis of particulates and infective agents }}$}

Materials can be rapidly transcytosed by $\mathrm{M}$ cells and delivered to lymphocytes and APCs in the intraepithelial pocket in as little as 10 min (Neutra et al., 1987). Materials which are known to be transcytosed by $M$ cells include adherent bacteria, virions, parasites, and prions (see Table 1-2 \& 1-3). M cells are also known to transport solid particles, including synthetic microspheres or beads (Pappo et al., 1989; Jepson et al., 1993c; Jepson et al., 1993d; Liu et al., 2005), carbon particles of India ink (Bockman et al., 1973), ferritin (Bye et al., 1984; Liebler et al., 1991), and liposomes (Childers et al., 1990; Clark et al., 2002), as well as, soluble macromolecules, including horseradish peroxidase (Bockman et al., 1973; Owen, 1977; Gebert et al., 1995a), cholera toxin (Frey et al., 1996), and lectins (reviewed in Gebert, 1997).

While immunologic sampling of antigens and microorganisms by $\mathrm{M}$ cells is intended to promote mucosal immunity, some pathogens have developed strategies to exploit this pathway to infect subepithelial cells, and spread systemically in some cases. Well-documented examples of opportunistic

pathogens that exploit M cells include Salmonella typhi, S. typhimurium, Shigella flexneri, Yersinia enterocolitica, and Y. pseudotuberculosis (see Table 1-2). 


\begin{tabular}{|c|c|c|}
\hline \multicolumn{3}{|c|}{ Table 1-2. Bacteria transcytosed by $M$ cells } \\
\hline Infective agent & Host/Model & Reference \\
\hline \multicolumn{3}{|l|}{ Bacteria } \\
\hline Vibrio cholerae & Rabbit PP & (Owen et al., 1986b) \\
\hline Campylobacter jejuni & Rabbit PP & (Walker et al., 1988) \\
\hline $\begin{array}{l}\text { Mycobacterium } \\
\text { paratuberculosis }\end{array}$ & Sheep \& goat PP & $\begin{array}{l}\text { (Sigurethardottir et al., } \\
2004 \text { ) }\end{array}$ \\
\hline Shigella flexneri & $\begin{array}{l}\text { Mouse PP } \\
\text { Rabbit PP }\end{array}$ & $\begin{array}{l}\text { (Jensen et al., 1998) } \\
\text { (Wassef et al., 1989; } \\
\text { Sansonetti et al., 1996) }\end{array}$ \\
\hline $\begin{array}{l}\text { Salmonella spp. } \\
\text { S. typhi } \\
\text { S. typhimurium }\end{array}$ & $\begin{array}{l}\text { Mouse PP } \\
\text { Mouse PP }\end{array}$ & $\begin{array}{l}\text { (Pascopella et al., 1995) } \\
\text { (Clark et al., 1994b; } \\
\text { Jones et al., 1994; } \\
\text { Jensen et al., 1998) }\end{array}$ \\
\hline $\begin{array}{l}\text { Escherichia coli } \\
\text { RDEC-1 }\end{array}$ & $\begin{array}{l}\text { Mouse PP } \\
\text { Rabbit PP }\end{array}$ & $\begin{array}{l}\text { (Tyrer et al., 2007) } \\
\text { (Inman et al., 1983; Von } \\
\text { Moll et al., 1997) }\end{array}$ \\
\hline EHEC (strain O157:H7) & Human \& bovine PP & (Phillips et al., 2000) \\
\hline $\begin{array}{l}\text { Yersinia spp. } \\
\text { Y. pseudotuberculosis } \\
\text { Y. enterocolitica }\end{array}$ & Mouse \& Rabbit PP & $\begin{array}{l}\text { (Grutzkau et al., 1990; } \\
\text { Clark et al., 1998) }\end{array}$ \\
\hline Listeria monocytogenes & Mouse PP & (Jensen et al., 1998) \\
\hline Group A Streptococci & Mouse NALT & (Park et al., 2003) \\
\hline Streptococcus pneumoniae & Mouse PP & (Tyrer et al., 2007) \\
\hline \multirow{2}{*}{$\begin{array}{l}\text { Non-typeable Haemophilus } \\
\text { influenzae }\end{array}$} & Guinea pig CALT & (Petris et al., 2007) \\
\hline & Mouse PP & (Tyrer et al., 2007) \\
\hline
\end{tabular}

$\mathrm{PP}=$ Peyer's patches

NALT $=$ Nasal-associated lymphoid tissue

CALT = conjunctival-associated lymphoid tissue 


\begin{tabular}{|c|c|c|}
\hline \multicolumn{3}{|c|}{ Table 1-3. Viruses, Prions, \& Protozoa transcytosed by M cells } \\
\hline Infective agent & Host/Model & Reference \\
\hline \multicolumn{3}{|l|}{ Viruses } \\
\hline MMTV virus & Mouse PP & (Weltzin et al., 1989) \\
\hline Poliovirus & $\begin{array}{l}\text { Human PP } \\
\text { M-cell cell culture model }\end{array}$ & $\begin{array}{l}\text { (Sicinski et al., 1990) } \\
\text { (Ouzilou et al., 2002) }\end{array}$ \\
\hline Type I reoviruses & $\begin{array}{l}\text { Mouse PP } \\
\text { Mouse colon } \\
\text { Rabbit PP } \\
\text { Rat BALT }\end{array}$ & $\begin{array}{l}\text { (Wolf et al., 1981) } \\
\text { (Owen et al., 1990) } \\
\text { (Helander et al., 2003) } \\
\text { (Morin et al., 1994) }\end{array}$ \\
\hline HIV-1 & $\begin{array}{l}\text { Mouse \& rabbit PP } \\
\text { M-cell cell culture model }\end{array}$ & $\begin{array}{l}\text { (Amerongen et al., 1991) } \\
\text { (Fotopoulos et al., 2002) }\end{array}$ \\
\hline \multicolumn{3}{|l|}{ Prions } \\
\hline Scrapie PrP & $\begin{array}{l}\text { Sheep PP } \\
\text { M-cell cell culture model }\end{array}$ & $\begin{array}{l}\text { (Heggebo et al., 2000) } \\
\text { (Heppner et al., 2001) }\end{array}$ \\
\hline \multicolumn{3}{|l|}{ Parasites } \\
\hline Cryptosporidium & Guinea pig PP & (Marcial et al., 1986) \\
\hline Giardia muris & Mouse PP & (Owen et al., 1979) \\
\hline
\end{tabular}

BALT = Bronchial-associated lymphoid tissue $\mathrm{PP}=$ Peyer's patches

$\operatorname{PrP}=$ Prion protein

HIV-1 = human immunodeficiency virus

MMTV = mouse mammary tumor virus 


\section{$\underline{M \text { cells and Immunizations }}$}

Transcytosis of luminal materials by $\mathrm{M}$ cells is the first step in generating an adaptive immune response to the sampled antigen. Next, APCs endocytose the antigen and migrate to local or distant lymphoid follicles to present fragments of peptides from phagocytosed materials to antigen-specific lymphoid cells. Primed, naive B and T lymphocytes proliferate and differentiate into slgAsecreting plasma cells or activated T cells, respectively, which then migrate back to either original and distant mucosal sites and function as part of the efferent arm of the mucosal immune response. Activated T cells directly kill infected cells, whereas plasma cells produce slgA which is transcytosed to the apical surface by non-follicular epithelial cells to neutralize, agglutinate and/or opsonize the original antigen (Gebert, 1997).

Antigens that specifically adhere to the apical surface of $\mathrm{M}$ cells tend to produce a more robust immune response than those that are non-adherent (de Aizpurua et al., 1988; Harokopakis et al., 1995). Similarly, pathogens or vaccines that can selectively bind to $\mathrm{M}$ cells are more efficiently transported across the epithelium and, therefore, have a greater opportunity to stimulate the mucosal immune system. M-cell attachment and subsequent stimulation of organized lymphoid tissue is the assumed mechanism by which an adaptive immune response is induced by the oral vaccines for poliomyelitis and typhoid fever, which contain attenuated strains of their respective M-cell-invasive pathogens (Kraehenbuhl et al., 2000). Current strategies for enhancing M-cellmediated immune responses to oral vaccines include, chemical conjugation, 
immunization with recombinant bacteria and viruses, and mucosal adjuvants (Shalaby, 1995).

\section{M cell Markers and Receptors}

The specificity of most $M$ cell markers is attributable to variations in the $M$ cell glycocalyx, and many studies have utilized lectins and anti-carbohydrate antibodies to distinguish $\mathrm{M}$ cells from neighboring epithelial cells (see Table 1-4). There is considerable heterogeneity of $\mathrm{M}$ cell glycoconjugates between and within species, and no single reliable marker has been identified. The apical surface of $\mathrm{M}$ cells can also be differentiated from surrounding cells by alkaline phosphatase activity. In the gut, $\mathrm{M}$ cells have reduced activity of the digestive enzyme alkaline phosphatase compared to absorptive enterocytes. Other $\mathrm{M}$ cell markers, summarized in Table 1-4, include the intermediate filament vimentin and differential expression of cytokeratin between $\mathrm{M}$ cells and enterocytes; however, the significance of variable expression of intermediate filaments is not fully understood.

Despite years of research, the identification of a universal, selective M-cell receptor has remained elusive; recent progress towards this goal has been made, as outlined below (Table 1-5).

Pattern recognition receptors (PRRs). The prospective of PRR expression by $M$ cells would seem consistent with the cell's role in the innate immune system, including specific binding and transcytosis of macromolecules and pathogens, as well as, the induction of adaptive immune responses. The first 


\begin{tabular}{|c|c|c|c|}
\hline Lectin/Marker & Specificity & $\begin{array}{l}\text { Anatomic } \\
\text { site }\end{array}$ & Reference \\
\hline \multicolumn{4}{|l|}{ Mouse } \\
\hline Ulex europaeus I (UEA-I) & $\alpha-L-f u c o s e$ & PP & $\begin{array}{l}\text { (Clark et al., 1993; Clark } \\
\text { et al., 1994a; Clark et al., } \\
\text { 1995) }\end{array}$ \\
\hline $\begin{array}{l}\text { Psophocarpus tetragonolobus II } \\
\text { (PTL-II) }\end{array}$ & D-galNAc & PP & (Clark et al., 1993) \\
\hline Ricinus communis I (RCA-I) & $\beta$-D-gal & Colon/rectum & (Giannasca et al., 1994b) \\
\hline $\begin{array}{l}\text { Reduced alkaline phosphatase } \\
\text { activity }\end{array}$ & & PP & $\begin{array}{l}\text { (Owen et al., 1983; Smith } \\
\text { et al., 1988) }\end{array}$ \\
\hline \multicolumn{4}{|l|}{ Rabbit } \\
\hline $\begin{array}{l}\text { Triticum vulgaris (wheat germ } \\
\text { agglutinin; WGA) }\end{array}$ & $\begin{array}{l}\text { D-glcNAc; } \\
\text { NeuNAc }\end{array}$ & PP & (Neutra et al., 1987) \\
\hline Ricinus communis I (RCA-I) & $\begin{array}{l}\beta \text {-D-gal; D- } \\
\text { galNAc }\end{array}$ & PP & (Neutra et al., 1987) \\
\hline Ricinus communis II (ricin, RCA II) & D-galNAc & PP & (Neutra et al., 1987) \\
\hline $\begin{array}{l}\text { Maackia amurensis lectin I \& II } \\
\text { (MAL-I \& MAL-II) }\end{array}$ & $\begin{array}{l}\alpha(2-3)- \\
\text { sialic acid }\end{array}$ & PP & (Helander et al., 2003) \\
\hline Dolichus biflorus (DBA) & $\alpha-D-g a l N A c$ & $\begin{array}{l}\text { cecal lymphoid } \\
\text { patch }\end{array}$ & (Gebert et al., 1993) \\
\hline Helix pomatia (HPA) & D-galNAc & $\begin{array}{l}\text { cecal lymphoid } \\
\text { patch }\end{array}$ & (Gebert et al., 1993) \\
\hline Glycine max (SBA) & D-galNaAc & $\begin{array}{l}\text { cecal lymphoid } \\
\text { patch }\end{array}$ & (Gebert et al., 1993) \\
\hline Ulex europaeus I (UEA-I) & $\alpha$-L-fuc & $\begin{array}{l}\text { cecal lymphoid } \\
\text { patch }\end{array}$ & (Gebert et al., 1993) \\
\hline Vicia villosa (VVA) & D-galNAc & $\begin{array}{l}\text { cecal lymphoid } \\
\text { patch }\end{array}$ & (Gebert et al., 1993) \\
\hline Wisteria floribunda (WFA) & D-galNAc & $\begin{array}{l}\text { cecal lymphoid } \\
\text { patch }\end{array}$ & (Gebert et al., 1993) \\
\hline Arachis hypogaea (PNA) & $\begin{array}{l}\beta-D-g a l(1- \\
\text { 3)-D- } \\
\text { galNAc }\end{array}$ & Appendix, PP & (Jepson et al., 1993b) \\
\hline Vimentin & & $\begin{array}{l}\text { Bronchus, } \\
\text { PP, appendix }\end{array}$ & $\begin{array}{l}\text { (Gebert et al., 1992; } \\
\text { Jepson et al., 1992; } \\
\text { Jepson et al., 1993b) }\end{array}$ \\
\hline $\begin{array}{l}\text { Reduced alkaline phosphatase } \\
\text { activity }\end{array}$ & & PP & (Jepson et al., 1993b) \\
\hline \multicolumn{4}{|l|}{ Pig } \\
\hline Cytokeratin 18 & & PP & (Gebert, 1994) \\
\hline \multicolumn{4}{|l|}{ Human } \\
\hline $\begin{array}{l}\text { Reduced alkaline phosphatase } \\
\text { activity } \\
\text { Sialyl Lewis A antigen }\end{array}$ & & $\begin{array}{l}\text { PP } \\
\text { PP, cecum }\end{array}$ & $\begin{array}{l}\text { (Smith et al., 1988; } \\
\text { Brandtzaeg et al., 1989) } \\
\text { (Giannasca et al., 1999) }\end{array}$ \\
\hline
\end{tabular}




\begin{tabular}{|c|c|c|c|}
\hline \multicolumn{4}{|c|}{ Table 1-5. M cell receptors } \\
\hline $\begin{array}{l}\text { M cell } \\
\text { receptor }\end{array}$ & Specificity & Species & \\
\hline $\begin{array}{l}\alpha(2-3) \text {-sialic } \\
\text { acid }\end{array}$ & reovirus & Rabbit PP & $\begin{array}{l}\text { (Helander et al., } \\
\text { 2003) }\end{array}$ \\
\hline $\begin{array}{l}\alpha 5 \beta 1 \\
\text { integrin }\end{array}$ & $\begin{array}{l}\text { Fibronectin- } \\
\text { binding proteins } \\
\text { on many bacteria }\end{array}$ & $\begin{array}{l}\text { Mouse PP and M- } \\
\text { cell cocultures }\end{array}$ & (Tyrer et al., 2006) \\
\hline$\beta 1$ integrin & & Mouse PP & (Clark et al., 1998) \\
\hline $\begin{array}{l}\text { CD155 } \\
\text { receptor }\end{array}$ & poliovirus & Human PP & (Iwasaki et al., 2002) \\
\hline CPE-R & $\begin{array}{l}\text { C. perfringens } \\
\text { enterotoxin }\end{array}$ & Mouse, human PP & (Lo et al., 2004) \\
\hline GM1 & Cholera toxin B & $\begin{array}{l}\text { All intestinal cells in } \\
\text { mice, rabbits, } \\
\text { human }\end{array}$ & (Frey et al., 1996) \\
\hline HLA-DR & & Human PP & (Ueki et al., 1995) \\
\hline ICAM-1 & & Human colon & (Ueki et al., 1995) \\
\hline $\begin{array}{l}\text { IgA specific } \\
\text { receptor }\end{array}$ & $\lg \mathrm{A}$ & Mouse PP & (Mantis et al., 2002) \\
\hline Laminin $\beta 3$ & $\begin{array}{l}\text { Putative prion } \\
\text { receptor }\end{array}$ & $\begin{array}{l}\text { Human duodenal \& } \\
\text { jejunal biopsies }\end{array}$ & $\begin{array}{l}\text { (Shmakov et al., } \\
2000 \text { ) }\end{array}$ \\
\hline Muc-2 & & Rabbit appendix & $\begin{array}{l}\text { (Lelouard et al., } \\
\text { 2001) }\end{array}$ \\
\hline PAF-R & PAF & $\begin{array}{l}\text { Mouse PP and M- } \\
\text { cell cocultures }\end{array}$ & (Tyrer et al., 2006) \\
\hline PGRP-S & $\begin{array}{l}\text { PG on Gram- } \\
\text { positive bacteria }\end{array}$ & Mouse PP & (Lo et al., 2003) \\
\hline TLR2 & $\begin{array}{l}\text { LTA on Gram- } \\
\text { positive bacteria }\end{array}$ & Mouse PP & (Chabot et al., 2006) \\
\hline TLR4 & $\begin{array}{l}\text { LPS on Gram- } \\
\text { negative bacteria }\end{array}$ & $\begin{array}{l}\text { Mouse PP and M- } \\
\text { cell cocultures }\end{array}$ & $\begin{array}{l}\text { (Tyrer et al., 2006; } \\
\text { Tyrer et al., 2007) }\end{array}$ \\
\hline
\end{tabular}

$\mathrm{CPE}-\mathrm{R}=\mathrm{C}$. perfringens enterotoxin receptor GM1 = ganglioside GM1

ICAM-1 = Intracellular Adhesion Molecule-1

$\lg A=$ immunoglobulin $A$

LTA = Lipotechoic acid

LPS = lipopolysaccharide

Muc-2 = rabbit equivalent of human mucin Muc2

SLAA $=$ Sialyl Lewis Antigen A

PAF-R = platelet activating factor-receptor

$\mathrm{PP}=$ Peyer's patches

PGRP-S = peptidoglycan recognition protein-S

TLR 2, 4 = toll-like receptor 2 and 4 
experiments which provided evidence that TLRs were involved in antigen sampling via $\mathrm{M}$ cells in the FAE was via the use of TOGA cDNA expression profiling to identify genes that were more highly expressed by mouse Peyer's patch $\mathrm{FAE}$ vs. non-FAE. A product of one of these enriched genes was the pattern recognition receptor PGRP-S (peptidoglycan recognition protein), which was found to co-localize with UEA-I positive M cells of the mouse Peyer's patches (Lo et al., 2003). Over the course of the past few years, TLRs have been documented on M cells in vivo. TLR-2 (Tohno et al., 2005) \& TLR-9 (Shimosato et al., 2005) have been identified on swine M cells. The pattern recognition receptors TLR-4, PAF-R (platelet activating factor-receptor), and $\alpha 5 \beta 1$ integrin have been documented on the surface of $\mathrm{M}$ cells from mouse Peyer's patches and in M-cell cocultures (Tyrer et al., 2006; Tyrer et al., 2007). Another study demonstrated TLR-2 expression on the epithelial surface of both FAE and villus epithelium, but only TLR-2 was internalized on FAE after challenge with peptidoglycan. LPS stimulation was also able to enhance microparticle uptake by FAE and induce DC migration into the FAE which suggests that other TLRs (i.e. the LPS receptor TLR-4) may also modulate FAE functions (Chabot et al., 2006). These studies provide insight into the types of receptors present on $\mathrm{M}$ cells, and may aid in the identification of a unique M-cell marker as well as the development of M-cell-specific mucosal vaccines.

\section{CHAPTER 2. LECTIN AND ANTIBODY STAINING IN VITRO}




\subsection{Abstract}

Organized lymphoid tissue has been identified at many mucosal locations. The epithelium above these regions, referred to as follicle-associated epithelium (FAE), contains a specialized cell type with antigen-sampling capabilities, known as the $M$ cell. A few studies which examined the FAE of conjunctival lymphoid tissue have noted that some cells share morphologic commonalities with $\mathrm{M}$ cells, but none have shown selective labeling or demonstrated functionality of these cells. This study aims to characterize the FAE of ocular lymphoid follicles and identify potential markers for the apical surface of $\mathrm{M}$ cells.

Lymphoid follicles were routinely observed as protruding domes in the fornix region of Guinea pig conjunctival whole mounts when tissue was examined under a stereoscope. Microscopic investigation of conjunctival FAE, using light microscopy (LM) and transmission electron microscopy (TEM), demonstrated cells with typical morphologic characteristics of $\mathrm{M}$ cells including irregular microvilli, a thin apical bridge, numerous membrane-bound vesicles, and a deeply invaginated basolateral membrane with immune cells in the intraepithelial pocket. Next, a panel of 12 lectins and 5 anti-carbohydrate antibodies were used to screen for differential binding to the apical surface of FAE on cross-sections of aldehyde-fixed follicles. Two sialyllactose binding lectins, Maackia amurensis leukoagglutinin I and II (MAL-I and MAL-II), were identified as potential M cells markers based on their selective labeling of a subset of epithelial cells overlying lymphoid follicles. 
This study demonstrates that the Guinea pig conjunctiva contains a cell with morphological characteristics of antigen-sampling $M$ cells. Yet, functional assays of $\mathrm{M}$ cell transcytotic capabilities are required to fully characterize this cell as a true $\mathrm{M}$ cell.

\subsection{Introduction}

The glycocalyx of the epithelial $\mathrm{M}$ cell has been found to differ from neighboring epithelial cells in both thickness and density. These differences are thought to reflect variations in saccharide composition of the glycocalyx, which can be discerned using lectins and antibodies with known carbohydrate-binding specificities. The selective binding of lectins and other carbohydrate-specific histochemical markers to the apical surface of $\mathrm{M}$ cells has been shown at many locations (summarized above), including tonsil (Gebert, 1996a), Peyer's patches (Neutra et al., 1987; Jepson, 1993; Giannasca et al., 1994b), appendix (Roy, 1987; Jepson, 1993), cecum (Gebert et al., 1993), nasal cavity (Giannasca et al., 1997), and bronchus (Gebert et al., 1992). The distinct glycocalyx displayed by $M$ cells suggested that they may play a role in selective adhesion to pathogens, especially bacterial or viral antigens that often bind to glycoconjugate moieties (Sharon, 1987; Ofek et al., 1988).

$M$ cells have wide, inter- and intraspecies variations in the glycoconjugates expressed on their apical surface. Characterization of M cells at new mucosal locations requires individual screening to determine which glycoconjugates are expressed on the apical surface of $\mathrm{M}$ cells at those 
locations. The goal of the following study was to identify an M-cell specific marker for the conjunctiva by screening a panel of lectins.

Most of the work presented in this chapter has been published: Meagher, C.K., Liu, H., Moore, C.P. and Phillips, T.E. (2005). "Conjunctival M cells selectively bind and translocate Maackia amurensis leukoagglutinin" Experimental Eye Research 80(4): 545-53. The Association for Research in Vision and Ophthalmology is the copyright holder of this work.

\subsection{Methods and Materials}

\section{$\underline{\text { Animals and surgical procedure }}$}

Two outbred, male Guinea pigs, between $4-5$ weeks old, were used in the study (Harlan, Indianapolis, IN). All experimental procedures used in this study conformed to the ARVO Statement for the Use of Animals in Ophthalmic and Vision Research and University of Missouri Animal Care and Use Committee guidelines.

Guinea pigs were given intramuscular injections of ketamine $\mathrm{HCl}(40$ $\mathrm{mg} / \mathrm{kg}$ ) and xylazine (5 mg/kg) for anesthesia and intraperitoneal injections of butorphanol ( $2 \mathrm{mg} / \mathrm{kg}$ ) were given for analgesia. Eyelids were sutured and orbits were exenterated, the cornea separated from the sclera and the conjunctival sac opened as previously described in detail (Moore et al., 1987). The corners of the preparation were pinned out onto a flat piece of dental wax with the mucosal surface facing upwards. After thorough rinsing with phosphate buffered saline 
(PBS: $138 \mathrm{mM} \mathrm{NaCl}, 2.67 \mathrm{mM} \mathrm{KCl}, 1.47 \mathrm{mM} \mathrm{KH}_{2} \mathrm{PO}_{4}, 8.06 \mathrm{mM} \mathrm{Na}_{2} \mathrm{HPO}_{4}, \mathrm{pH}$ 7.4), the conjunctival flat mount preparation was fixed for $2 \mathrm{hr}$ in $2 \%$ PF (2\% freshly depolymerized paraformaldehyde in $70 \mathrm{mM} \mathrm{NaCl}, 30 \mathrm{mM}$ HEPES, $2 \mathrm{mM}$ $\mathrm{CaCl}_{2}, \mathrm{pH}$ 7.4). Following fixation and rinsing, the tissues were dissected using a stereoscope with conventional white light illumination to aid dissection. All follicles used in the present study were dissected from either the superior or inferior fornix region. Since no difference between superior and inferior forniceal follicles was perceived, no distinction is made in the presentation of the data. Non-follicular forniceal tissue was used as controls in post-embedding studies. Nembutal $(100 \mathrm{mg} / \mathrm{kg})$ was used to euthanize animals.

\section{$\underline{\text { Tissue processing for fluorescent microscopy }}$}

Control tissue for immunofluorescence was fixed for $2 \mathrm{hr}$ in $2 \% \mathrm{PF}$, rinsed in $50 \mathrm{mM}$ glycine in HEPES wash buffer (HWB: $70 \mathrm{mM} \mathrm{NaCl}, 30 \mathrm{mM}$ HEPES, 2 $\mathrm{mM} \mathrm{CaCl} 2, \mathrm{pH} 7.4$ ), dehydrated with a series of increasing concentrations of ethanol, and then embedded in butyl-methylmethacrylate (BMMA) resin and polymerized at $4^{\circ} \mathrm{C}$ (Baskin et al., 1996). Before staining, semi-thin $0.5 \mu \mathrm{m}$ sections were etched for 10 min in acetone, rehydrated in a series of rinses with decreasing concentrations of ethanol, and washed with HWB. Antigen retrieval was performed at $90^{\circ} \mathrm{C}$ for $10 \mathrm{~min}$ in $100 \mathrm{mM}$ glycine $(\mathrm{pH} 9.6)$, and slides were washed again with HWB and blocked for $1 \mathrm{hr}$ in $1.0 \%$ BSA in HWB then rinsed again with HWB and blocked for $1 \mathrm{hr}$ in $1.0 \%$ BSA in HWB then rinsed with HWB. 


\section{Lectins and antibodies}

Lectins and primary antibodies used in these studies are listed in Table 2-

1. All lectins (MAL-I, MAL-II, SNA, UEA, ECL, Jac, VVA, GSL-II, DSL, LEL, STL) were purchased from Vector Laboratories (Burlingame, CA) except LPA (E-Y Labs, San Mateo, CA). The monoclonal antibody anti-sialyl Lewis ${ }^{\mathrm{x}}$ (clone KM93) and anti-sialyl Lewis ${ }^{\mathrm{A}}$ (clone KM231) were purchased from Kamiya Biomedical Company (Seattle, WA). Monoclonal antibodies against Lewis ${ }^{A}$ (clone 121SLE), Lewis $^{\mathrm{B}}$ (clone LWB01) and Lewis ${ }^{\mathrm{X}}$ (clone 12C02) were from Labvision (Freemont, CA) Secondary labels included mouse anti-biotin (Jackson ImmunoResearch Labs, West Grove, PA), Alexa 488 conjugated goat antimouse IgG (Molecular Probes, Eugene, OR) and $10 \mathrm{~nm}$ colloidal gold labeled goat anti-mouse IgG and goat anti-biotin (Electron Microscopy Sciences, Fort Washington, PA). Control slides of conjunctiva demonstrated the secondary antibodies did not cross-react when applied alone or after non-immune primary antibodies (data not shown). Nuclei were counterstained with 300 nM DAPI (4',6-diamidino-2-phenylindole).

\section{$\underline{\text { Tissue staining for fluorescence microscopy }}$}

In some experiments, sections were incubated for $3 \mathrm{hr}$ with $100 \mu \mathrm{l}$ of 0.25 U neuraminidase (type V, from Clostridium perfringens; Sigma, St. Louis, MO) in buffer ( $50 \mathrm{mM}$ sodium acetate, $4 \mathrm{mM} \mathrm{CaCl}, 110 \mathrm{mM} \mathrm{NaCl}, \mathrm{pH} 5.0$ ) before blocking. After neuraminidase treatment, sections were blocked and stained with the same protocol as untreated sections. For the initial screening of the lectin 
panel, all biotinylated lectins were used at $2.5 \mu \mathrm{g} / \mathrm{ml}$. Sections were incubated for $6 \mathrm{hr}$ in each of the lectins followed by an overnight incubation in $2 \mu \mathrm{g} / \mathrm{ml}$ mouse anti-biotin. Other sections were incubated in $10 \mu \mathrm{g} / \mathrm{ml}$ mouse anti-Lewis carbohydrate epitope antibodies overnight. Following extensive rinsing, all sections were stained for $6 \mathrm{hr}$ with $2 \mu \mathrm{g} / \mathrm{ml}$ Alexa 488 conjugated goat antimouse IgG + $300 \mathrm{nM}$ DAPI. All antibodies were diluted in 0.1\% BSA in HWB and slides were washed $3 \times 5$ min in HWB between incubations. Acrylic resin crosssections were examined using wide-field fluorescence microscopy.

\section{Tissue preparation for TEM}

Flat mounts were fixed for 2 hrs in PFG (2.5\% glutaraldehyde and $2 \%$ paraformaldehyde in HWB) and then rinsed with $50 \mathrm{mM}$ glycine in HWB to block free aldehyde groups. Following dissection, the isolated follicles and their surrounding tissue were en bloc stained with $0.5 \%$ uranyl acetate in $25 \%$ ethanol for $1 \mathrm{hr}$. After infiltration and embedding in EmBed 812 (Electron Microscopy Sciences, Fort Washington, PA), ultrathin sections $(50-80 \mathrm{~nm})$ were collected on grids. Grids were rinsed with $\mathrm{dH}_{2} \mathrm{O}$ before counterstaining with uranyl acetate and Reynold's lead citrate solution.

\subsection{Results}

Morphological characterization of conjunctival FAE 
Numerous, large clusters of lymphoid follicles were routinely observed using a stereoscope in the fornix region of the conjunctiva in Guinea pigs between three and five weeks old. Cross-sections of embedded lymphoid follicles demonstrated that goblet cells were plentiful in the surrounding non-FAE and absent or rarely present in the epithelium above these follicles (Figure 2-1). Within the FAE, cells with the morphologic phenotype of classical M cells, including a thin apical bridge and deeply invaginated basolateral membrane forming intraepithelial pockets which encompassed lymphocytes and APCs. Using TEM these cells contained numerous tubulo-vesicular endosomes and an irregular apical boarder consisting of more infrequent and pleomorphic microvilli and microfolds (see Figure 2-2). These appreciable differences easily distinguish FAE and non-FAE cells.

\section{MAL-I and MAL-Il preferentially label a subset of cells in the conjunctival FAE}

A panel of 12 lectins and 5 Lewis carbohydrate antigen-specific antibodies was screened on BMMA sections of fixed Guinea pig conjunctiva to identify lectins which selectively labeled the apical membranes of cells within the FAE (Table 2-1). All of the lectins and anti-Lewis antibodies stained some of the cells or fibers within the follicle or lamina propria. Our interests focused on selective labeling of the apical membrane of the epithelial cells since those are the only glycoconjugates which would normally be exposed to the external environment. None of the anti-Lewis epitope antibodies stained epithelia within the fornix region (data not shown). Seven lectins (UEA-I, ECL, Jacalin, VVA, LEL, STL, 
DSL) stained the apical surface of all epithelial cells in both the follicle and nonfollicle regions (Figures 2-7 to 2-10, 2-12, 2-14). LPA weakly stained the apical surface of all FAE cells and goblet cells but not the stratified epithelium in the non-FAE regions (Figure 2-6). SNA and GSL-II failed to stain the membranes of any conjunctival epithelial cells (Figure $2-5 \& 11$ ). While all lectins above stained either all or none of the apical membranes of conjunctival epithelial cells, MAL-I and MAL-II were the only lectins that selectively labeled a subset of cells of the FAE (Figures 2-1 \& 2). These two lectins intensely stained the apical surface of cells which had basolateral membranes contacting intraepithelial lymphoid pockets within the FAE (Figures 2-15A and B). Additionally, both lectins strongly labeled intracellular mucin stores and endothelial cell membranes and more diffusely stained the cytoplasm of some epithelial cells and lymphocytes. There was no apical membrane labeling of non-FAE epithelial cells by MAL-II and only weak labeling of occasional non-FAE cells by MAL-I. MAL-I stained the FAE slightly more intensely than MAL-II. Based on these results, we investigated whether MAL-I could selectively label conjunctival M cells in vivo (see Chapter 3).

\section{MAL-I and MAL-II binding to M cells requires sialic acid}

MAL-I and MAL-II both bind to carbohydrate moieties containing NeuAca(2-3)Gal (Yamamoto et al., 1997). To determine if these epitopes are required for MAL-I and II binding to the apical surface of M cells, BMMA sections were treated with neuraminidase, which hydrolyzes $\alpha(2-3), \alpha(2-6), \alpha(2-8)-$ glycosidic linkages of terminal sialic acid residues of various glycoconjugates. 
The selective apical membrane binding of MAL-I on mock-treated control sections (Figure 2-16A) was eliminated by neuraminidase pre-treatment although some binding to lymphocytes and endothelium remained (Figure 2-16B). Neuraminidase pre-treatment similarly prevented MAL-II staining of the FAE (data not shown). These findings demonstrate that both lectins are binding to an epitope on $\mathrm{M}$ cells that requires the presence of sialic acid. 


\subsection{Figures}

Table 2-1. Lectin panel epitopes and binding specificity to apical membranes of conjunctival epithelial cells.

\begin{tabular}{|c|c|c|c|c|}
\hline \multirow[b]{2}{*}{$\begin{array}{l}\text { Lectin or } \\
\text { antibody }\end{array}$} & \multirow[b]{2}{*}{ Epitopes } & \multicolumn{3}{|c|}{ Non-FAE } \\
\hline & & FAE & $\begin{array}{l}\text { Squamous } \\
\text { epithelium }\end{array}$ & $\begin{array}{l}\text { Goblet } \\
\text { cells }\end{array}$ \\
\hline $\begin{array}{l}\text { MAL-I (Maackia } \\
\text { Amurensis lectin I) }\end{array}$ & $\begin{array}{l}\text { NeuaAca(2-3)Galß(1-4) } \\
\text { GlcNAc,(Knibbs et al., 1991) } \\
\text { Galß(1-4)GlcNAc }\end{array}$ & $-\&+++^{*}$ & $-\&+^{*}$ & - \\
\hline $\begin{array}{l}\text { MAL-II (Maackia } \\
\text { Amurensis lectin II) }\end{array}$ & $\begin{array}{l}\text { NeuaAca(2-3)Galß(1-4) } \\
\text { GlcNAc, NeuAca(2-3)Galß(1- } \\
\text { 3) [NeuAca(2-3)]GalNAc } \\
\text { (Yamamoto et al., 1997) }\end{array}$ & $-\&+++^{*}$ & - & - \\
\hline $\begin{array}{l}\text { SNA (Sambucus } \\
\text { nigra agglutinin) }\end{array}$ & $\begin{array}{l}\text { NeuaAca(2-6)Galß1- } \\
\text { 4GlcNAc(Knibbs et al., 1991; } \\
\text { Yamamoto et al., 1997) }\end{array}$ & - & - & - \\
\hline $\begin{array}{l}\text { LPA (Limulus } \\
\text { polyphemus } \\
\text { agglutinin) }\end{array}$ & Neu5Ac & + & - & + \\
\hline $\begin{array}{l}\text { UEA-I (Ulex } \\
\text { europeus } \\
\text { agglutinin-I) }\end{array}$ & Fuca(1-2)Gal & +++ & +++ & +++ \\
\hline $\begin{array}{l}\text { ECL (Erythrina } \\
\text { cristagalli lectin) }\end{array}$ & Galß(1-4)GlcNAc & +++ & +++ & +++ \\
\hline $\begin{array}{l}\text { Jacalin (Artocarpus } \\
\text { integrifolia) }\end{array}$ & $\begin{array}{l}\text { Galß(1-3)GalNAc; Gala(1-6) } \\
\text { Gal(Giannasca et al., 1994b) }\end{array}$ & +++ & +++ & +++ \\
\hline $\begin{array}{l}\text { WA (Vicia villosa } \\
\text { agglutinin) }\end{array}$ & $\begin{array}{l}\text { GalNAca(1,3)Gal, (Giannasca } \\
\text { et al., 1994b) } \\
\text { D-Man, D-Glc }\end{array}$ & +++ & +++ & +++ \\
\hline $\begin{array}{l}\text { GSL-II (Griffornia } \\
\text { simplicifolia lectin II) }\end{array}$ & $\alpha$ or $\beta-$ GlcNAc & - & - & - \\
\hline $\begin{array}{l}\text { DSL (Datura } \\
\text { stramonium lectin) }\end{array}$ & $\begin{array}{l}\beta(1,4) \text { GlcNAc, LacNAc } \\
\text { oligomers }\end{array}$ & ++ & +++ & +++ \\
\hline $\begin{array}{l}\text { LEL (Lycopersicon } \\
\text { esculentum lectin) }\end{array}$ & GlcNAc oligomers & +++ & +++ & +++ \\
\hline $\begin{array}{l}\text { STL (Solanum } \\
\text { tuberosum lectin) }\end{array}$ & GlcNAc oligomers \& MurNAc & +++ & +++ & +++ \\
\hline Anti-sialyl Lewis ${ }^{A}$ & $\begin{array}{l}\text { Neu5Aca(2-3)Galß(1-3) } \\
\text { GlcNAc[Fuca(1-4)] }\end{array}$ & - & ND & - \\
\hline Anti-sialyl Lewis ${ }^{\mathrm{x}}$ & $\begin{array}{l}\text { Neu5Ac(2,3)Galß(1-4) } \\
\text { GlcNAc[Fuc(1-3)] }\end{array}$ & - & ND & ND \\
\hline
\end{tabular}

- = no binding, $+=$ weak binding, $++=$ moderate binding, +++ = intense binding,

* $=$ binding to only a subpopulation of cells (otherwise binding to all cells),

$\mathrm{ND}=$ not determined 


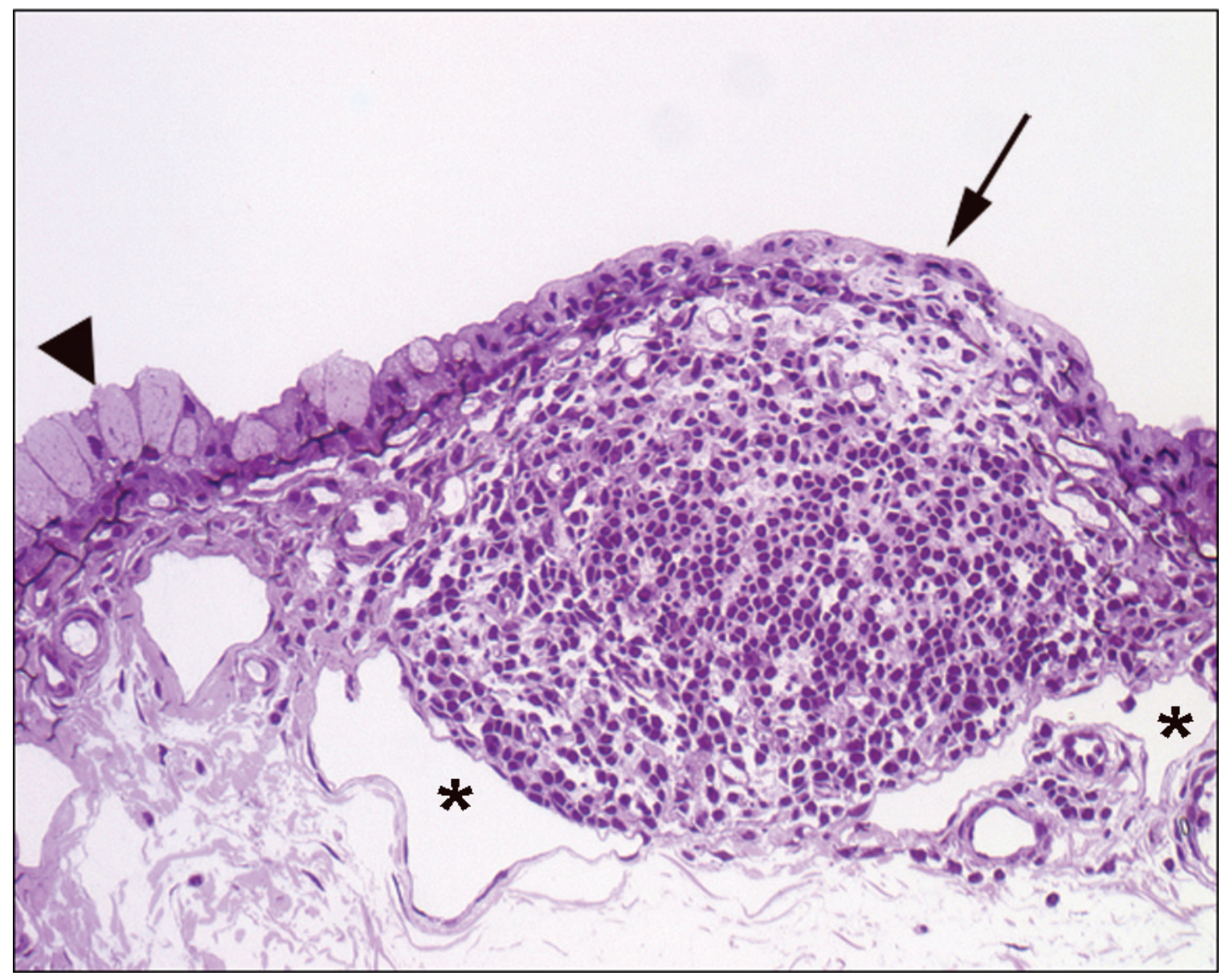

Figure 2-1. Lymphoid follicle. Semi-thin $(0.5 \mu \mathrm{m})$ section of a Guinea pig conjunctival follicle. Goblet cells (arrow head) full of mucin granules are seen in the non-FAE. FAE (arrow) sits atop a round follicle which is surrounded with lymphatics (asterisks). Stained with Toluidine blue (1\% toluidine blue and $1 \%$ sodium borate). 

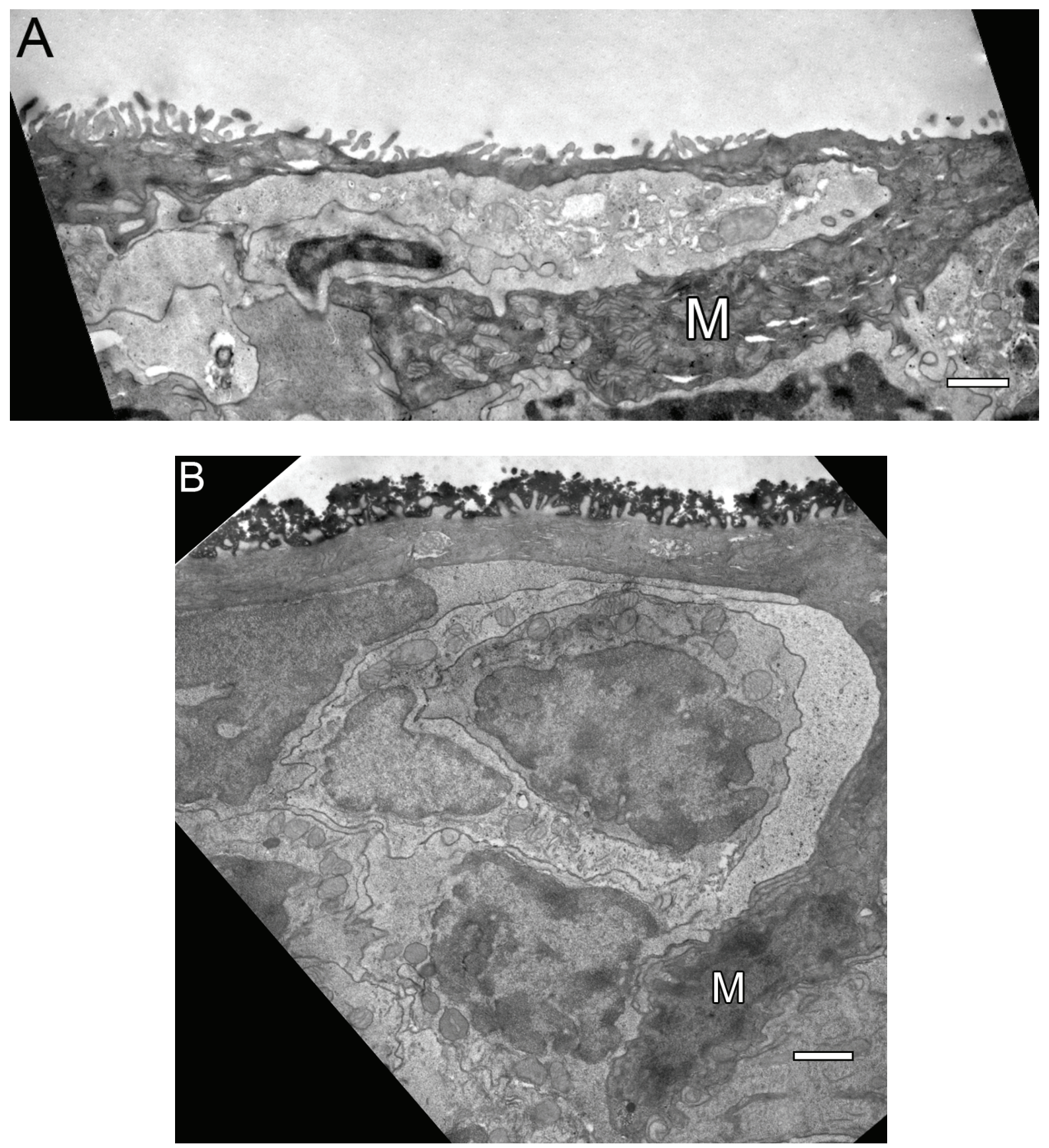

Figure 2-2. TEM of $\mathbf{M}$ cells. $M$ cells in these images have typical morphologic features of $M$ cells $(M)$ including a thin cytoplasmic bridge, a basolateral pocket filled with lymphocytes, and an irregular microvilli border. Image B is a good example of a lymphoid pocket; the glycocalyx was stained with a lectin conjugated to horseradish peroxidase (HRP) and developed with 3,3'Diaminobenzidine (DAB) which is not relevant to this figure (B). Scale bar (A \& B): $1 \mu \mathrm{m}$. 

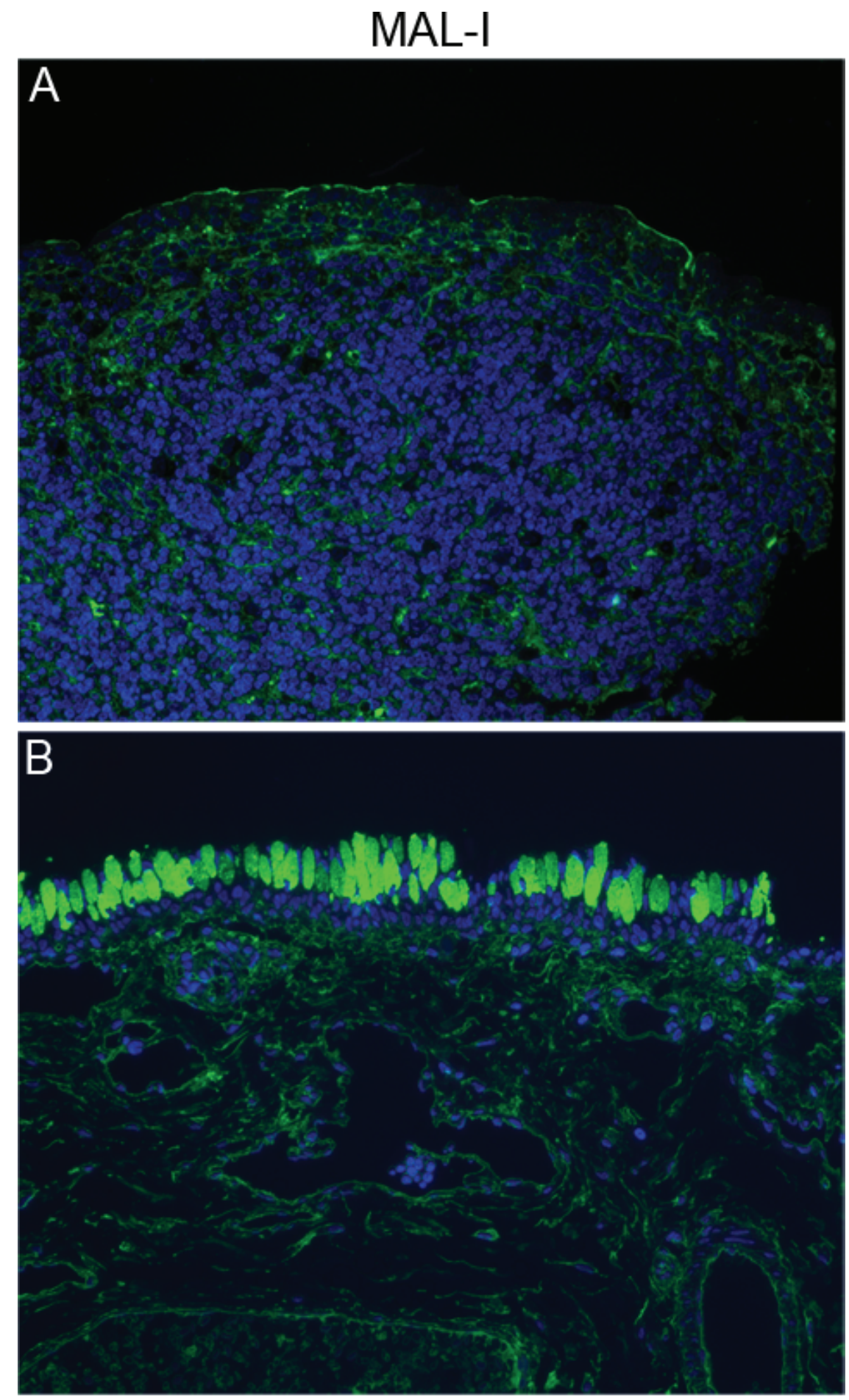

Figure 2-3. MAL-I staining (green) on conjunctival FAE (A) and non-FAE (B). MALI labels the apical surface of a subset of FAE cells (A). Intracellular mucin is also labeled with MAL-I (B). In both images, MAL-I stains the cytoplasm of fibroblasts, endothelium, and immune cells (A \& B). Nuclei are counterstained with DAPI (blue). 

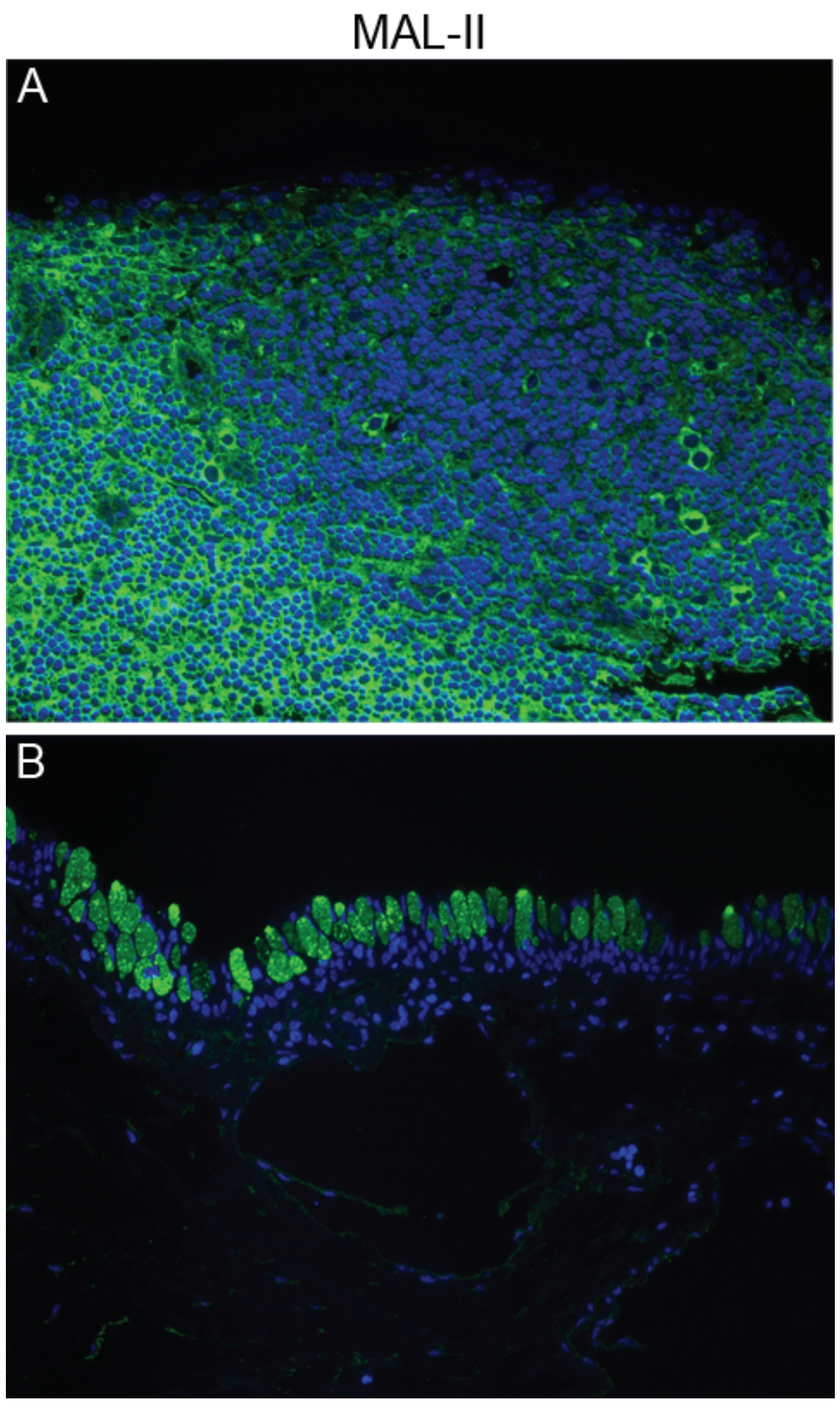

Figure 2-4. MAL-II staining (green) on conjunctival FAE (A) and non-FAE (B). MAL-II labels the apical surface of a subset of FAE cells $(A)$. Intracellular mucin is also labeled with MAL-I (B). In both images, MAL-II stains the cytoplasm of fibroblasts, endothelium, and immune cells (A \& B). Nuclei are counterstained with DAPI (blue). 


\section{SNA}
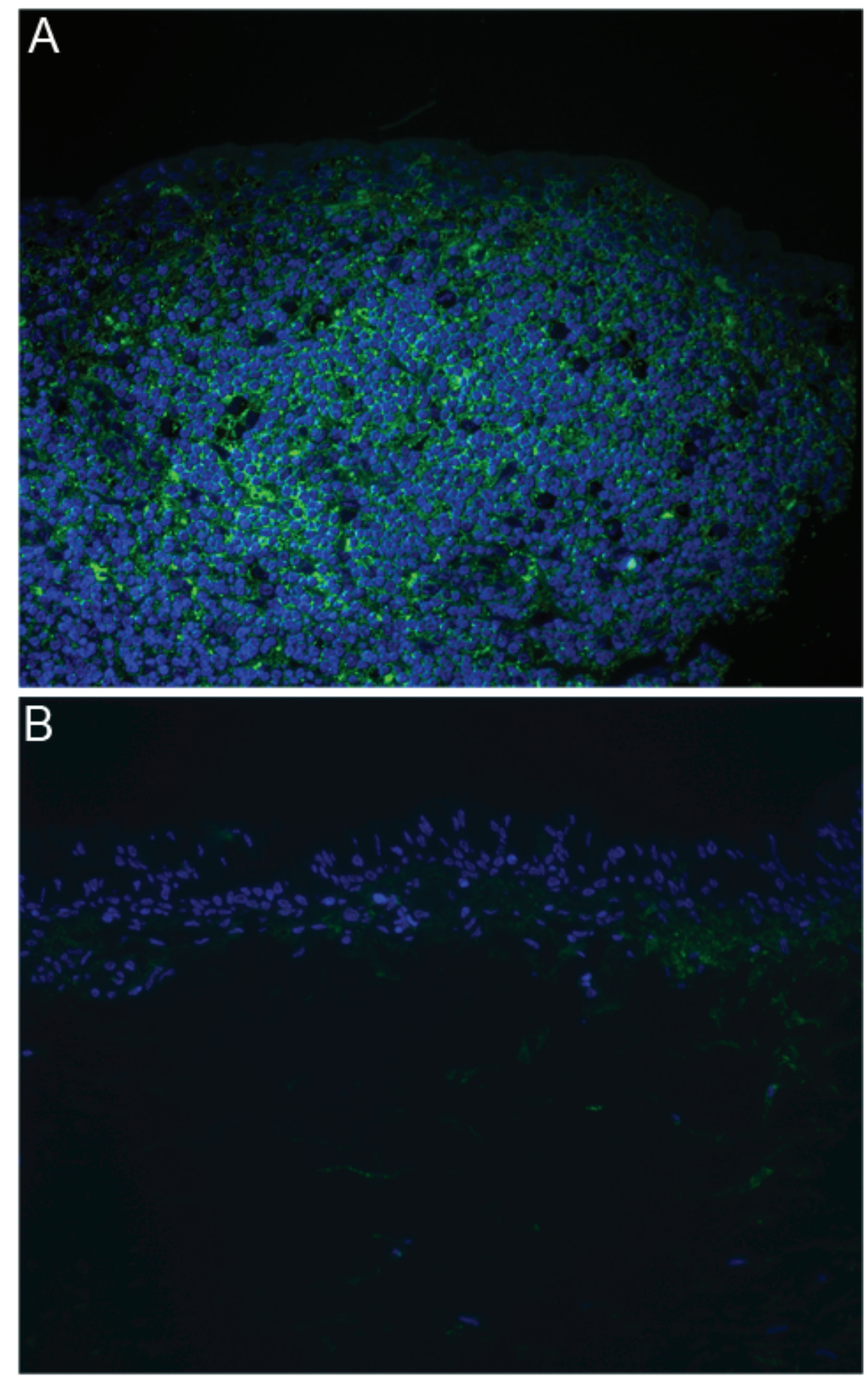

Figure 2-5. SNA staining (green) on conjunctival FAE (A) and non-FAE (B). SNA does not label the apical surface of FAE $(A)$ or non-FAE cells $(B)$. In the lamina propria, SNA strongly stains immune cells in the follicle region (A) and weakly stains fibroblasts (B). Nuclei are counterstained with DAPI (blue). 


\section{LPA}
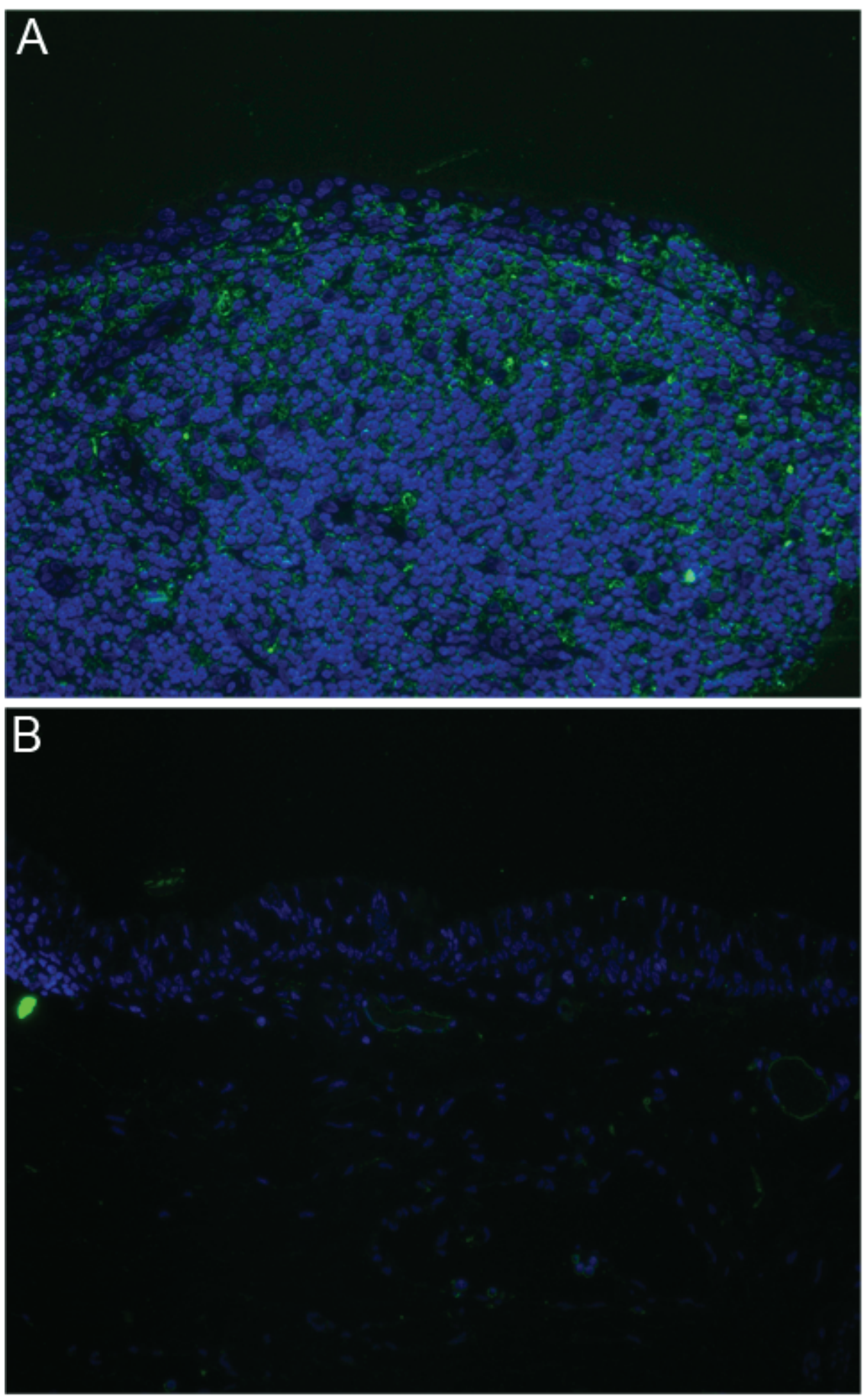

Figure 2-6. LPA staining (green) on conjunctival FAE (A) and non-FAE (B). LPA weakly labels the apical surface of FAE cells (A) and goblet cells (B). In the lamina propria, LPA weakly stains the cytoplasm of fibroblasts, endothelium, and immune cells (A \& B). Nuclei are counterstained with DAPI (blue). 


\section{UEA}
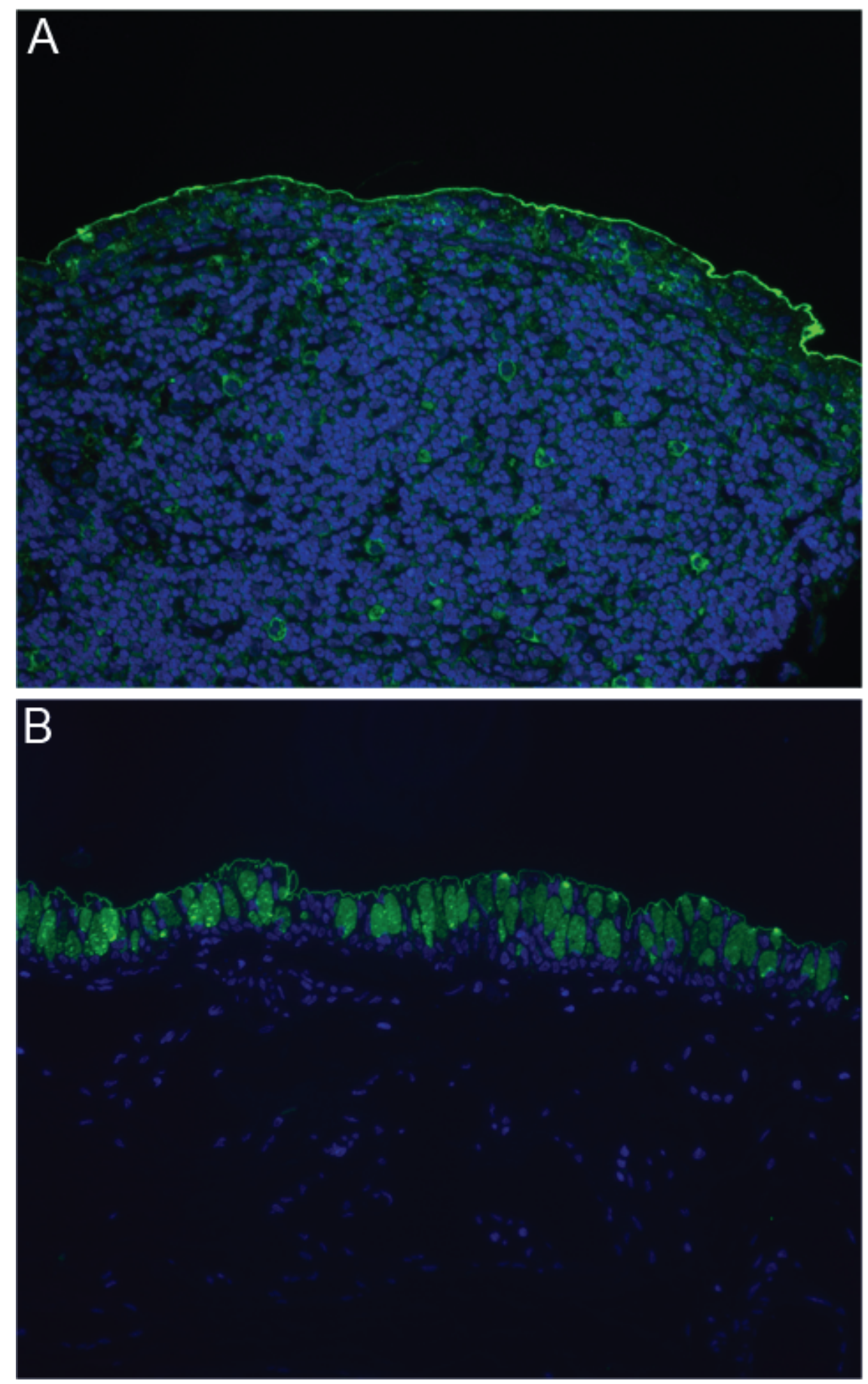

Figure 2-7. UEA-I (green) staining on conjunctival $F A E(A)$ and non-FAE (B). UEA-I labels the apical surface of all FAE and non-FAE. Immune cells (A) and goblet cell mucins (B) are heterogeneously stained by UEA-I. Nuclei are counterstained with DAPI (blue). 


\section{ECL}
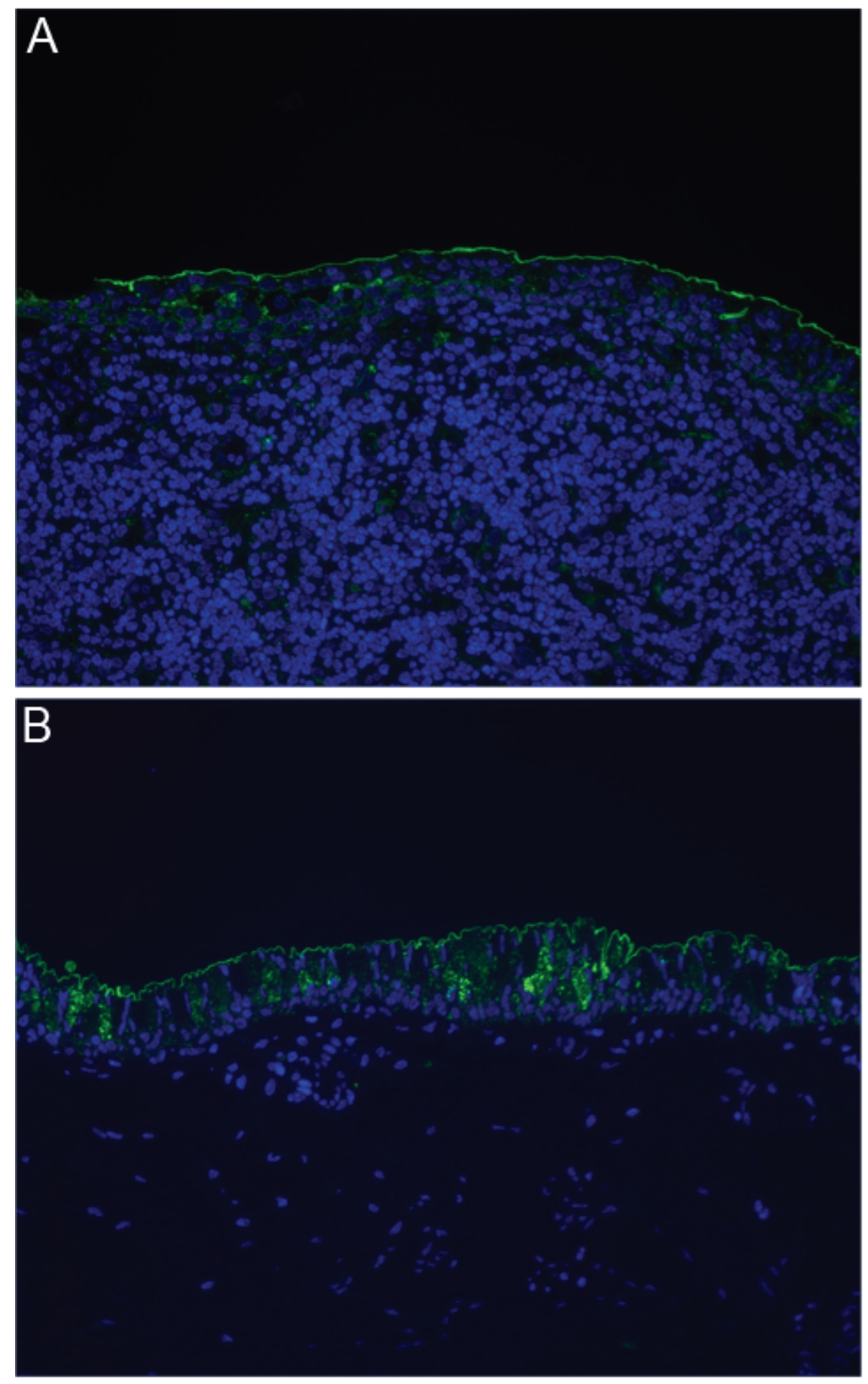

Figure 2-8. ECL staining (green) on conjunctival FAE (A) and non-FAE (B). ECL labels the apical surface of all FAE and non-FAE. ECL staining of immune cells $(A)$ and goblet cell mucin $(B)$ is weak and heterogeneous. Nuclei are counterstained with DAPI (blue). 

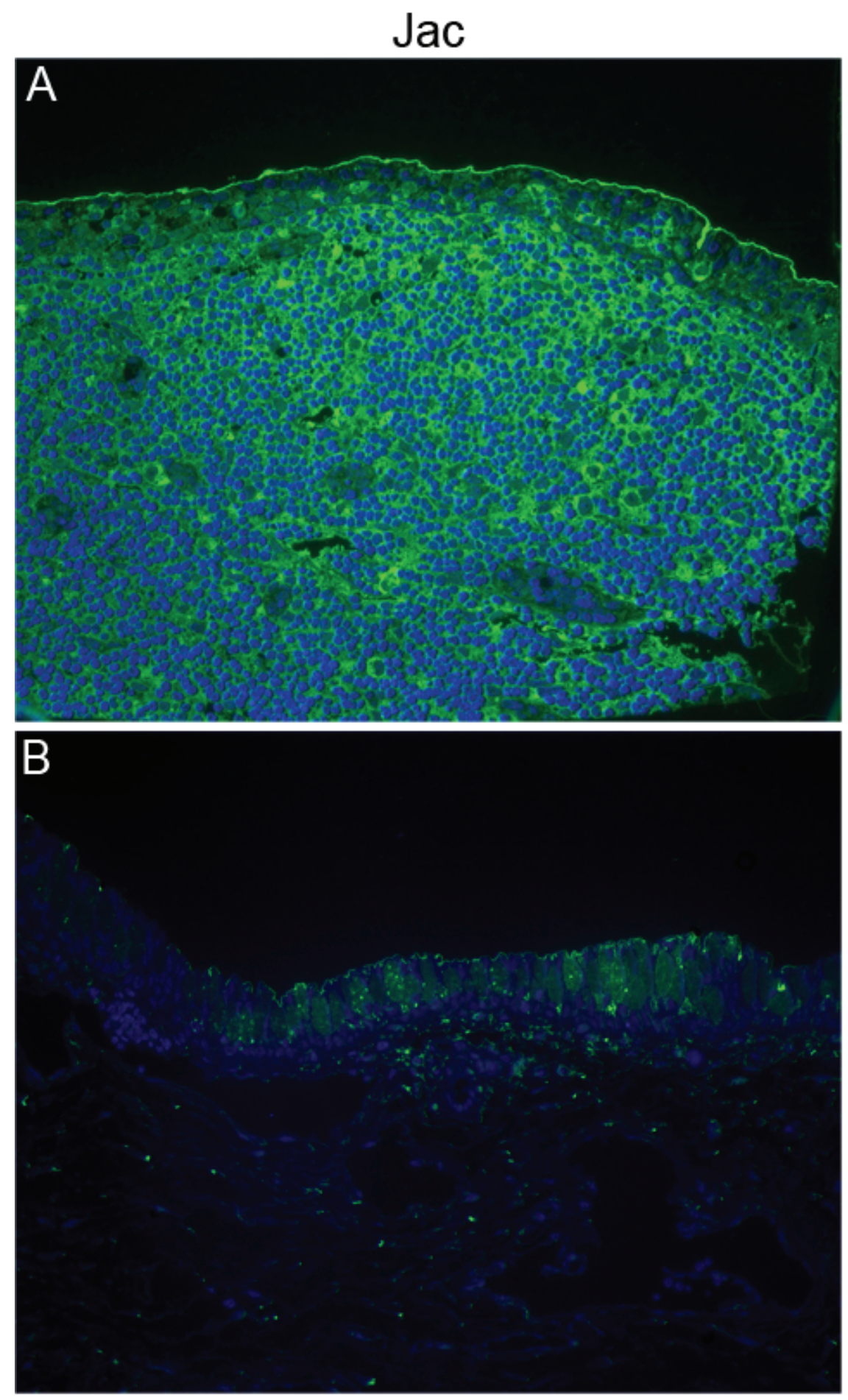

Figure 2-9. Jac staining (green) on conjunctival FAE (A) and non-FAE (B). Jac labels the apical surface of all FAE and non-FAE. The cytoplasm of all cells in the follicle region diffusely stains with Jac $(A)$. In the non-FAE regions, goblet cell mucins and occasional immune cells are weakly stained while fibroblasts have some bright punctate labeling by Jac (B). Nuclei are counterstained with DAPI (blue). 


\section{VVA}
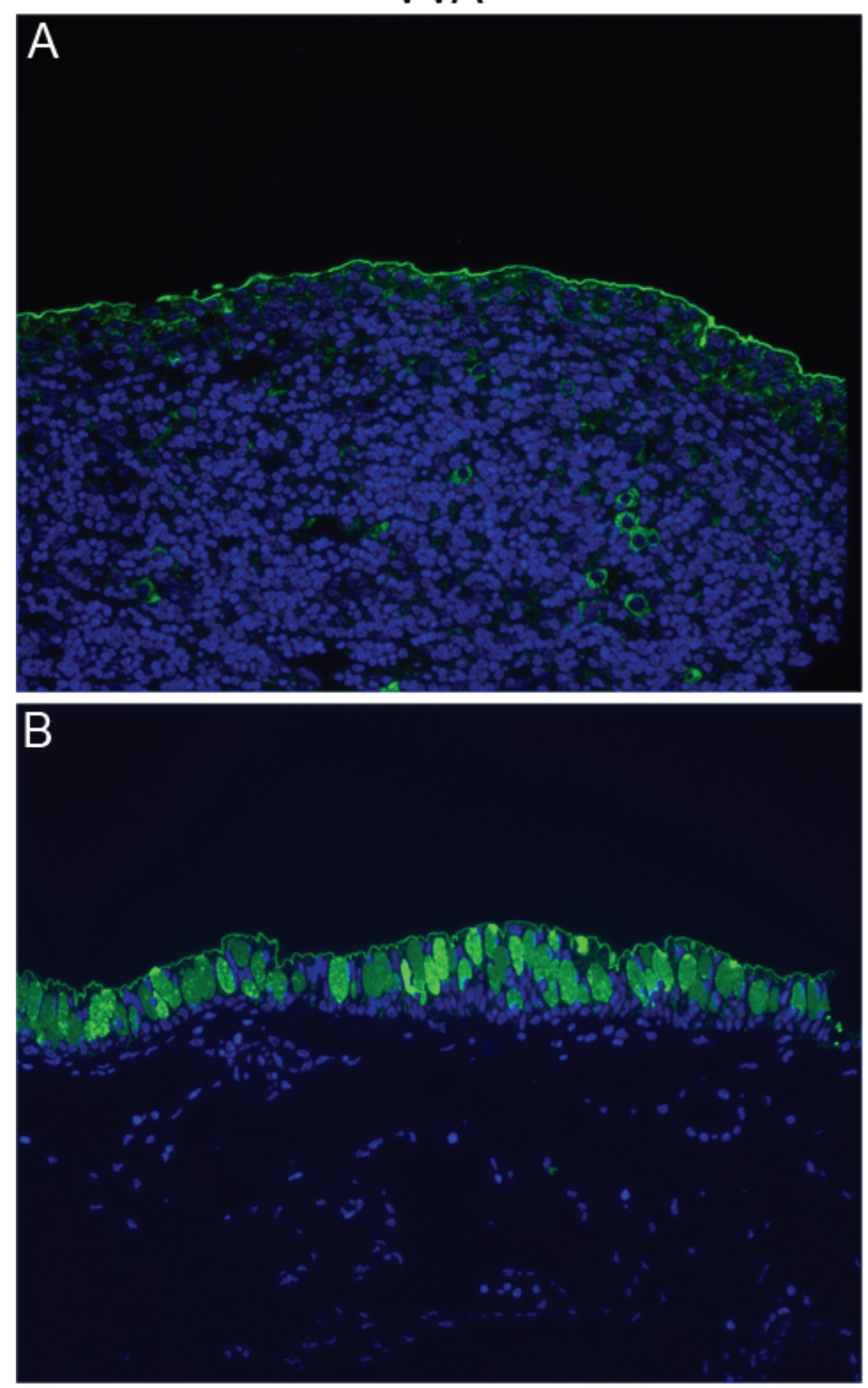

Figure 2-10. VVA staining (green) on conjunctival FAE (A) and non-FAE (B). VVA labels the apical surface of all FAE and non-FAE. Goblet cell mucin is also labeled by VVA (B). VVA stains a subset of immune cells including cells that appear to be antigen presenting cells $(A)$ in the follicle. Nuclei are counterstained with DAPI (blue). 


\section{GSL-II}
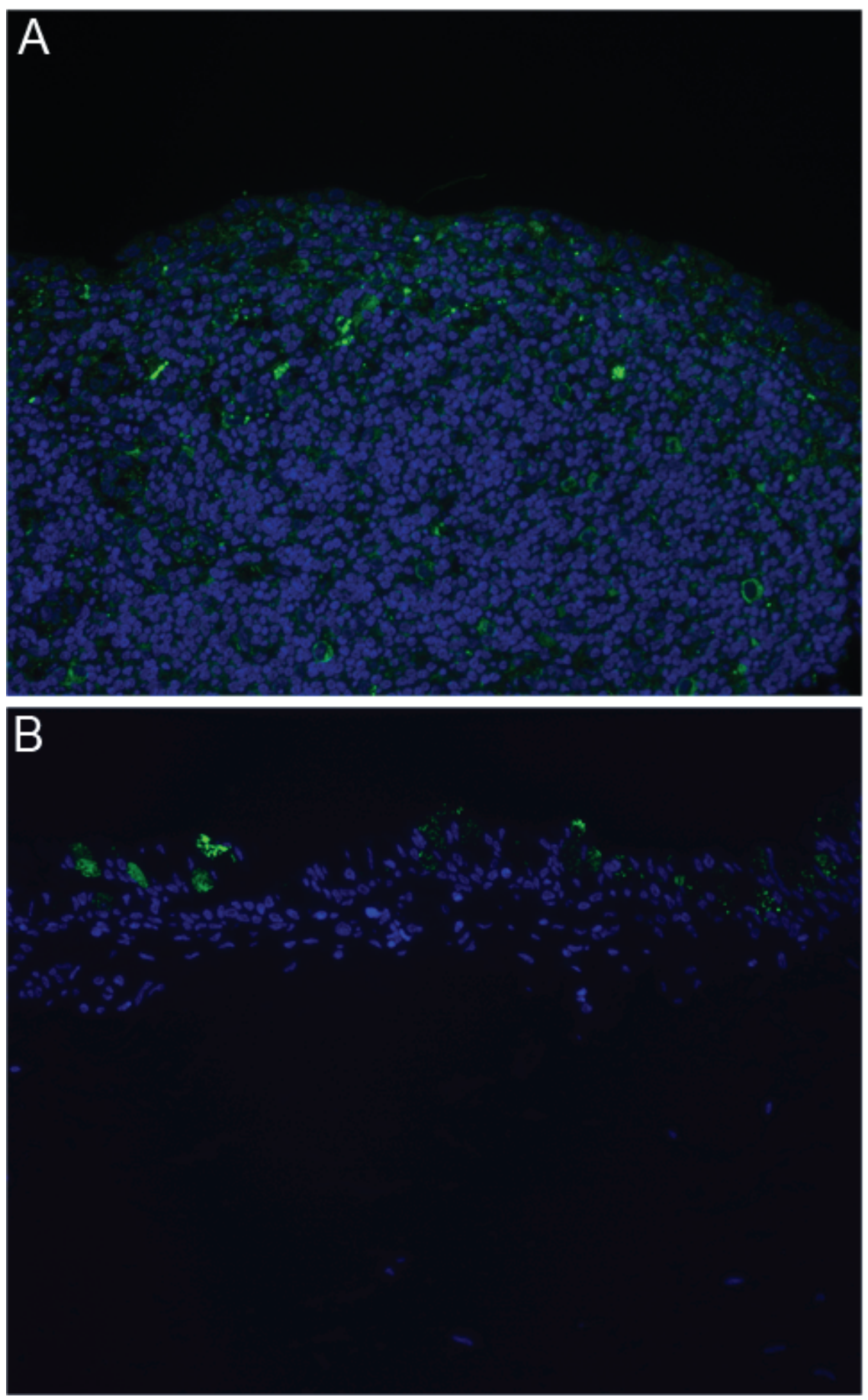

Figure 2-11. GSL-Il staining (green) on conjunctival FAE (A) and non-FAE (B). GSL-II does not label the apical surface of FAE (A) or non-FAE cells (B). A subset of goblet cell mucin is stained by GSL-II. This lectin also stains some of the immune cells in the follicle region (A). Nuclei are counterstained with DAPI (blue). 


\section{DSL}
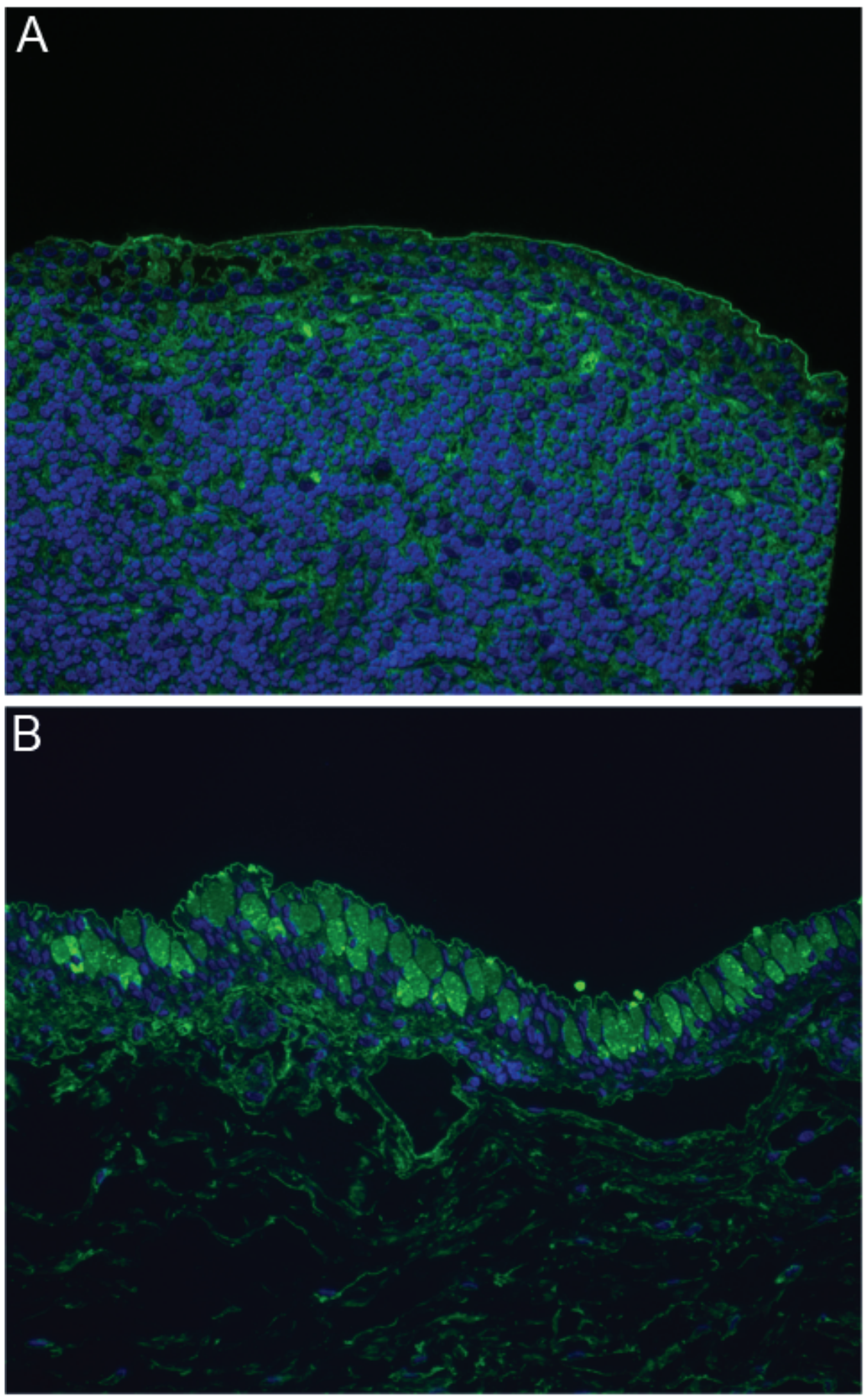

Figure 2-12. DSL staining (green) on conjunctival FAE (A) and non-FAE (B). DSL labels the apical surface of all FAE and non-FAE. The cytoplasm of all cells in the follicle region diffusely stains with DSL (A). In the non-FAE regions, goblet cell mucins and the cytoplasm of immune cells and fibroblasts is weakly stained by DSL (B). Nuclei are counterstained with DAPI (blue). 


\section{LEL}
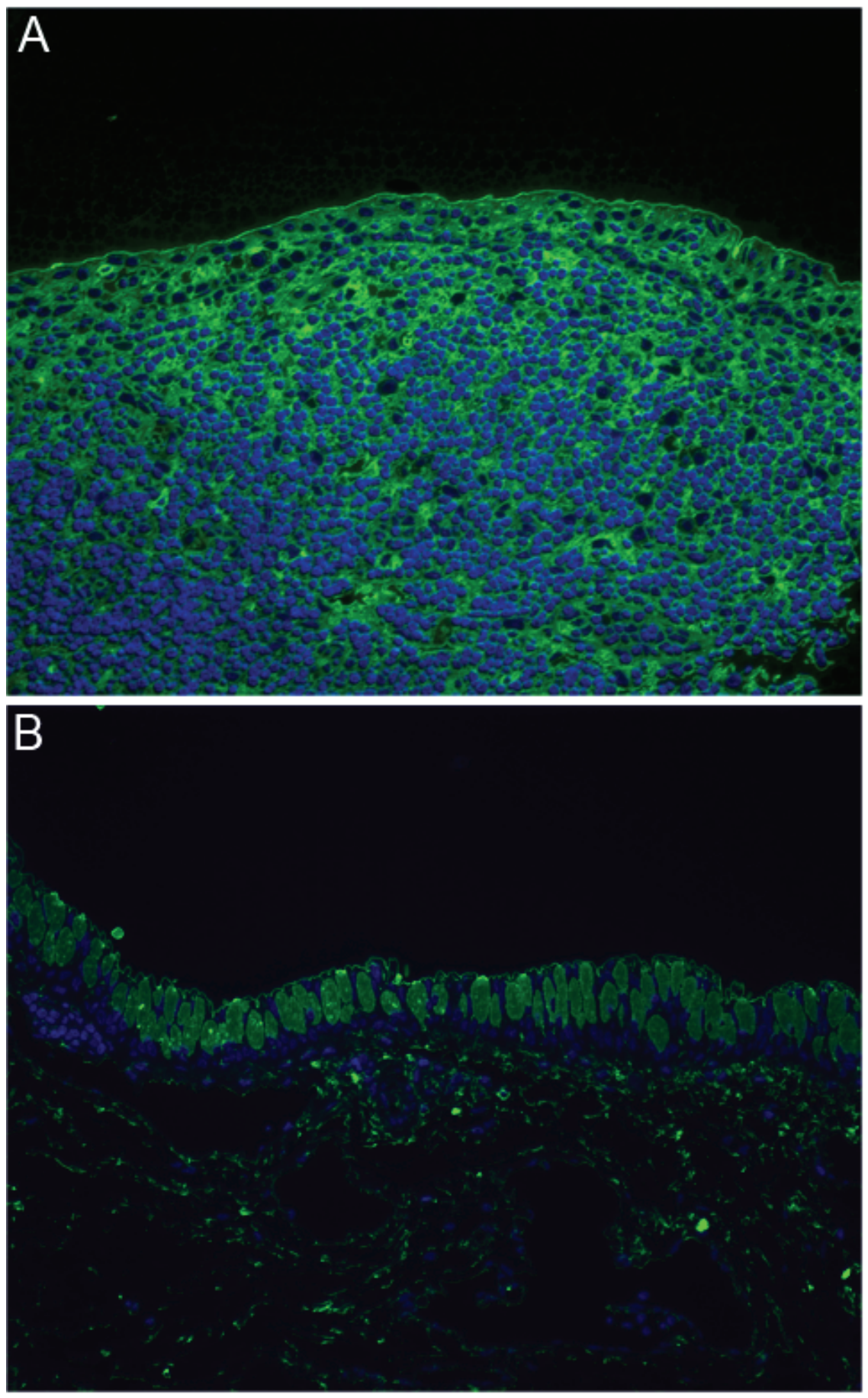

Figure 2-13. LEL staining (green) on conjunctival FAE (A) and non-FAE (B). LEL labels the apical surface of all FAE and non-FAE. The cytoplasm of all cells in the follicle region strongly and diffusely stains with LEL $(A)$. In the non-FAE regions, goblet cell mucins and the cytoplasm of immune cells and fibroblasts are stained by LEL (B). Nuclei are counterstained with DAPI (blue). 

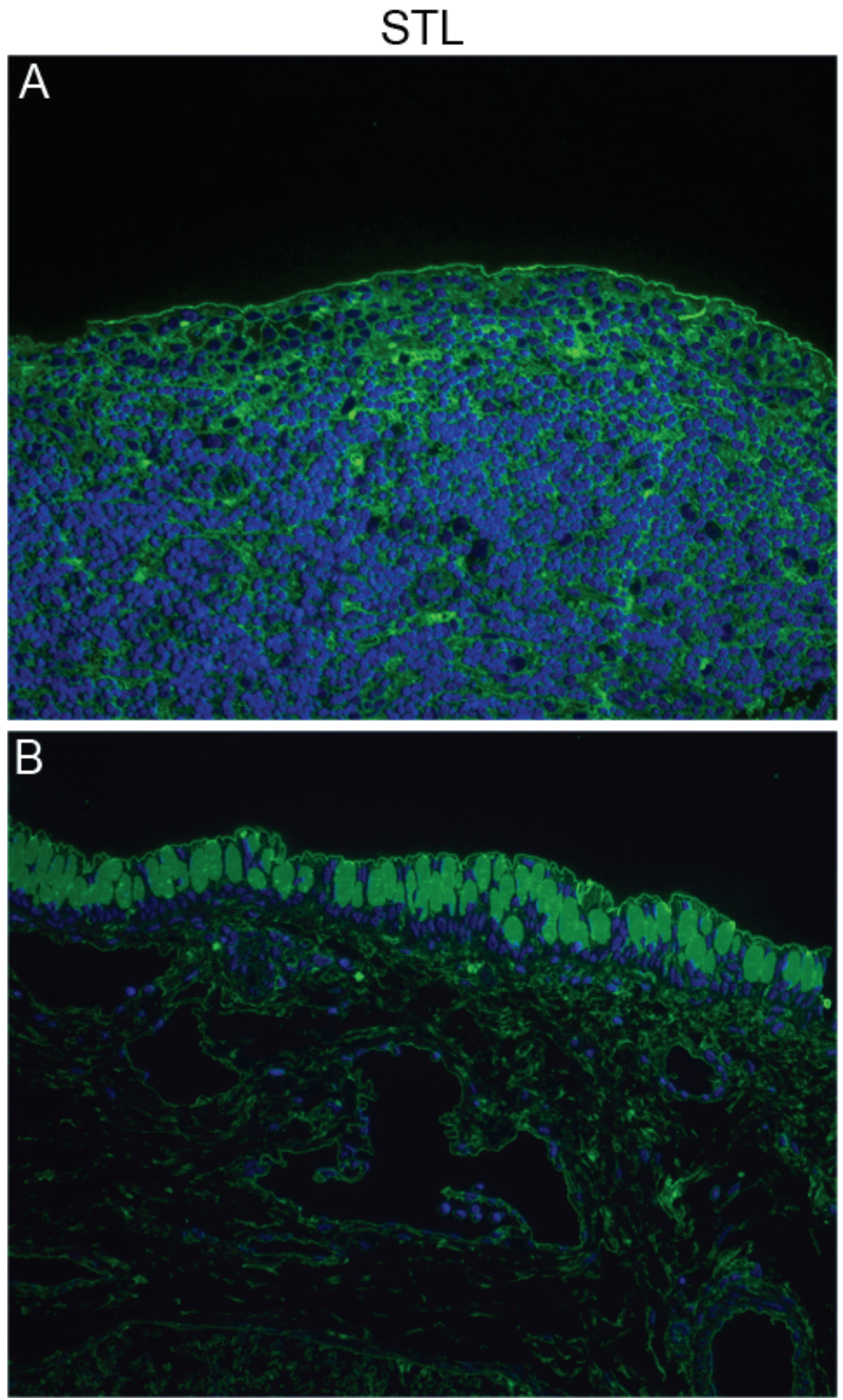

Figure 2-14. STL (green) staining on conjunctival FAE (A) and non-FAE (B). STL labels the apical surface of all FAE and non-FAE. The cytoplasm of all cells in the follicle region diffusely stains with STL $(A)$. In the non-FAE regions, goblet cell mucins and the cytoplasm of immune cells, fibroblasts, and endothelium is stained by LEL (B). Nuclei are counterstained with DAPI (blue). 

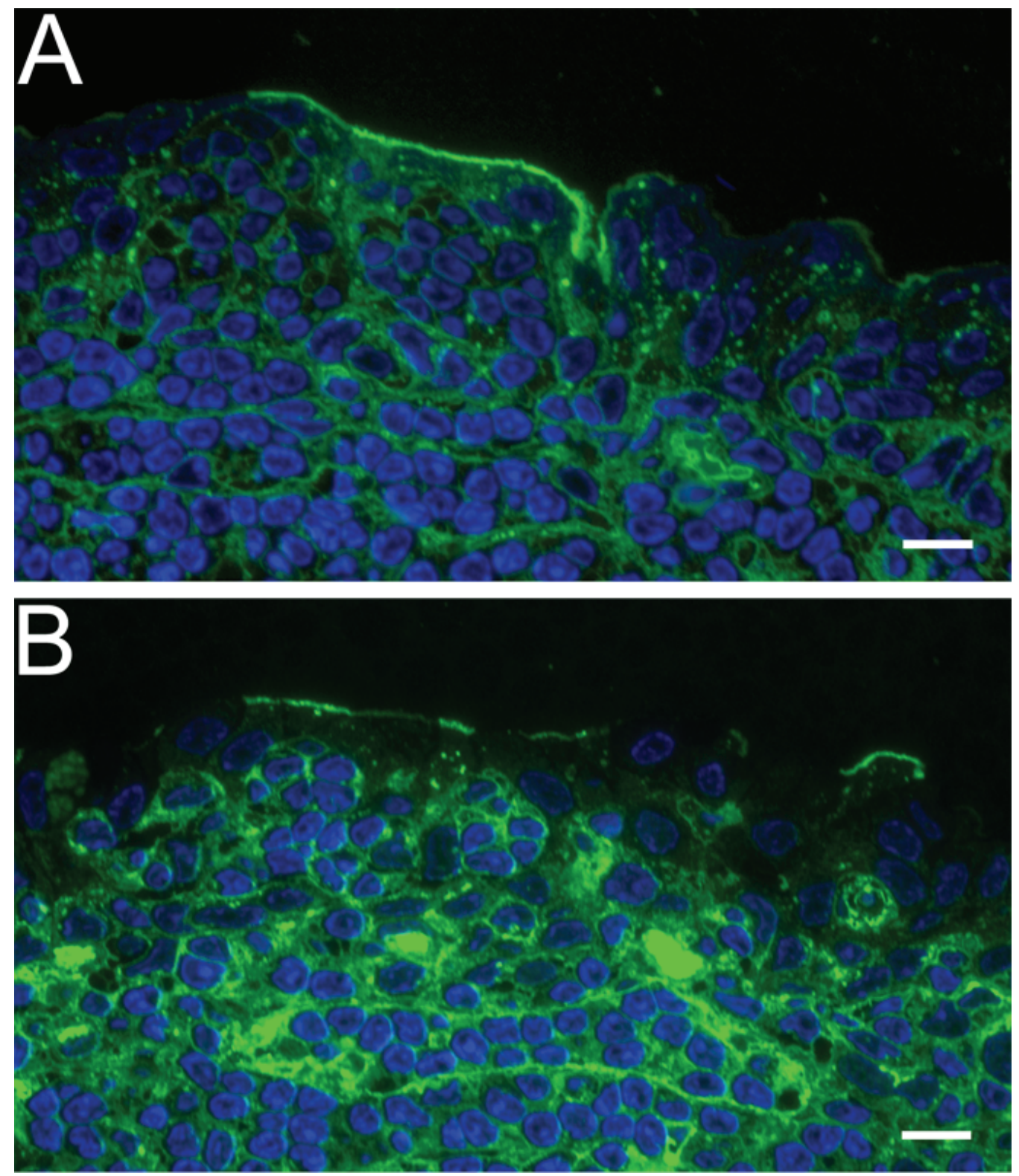

Figure 2-15. MAL-I (A) and MAL-II (B) selective labeling of the apical surface of Guinea pig conjunctival FAE. Semi-thin sections stain with MAL-Ifluorescein $(A)$ or biotinylated MAL-II secondarily labelled with mouse anti-biotin followed by Alexa 488 conjugated goat anti-mouse lgG. Both lectins (green) labeled the apical surface of epithelial cells associated with intraepithelial lymphoid pockets. Nuclei are counterstained with DAPI (blue). Scale bar (A, B): $10 \mu \mathrm{m}$. 

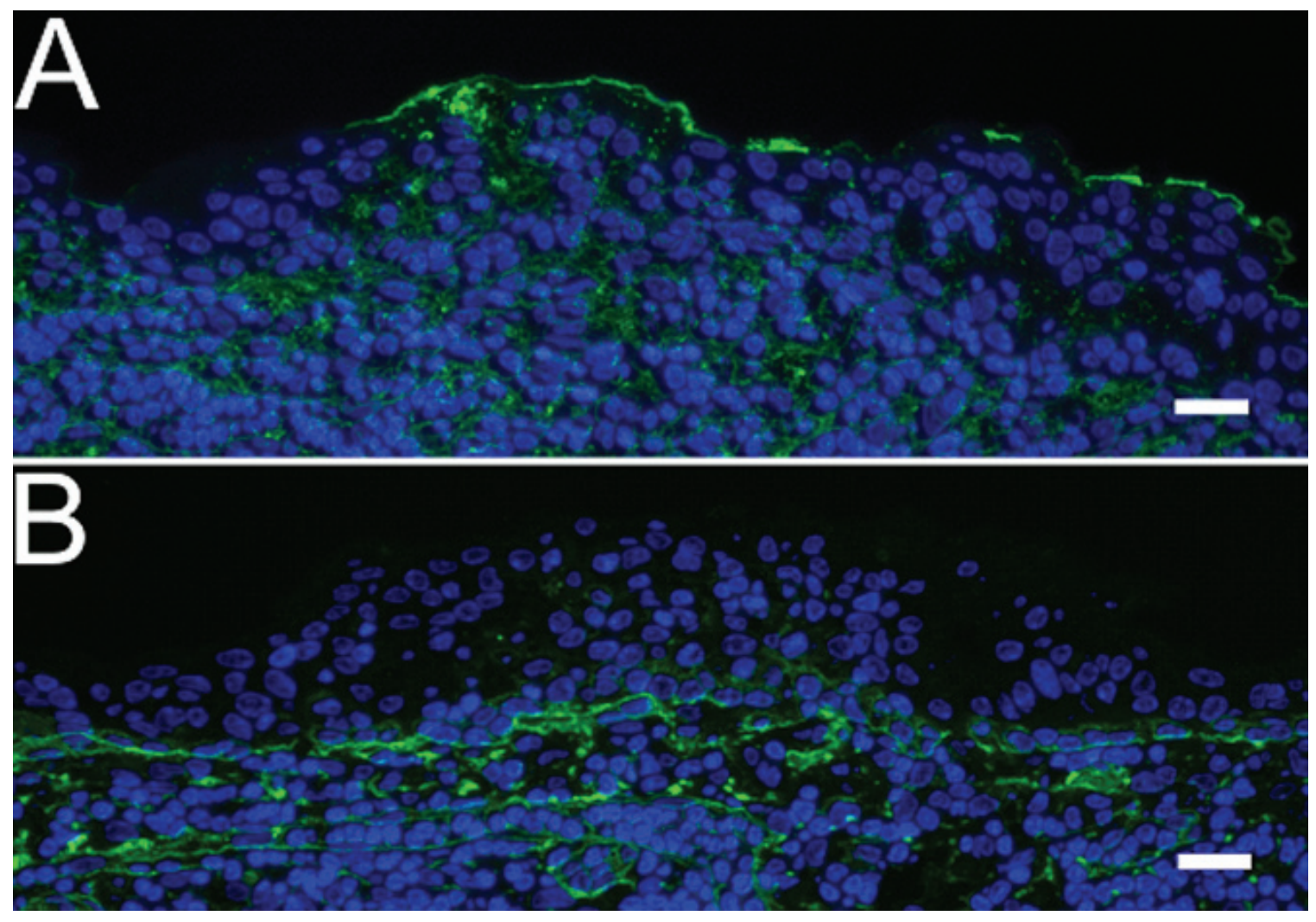

Figure 2-16. Neuraminidase pre-treatment abolished MAL-I binding to the apical surface of conjunctival FAE sections. Conjunctival FAE sections were pre-treated with either control buffer or neuraminidase and then incubated with MAL-I-fluorescein. MAL-I bound to the apical surface (arrows) of a subset of FAE cells in mock-treated sections (A) but was absent following neuraminidase exposure (B). Nuclei have been counterstained blue using DAPI. Scale bar: 20 $\mu \mathrm{m}$. 


\subsection{Discussion}

Our findings demonstrate intense MAL-I staining limited to the apical membranes of a subset of FAE cells and occasional weak staining in non-FAE regions. This staining pattern is analogous to findings of intestinal M-cell-specific lectins, for example, the fucose binding lectin UEA-I intensely labels $M$ cells in the mouse Peyer's patches, accompanied by much weaker labeling of a limited number of enterocytes on adjacent villi (Giannasca et al., 1994a). Further investigations are now necessary to determine whether this putative $\mathrm{M}$ cell marker can be transcytosed in vivo; thereby demonstrating a true, functional $\mathrm{M}$ cell in the Guinea pig conjunctiva.

Both MAL-I and MAL-II have been reported to preferentially bind to oligosaccharides with an $\alpha(2-3)$ linked terminal sialic acid. MAL-I was shown to bind $10 x$ stronger to Neu5Aca(2-3)Galß(1-4)GlcNAc than asialo-Galß(14)GIcNAc epitope (Knibbs et al., 1991). Alternative oligosaccharide moieties bound poorly, such as an $\alpha(2-6)$ linked terminal sialic acid or a Gal $\beta(1-3)$ GlcNAc linkage (Knibbs et al., 1991). Similarly, MAL-Il was shown to bind sialoglycopeptides much more strongly than the corresponding asialo-glycopeptides (Yamamoto et al., 1997). In the present study, two pieces of additional evidence argue that MAL-I and MAL-II bind to the sialylated epitope rather than Gal $\beta(1-$ 4)GIcNAc. First, MAL-I and MAL-II binding was eliminated when the sections are pre-treated with neuraminidase which cleaves sialylated groups. Second, the Galß(1-4)GlcNAc binding lectin ECL stained all epithelial cells in the Guinea pig conjunctiva, whereas MAL-I and MAL-II did not stain the non-FAE either before 
or after neuraminidase treatment. Fucosylation of the sialyllactose epitope was unlikely since the anti-sialyl Lewis ${ }^{x}$ antibodies failed to stain the conjunctival FAE. It is possible that the sialyllactose epitope, Neu5Aca(2-3)Galß(1-4)GIcNAc, plays a significant role in the antigen-sampling capabilities of conjunctival $\mathrm{M}$ cells, since there are several pathogens known to bind sialyllactose, including reovirus (Connolly et al., 2001a), influenza virus (Gambaryan et al., 1997), Helicobacter pylori (Hirmo et al., 1998b), and Mycoplasma pneumoniae (Roberts et al., 1989a).

The non-selective distribution of staining of the apical membranes of all conjunctival epithelium by the majority of the lectins tested in the present study may be a consequence of aldehyde fixation which increases the availability of carbohydrate binding sites in the glycocalyx, and consequently decreases selective labeling by lectins (Frisch et al., 1990).

In vitro studies from this chapter lead to the identification of a potential $\mathrm{M}$ cell marker. We can test whether this lectin is a marker for the apical membrane of $\mathrm{M}$ cells, since specific binding may trigger transcytosis. The next series of experiments will focus on the ability of these cells to internalize MAL-I in vivo. 


\section{CHAPTER 3. MAL-I UPTAKE STUDIES IN VIVO}

\subsection{Abstract}

Antigen-sampling $M$ cells are found in the follicle-associated epithelium (FAE) above organized lymphoid tissue in many mucosae. They play a key role in initiating the mucosal immune response and act as a site of entry for opportunistic pathogens. M cells have been extensively studied in the respiratory and gastrointestinal mucosal associated lymphoid tissue (MALT), but their presence in the ocular MALT has not been confirmed. Previous experiments in our lab identified Maackia amurensis leukoagglutinin I and II (MAL-I and MAL-II) as potential conjunctival $\mathrm{M}$ cell markers based on a screening of 12 lectins and 5 carbohydrate epitope antibodies on aldehyde-fixed follicles (Chapter 2). In order to determine whether these potential markers are specific for $\mathrm{M}$ cells, transcytosis, a defining functional characteristic of $\mathrm{M}$ cells, must be demonstrated by this cell population. This study uses MAL-I to investigate the presence of functional $\mathrm{M}$ cells in the Guinea pig conjunctiva.

Biotinylated or fluorescein conjugated MAL-I was then instilled into conjunctival sacs in vivo for $15-60$ min. Specimens were assessed by epifluorescence stereomicroscopy, confocal scanning laser microscopy and transmission and scanning electron microscopy (TEM \& SEM). Selective labeling of a subset of epithelial cells overlying lymphoid follicles was observed following in vivo exposure to MAL-I. MAL-I labeling was restricted to cells with sparse, irregular microvilli. Furthermore, cells preferentially-labeled with MAL-I were found to internalize the lectin during a $60 \mathrm{~min}$ in vivo exposure. Cells, 
which contained numerous MAL-I-labeled intracellular vesicles, transcytosed this lectin to the basolateral membrane, where it was taken up by intraepithelial immune cells, within a 45 min in vivo incubation.

This study demonstrates that the Guinea pig conjunctiva contains a cell with morphological and functional characteristics of antigen-sampling $\mathrm{M}$ cells. Additionally, the apical surface of M cells in the Guinea pig conjunctiva, but not adjacent epithelial cells, are consistently labeled by the sialyllactose-binding lectin, MAL-I.

\subsection{Introduction}

$M$ cells were first discovered in the FAE of gastrointestinal Peyer's patches (Owen et al., 1974b). Subsequent studies identified M cells in tonsils, nasal cavities, and the bronchi (Spit et al., 1989b; Gebert et al., 1992; Gebert et al., 1995b). Cells with the typical morphological characteristics of $M$ cells have been reported in the Guinea pig and canine conjunctival FAE; however, definitive evidence of selective binding and transcytosis by these putative $\mathrm{M}$ cells was lacking (Latkovic, 1989; Giuliano et al., 2002). In the present study, we demonstrate that the Guinea pig conjunctival FAE contains cells which preferentially bind and translocate macromolecular tracers, like true intestinal M cells.

Most of the work presented in this chapter has been published: Meagher, C.K., Liu, H., Moore, C.P. and Phillips, T.E. (2005). "Conjunctival M cells selectively bind and translocate Maackia amurensis leukoagglutinin" 
Experimental Eye Research 80(4): 545-53. The Association for Research in Vision and Ophthalmology is the copyright holder of this work.

\subsection{Methods and Materials}

\section{$\underline{\text { Animals and surgical procedure }}$}

Eleven outbred, male Guinea pigs, between 28 - 31 days old, were used in the study (Harlan, Indianapolis, IN). All experimental procedures used in this study conformed to the ARVO Statement for the Use of Animals in Ophthalmic and Vision Research and University of Missouri Animal Care and Use Committee guidelines.

Guinea pigs were anesthetized with intramuscular injections of ketamine $\mathrm{HCl}(40 \mathrm{mg} / \mathrm{kg})$ and xylazine $(5 \mathrm{mg} / \mathrm{kg}$ ) and given intraperitoneal injections of butorphanol (2 mg/kg) for analgesia. Eyelids were sutured to create a partially sealed conjunctival sac. Twenty microliters of lectin $(500 \mu \mathrm{g} / \mathrm{ml} \mathrm{MAL-I})$ in sterile phosphate buffered saline (PBS: $138 \mathrm{mM} \mathrm{NaCl}, 2.67 \mathrm{mM} \mathrm{KCl}, 1.47 \mathrm{mM} \mathrm{KH}_{2} \mathrm{PO}_{4}$, $8.06 \mathrm{mM} \mathrm{Na}_{2} \mathrm{HPO}_{4}, \mathrm{pH} 7.4$ ) was instilled into conjunctival sacs in vivo and incubated for 15,45 , or $60 \mathrm{~min}$. The orbits were exenterated, the cornea separated from the sclera and the conjunctival sac opened as previously described in detail (Moore et al., 1987). The corners of the preparation were pinned out onto a flat piece of dental wax with the mucosal surface facing upwards. After thorough rinsing with PBS, the conjunctival flat mount preparation was immersed in the appropriate aldehyde fixative as described below. Following fixation and rinsing, the tissues were dissected using a 
stereomicroscope with either conventional white light or epi-fluorescent illumination. The follicles used in the present study were taken from the fornix region. Since there was no detectable difference in superior and inferior forniceal follicles, no distinction is made in the presentation of the data. Control tissue (non-follicular regions) used in post-embedding studies was also obtained from forniceal regions. Animals were euthanized with Nembutal (100 mg/kg).

\section{Lectins and antibodies}

Lectins and primary antibodies used in these studies included fluorescein conjugated MAL-I, rhodamine conjugated WGA (wheat germ agglutinin), and biotinylated MAL-I and MAL-II. Lectins were purchased from Vector Laboratories (Burlingame, CA). Secondary labels included mouse anti-biotin (Jackson ImmunoResearch Labs, West Grove, PA), Alexa 488 conjugated goat antimouse IgG (Molecular Probes, Eugene, OR) and $10 \mathrm{~nm}$ colloidal gold labeled goat anti-mouse IgG and goat anti-biotin (Electron Microscopy Sciences, Fort Washington, PA). Secondary antibodies did not cross-react with sections of conjunctiva when applied alone or after non-immune primary antibodies (data not shown). WGA-rhodamine was used to counterstain some whole mount follicles $(50 \mu \mathrm{g} / \mathrm{ml})$ and cryostat sections $(1 \mu \mathrm{g} / \mathrm{ml})$, and $300 \mathrm{nM}$ DAPI (4',6-diamidino-2phenylindole) was used to counterstained nuclei.

$\underline{\text { Tissue processing for fluorescent microscopy }}$ 
MAL-I-fluorescein labeled whole mounts ( $n=8$ eyes from 6 animals) were fixed for $2 \mathrm{hr}$ in $2 \% \mathrm{PF}$ (2\% freshly depolymerized paraformaldehyde in $70 \mathrm{mM}$ $\mathrm{NaCl}, 30 \mathrm{mM}$ HEPES, $2 \mathrm{mM} \mathrm{CaCl}$, $\mathrm{pH}$ 7.4), rinsed in $50 \mathrm{mM}$ glycine in HEPES wash buffer (HWB: $70 \mathrm{mM} \mathrm{NaCl}, 30 \mathrm{mM}$ HEPES, $2 \mathrm{mM} \mathrm{CaCl}_{2}, \mathrm{pH} 7.4$ ) then viewed by epi-fluorescent stereomicroscopy and confocal scanning laser microscopy. After viewing, some tissues were dissected into small pieces $(\sim 2$ $\mathrm{mm} \times 2 \mathrm{~mm}$ ), infiltrated with $30 \%$ sucrose and frozen in Tissue-Tek O.C.T. (Electron Microscopy Sciences). Cryosections (5 $\mu \mathrm{m}$ thick) were prepared from frozen blocks of tissue and examined using wide-field and confocal fluorescence microscopy.

\section{$\underline{\text { Tissue processing for Scanning Electron Microscopy }}$}

Tissues previously labeled with MAL-I-biotin in vivo for SEM $(\mathrm{n}=5$ eyes from 3 animals) were fixed for $2 \mathrm{hr}$ in PFG (2.5\% glutaraldehyde and $2 \%$ paraformaldehyde in HWB) and then thoroughly rinsed in $50 \mathrm{mM}$ glycine in HWB. Follicles and surrounding non-FAE tissues from the fornix were then dissected out and incubated in 1:10 gold conjugated goat anti-biotin in $0.1 \%$ acetylated BSA (Electron Microscopy Sciences) for $60 \mathrm{~min}$. The diameter of the gold particles was subsequently increased using a gold enhancement kit for 20 min according to the manufacturer's protocol (Nanoprobes, Yaphank, NY). Tissues were then osmicated for $2 \mathrm{hr}$ in $1 \% \mathrm{OsO}_{4}$ in $\mathrm{HWB}$, rinsed in deionized water $\left(\mathrm{dH}_{2} \mathrm{O}\right)$ and dehydrated with an ethanol series which was followed by up with critical point drying with a Tousimis Auto-Samdri 815 automatic critical point dryer 
(CPD) (Tousimis Research Corporation, Rockville, MD) and carbon coating with an Emitech 950 Turbo Evaporator (Emitech LTD., Kent, England). The specimens were viewed with a Hitachi S-4700 Field Emission Scanning Electron Microscope (FESEM) (Hitachi, LTD., Tokyo, Japan) using secondary electron and backscattered electron (SE or BSE) imaging with an acceleration voltage of $10 \mathrm{KeV}$ and beam current of $20 \mu \mathrm{A}$. Adobe Photoshop (San Jose, CA) was used to overlay images captured using SE and BSE signals.

\section{Tissue preparation for Transmission Electron Microscopy}

MAL-I-biotin labeled flat mounts ( $\mathrm{n}=9$ eyes from 8 animals) were fixed for $2 \mathrm{hrs}$ in PFG and then rinsed with $50 \mathrm{mM}$ glycine in HWB. Following dissection, the isolated follicles and surrounding tissue were en bloc stained with $0.5 \%$ uranyl acetate in $25 \%$ ethanol for $1 \mathrm{hr}$ and then infiltration and embedding in LR Gold acrylic resin at $4^{\circ} \mathrm{C}$. Ultrathin sections $(50-80 \mathrm{~nm})$ were collected on Formvar and carbon-coated nickel grids. Grids were preincubated on drops of Aurion goat gold conjugate blocking solution (Electron Microscopy Sciences) for 30 min to prevent non-specific binding. Immunolabeling was performed on $25 \mu \mathrm{l}$ drops of $1.3 \mu \mathrm{g} / \mathrm{ml}$ mouse anti-biotin followed by a $1: 40$ dilution of gold labeled goat anti-mouse in $0.1 \%$ acetylated BSA. Finally, grids were washed on drops of

$0.1 \%$ acetylated BSA between incubations and rinsed with $\mathrm{dH}_{2} \mathrm{O}$ before counterstaining with saturated uranyl acetate solution and Reynold's lead citrate solution. Images were collected on a JEOL 1200EX transmission electron microscope (TEM) (JEOL, LTD.; Tokyo, Japan). 


\section{Image Analysis}

In order to compare total MAL-I-labeled surface area of FAE vs. non-FAE specimens, a series of 10 to 25 SEM images at 2000x were taken of nine follicles (3 each from 3 different eyes). Each set of images was then combined into a single montage of the entire follicle. After inserting the backscatter detector, high contrast BSE images of the higher atomic number colloidal gold particles were obtained. These images were thresholded using image analysis software. Using Adobe Photoshop, a line was drawn around the perimeter of each follicle which created a unique shape. The unique shape created by outlining each follicle, was then randomly superimposed on an adjacent non-FAE control region. Photoshop was also used to outline the individual cells within each region. The MetaMorph image analysis software package (Universal Imaging, Inc., Downington, PA) was used to acquire total area of FAE and non-FAE regions, as well as, the percentage of gold-labeled cell surface area. Positively staining $(+++)$ cells were defined as those with gold labeling accounting for at least $10 \%$ of the cell's surface area. Data was compared using Student's t-test.

\subsection{Results}

\section{MAL-I in vivo labeling of conjunctival whole mounts}

When a whole mount preparation of the Guinea pig conjunctiva is examined with conventional bright-field stereomicroscopy, large follicles appear 
as conspicuous dome-like protrusions from the forniceal mucosa and are often accompanied by distinctive branching of blood vessels around their perimeter. Smaller follicles were more subtle and harder to identify. In order to see if labeling with the putative M-cell-marker MAL-I would aid identification of follicles, MAL-I-fluorescein was incubated in the conjunctival sac for $60 \mathrm{~min}$ in vivo and then examined with fluorescent stereomicroscopy. After labeling, MAL-I was noted to preferentially label cells within the FAE, and all follicles were now easily identifiable as brightly speckled green fluorescent mounds in contrast with the flat, dimly illuminated surrounding tissue (Figure 3-1). Consistent with MAL-I staining on fixed sections, stereoscopic examination of in vivo labeled tissues confirmed that MAL-I labeling was weak or absent in non-FAE regions. Most follicles were found in the fornix region with occasional outlying follicles in the palpebral and bulbar regions. Each eye contained between 4 to 30 follicles or clusters of follicles with a slight tendency for more follicles in the inferior conjunctiva compared to the superior region. Consecutive cross-sectional views showed that many of the larger MAL-I-fluorescein stained regions were actually clusters of closely situated follicles.

\section{Characterization of MAL-I surface labeled cells using confocal microscopy}

MAL-I intensely labeled the apical surface of a subset of cells on FAE whole mounts which created a mosaic pattern when viewed by confocal microscopy. The strongly labeled cells had variable surface profiles which were frequently elongated polygons with sporadic stellate projections but sometimes 
were smaller and square shaped. WGA-rhodamine, which was found to bind to the apical surface of all FAE, was used to better visualize the rest of the epithelium cells which were not labeled by MAL-I. When MAL-I labeled whole mount tissues were counterstained with WGA-rhodamine in vitro and viewed by confocal microscopy, MAL-I labeled cells were interspersed amongst cells labeled by WGA (Figure 3-2).

\section{SEM characterization of MAL-I labeled cells}

Three epithelial cell types based on morphologically distinct apical surfaces were observed in association with follicles of the conjunctiva by SEM. Goblet cells were easily distinguished from all other cell types by their characteristic circular apical profile. The majority of epithelial cells observed were in a "cobblestone" arrangement, having a variety of polygonal shapes from small squares to large rectangles with a regular carpeting of $\sim 350 \mathrm{~nm}$ long microvilli (Figure 3-3). Lastly, there were also cells with various shapes resembling the MAL-I-fluorescein labeled cells seen with confocal microscopy. These cell profiles, which included elongated polygons with random stellate projections and some that were more square and variable in size, were also labeled with MAL-I-biotin and secondarily labeled with gold. Gold particles in this BSE image were pseudo-colored to dramatically demonstrate the unusual apical profiles of these cells (Figure 3-4). At higher power, these cells could be seen to have irregular microvilli or microplicae that were more sparse and variable in length $(\sim 0.1 \mu \mathrm{m}$ to $1 \mu \mathrm{m})$ than normal epithelial microvilli (Figure 3-3B). 


\section{MAL-I internalization}

To test whether the cells which preferentially bound MAL-I were able to subsequently internalize the lectin, follicles were exposed to MAL-I-fluorescein for $60 \mathrm{~min}$ in vivo. Cryosections prepared from this tissue were viewed by confocal microscopy and revealed that a subset of FAE cells was packed with endosomes containing MAL-I (Figure 3-5). These findings confirm that a cell type within the FAE is able to selectively bind and endocytose MAL-I. Cells in cryostat sections of non-FAE regions were not labeled on their apical surfaces nor did they show any evidence that they endocytosed MAL-I.

\section{$\underline{T E M}$ characterization of MAL-I labeled cells}

After finding that a portion of the FAE cells could internalize MAL-I, it was necessary to determine whether these cells possessed the ability to perform transcytosis, a defining functional characteristic of $M$ cells. TEM was used to establish whether transcytosis had occurred by identifying MAL-I within the intraepithelial pocket and lymphocytes which were adjacent to epithelial cells that had numerous endosomes filled with MAL-I. After a $45 \mathrm{~min}$ in vivo incubation with biotinylated MAL-I, follicles were dissected out and embedded into LR Gold. Indirect staining to detect MAL-I with $10 \mathrm{~nm}$ gold was performed on thin sections. Cells which had endocytosed MAL-I into vacuoles and subsequently delivered their contents to the intraepithelial pocket were identified by abundant gold labeling within intracellular vesicles, and along the basolateral membrane (Figure 
3-6). Sparse labeling was observed inside the intraepithelial lymphoid cells at this time point. Furthermore, these cells which demonstrated transcytosis of lectin had morphological features of $\mathrm{M}$ cells; i.e. the cells were in direct contact with intraepithelial lymphocytes, contained many vesicles, and had sparse microvilli. FAE cells not associated with lymphoid pockets, as well as, non-FAE cells were not labelled with gold (data not shown).

\section{Characterization of MAL-I-labeling on FAE vs. non-FAE cells by SEM}

MAL-I-labeling of the apical surface of cells within the FAE and non-FAE was characterized by SEM. Conjunctival sacs were incubated with biotinylated MAL-I for 15 min in vivo, fixed, and indirectly labeled with $10 \mathrm{~nm}$ gold followed by gold enhancement. Computer assisted morphometric analysis was used to identify positively labeled (+++) cells which we defined as those with $>10 \%$ of their total apical surface area covered by gold in the BSE images. The number of labeled cells was significantly greater $(p<0.01)$ in the FAE region $(3.35 \pm 0.69$ per $1000 \mu \mathrm{m}^{2}$; mean \pm std. dev.) than in the non-FAE areas $(0.09 \pm 0.12 ; n=3$ follicles or non-FAE regions each from 3 eyes). BSE and SE images revealed that labeled cells displayed $\mathrm{M}$ cell morphologic characteristics, including sparse microvilli that varied in length intermixed with microplicae (Figure 3-3B).

\subsection{Figures}




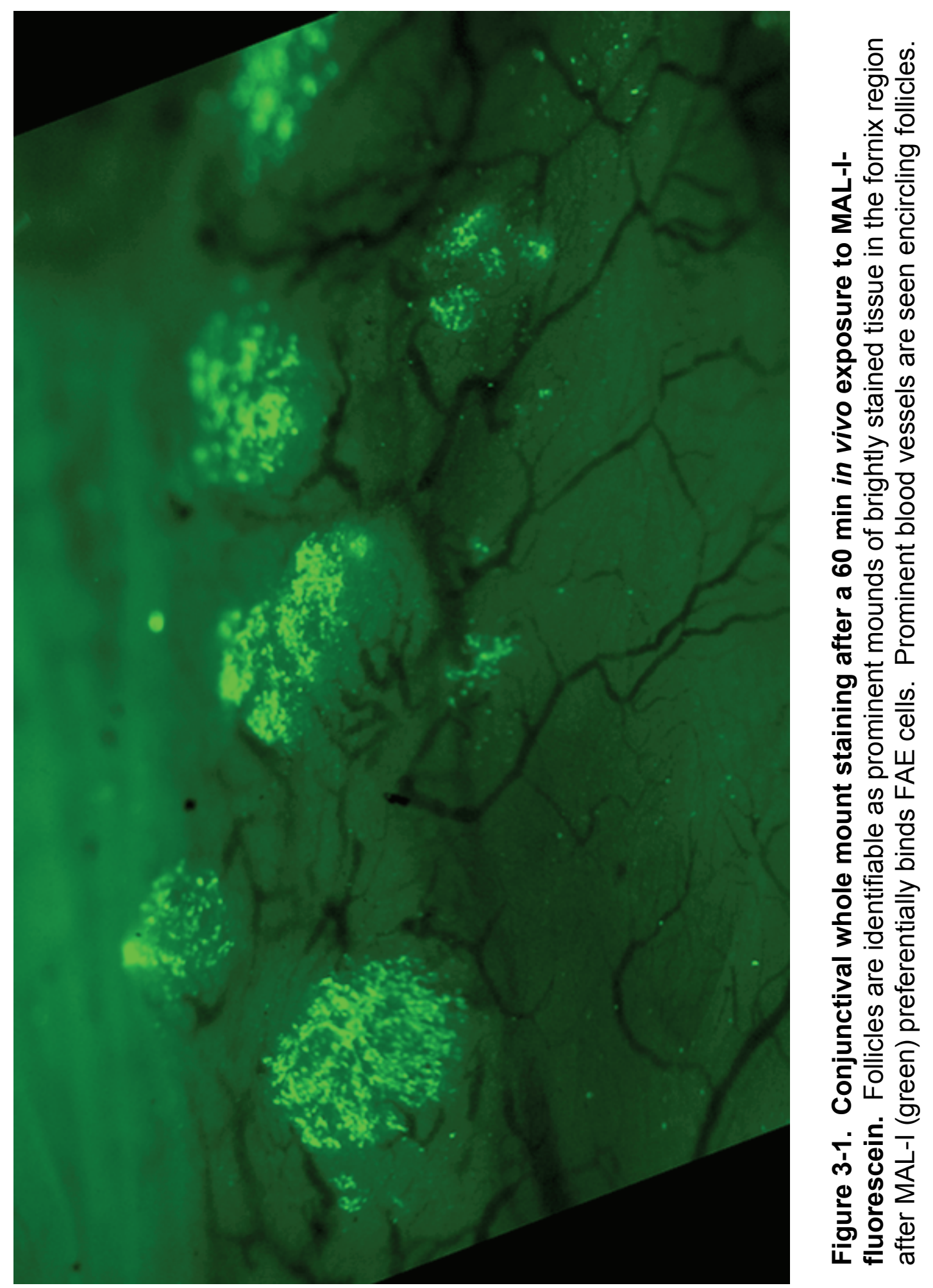




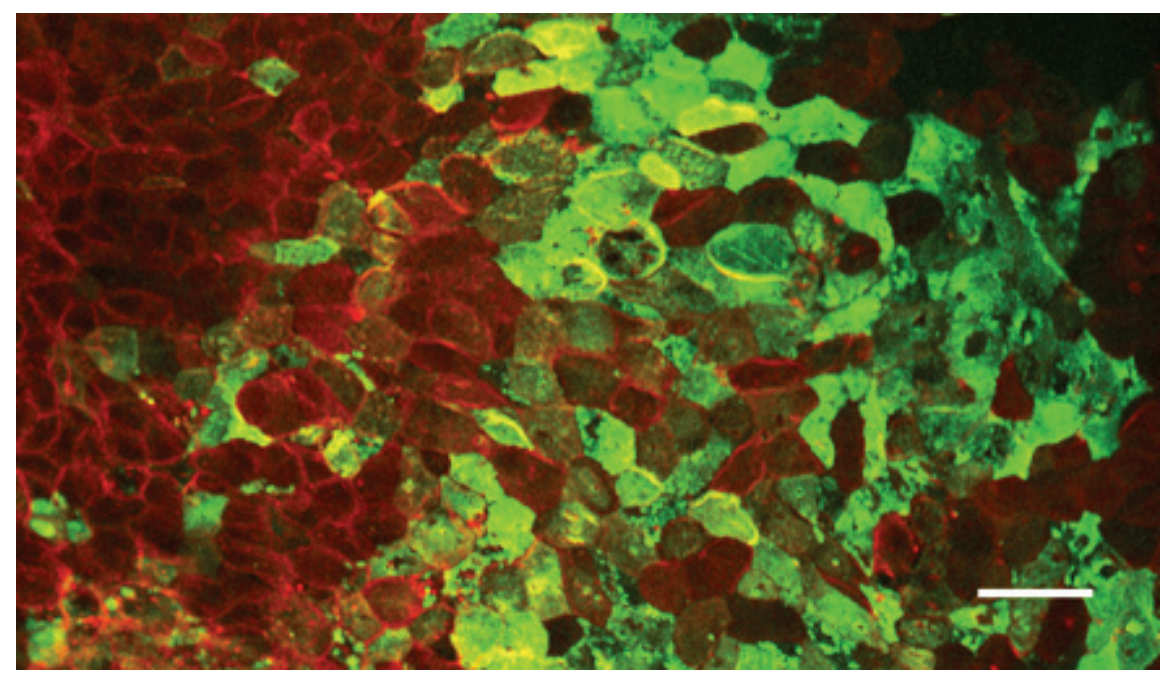

Figure 3-2. Conjunctival whole mount staining after a $60 \mathrm{~min}$ in vivo

exposure to MAL-I-fluorescein. Confocal microscopy was used to view follicles labeled in vivo with MAL-I (green) and counterstained with WGA-rhodamine (red) in vitro. Brightly stained MAL-I cells are generally elongated with stellate processes and intermingled amongst the neighboring WGA-stained cells. Scale bar: $30 \mu \mathrm{m}$. 

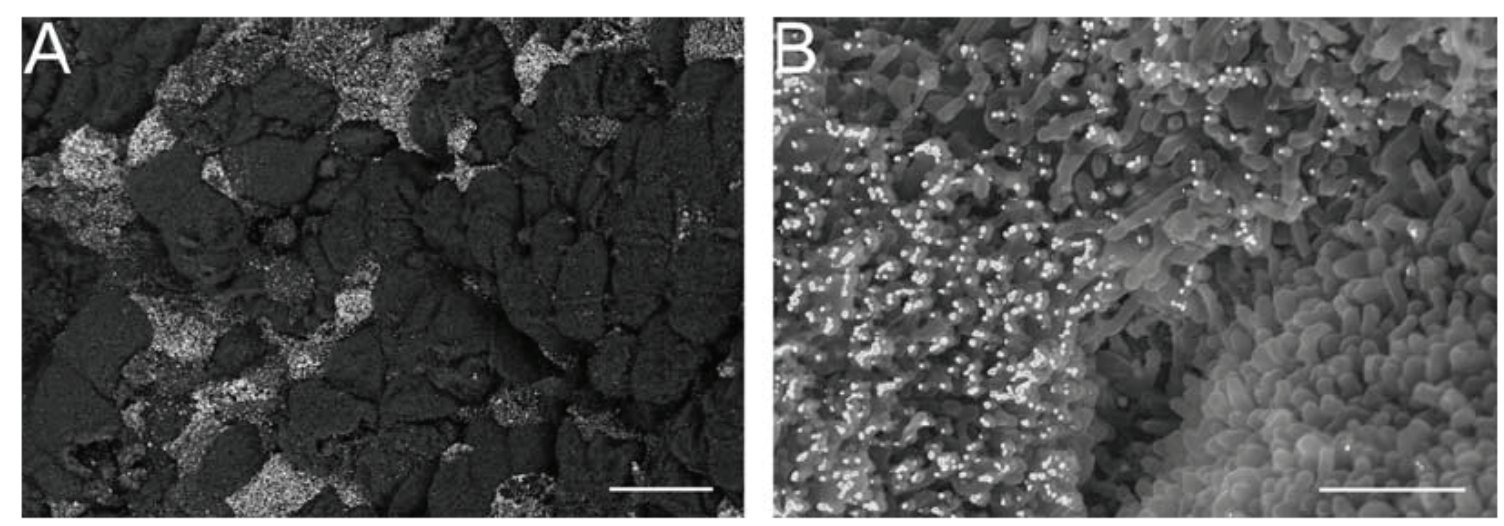

Figure 3-3. Preferential adherence of MAL-I to the apical surface of certain conjunctival FAE cells. Conjunctival tissue exposed to biotinylated MAL-I in vivo for 15 min followed by detection with a gold conjugated secondary antibody and gold enhancement. BSE view shows a selective labeling pattern similar to Figure 3-2 (A). A closer view using a BSE image overlaid on the SE image, shows irregularity in microvilli length and density of the labeled cell compared with the more uniform microvilli on the adjoining unlabeled cell $(B)$. Scale bars: (A) $10 \mu \mathrm{m}$; (B) $1 \mu \mathrm{m}$. 


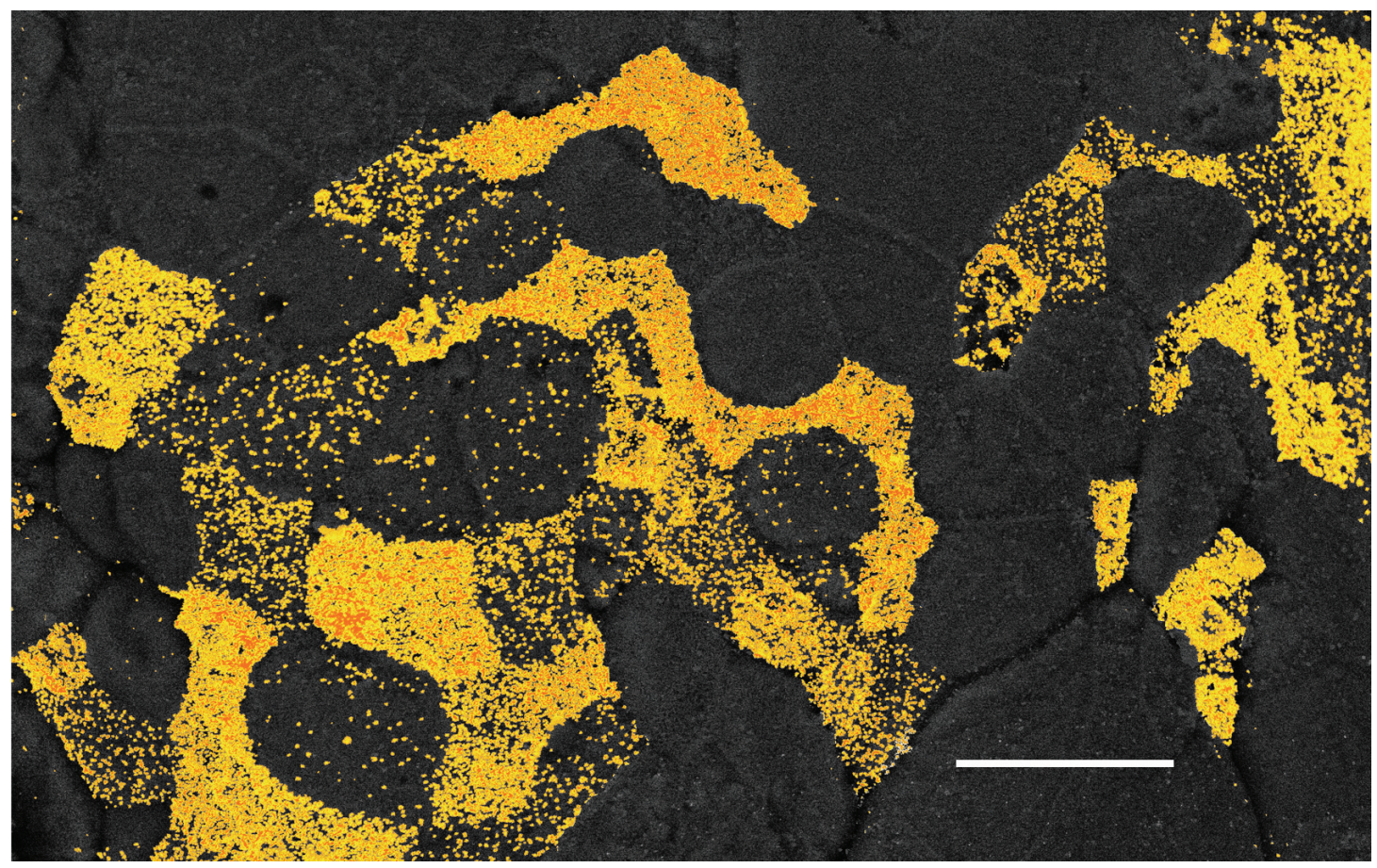

Figure 3-4. Pseudo-colored BSE image of MAL-I labeled cells. The apical surface of FAE was labeled with MAL-I after a 15 minute in vivo incubation with the lectin. MAL-I was indirectly labeled with gold and a BSE image was captured using SEM. Adobe Photoshop was used to pseudocolor gold labeling. Scale bar: $10 \mu \mathrm{m}$. 


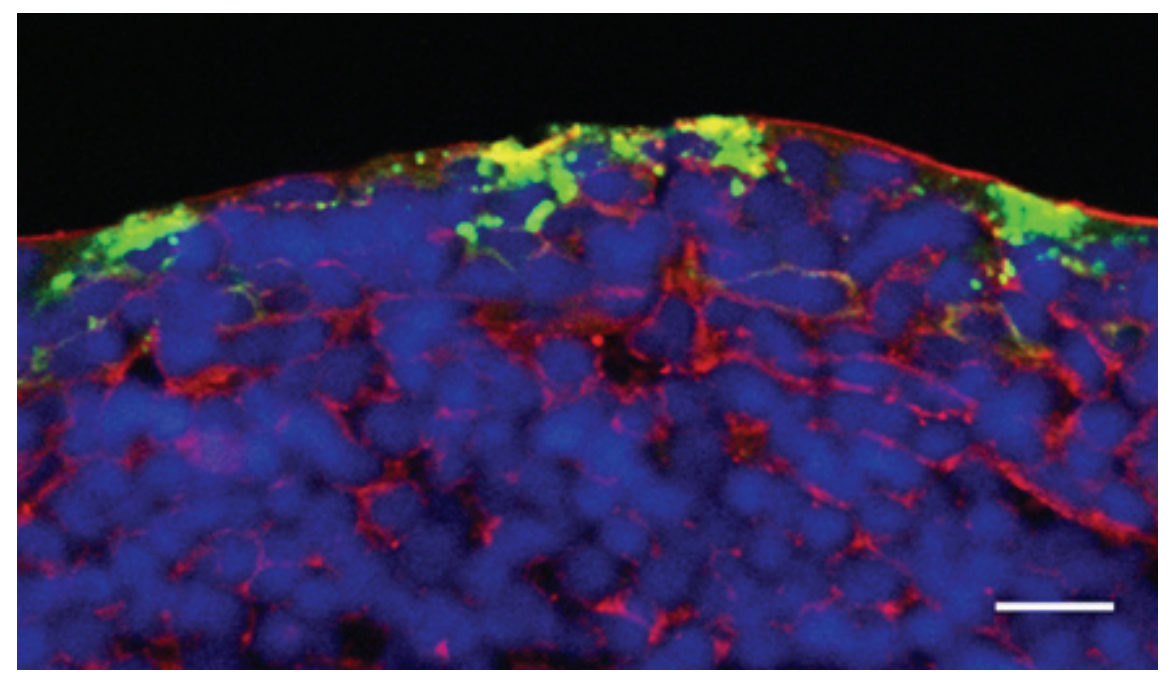

Figure 3-5. MAL-I internalization by conjunctival FAE cells. Cryostat sections $(5 \mu \mathrm{m})$ were prepared following in vivo staining with MAL-I-fluorescein for 60 min. Sections were counterstained with DAPI and WGA-rhodamine (red). Labeled cells were only found over follicles. Scale bar: $30 \mu \mathrm{m}$. 


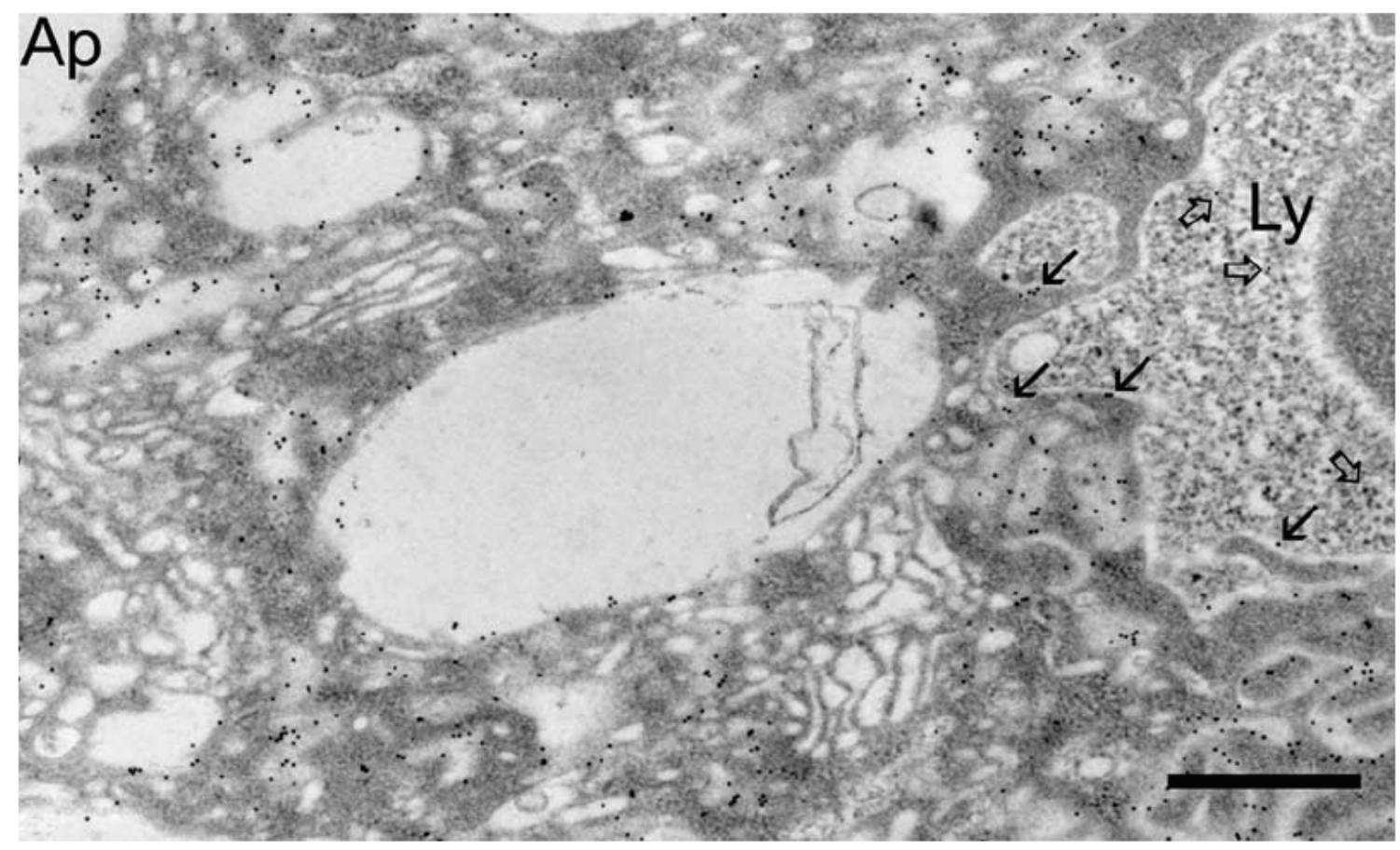

Figure 3-6. MAL-I transcytosis by a subset of FAE cells. Biotinylated MAL-I was exposed to the conjunctival sac for $45 \mathrm{~min}$. LR Gold sections were immunostained with a gold conjugated secondary antibody to detect biotinylated MAL-I. MAL-I was found in tubular-vesicular endosomes, along the basolateral membranes, including the membrane bordering the intraepithelial pocket filled with lymphocytes (thin arrows). Gold labeling can be found in the cytoplasm of the intraepithelial lymphoid cells at this time (thick arrows). Ap = apical surface; Ly = lymphocyte. Scale bar: $0.5 \mu \mathrm{m}$. 


\subsection{Discussion}

The question of whether the conjunctival FAE contains an antigensampling M cell such as found in other organized MALT has been the subject of debate (Chodosh et al., 1998c; Zierhut et al., 1998). Previous studies from our lab have identified the leguminous lectins, MAL-I and MAL-II, as potential M-cell markers in the Guinea pig conjunctiva. MAL-I and MAL-II were shown to specifically label a subset of FAE cells within fixed conjunctival sections and tissues exposed in vivo. Importantly, MAL-I labeling provided an effective tool for identifying follicles in whole mount conjunctiva, thereby demonstrating that the FAE contains a distinct cell type with a unique glycocalyx. In vivo studies demonstrated that MAL-I was internalized by cells containing an extensive tubulo-vesicular network, and subsequently transcytosed to basolateral membranes. The majority of cells that internalized MAL-I were closely associated with intraepithelial lymphoid cells that invaginated their basolateral membrane and gave rise to a thin apical bridge. The distinctive morphological characteristics, together with functional properties of the MAL-I labeled cells, unequivocally establish them as the conjunctival equivalent of $\mathrm{M}$ cells at other mucosal surfaces.

Previous studies have relied solely on morphological characteristics to identify M cells in the conjunctiva of Guinea pig, rabbit, and dog (Chandler et al., 1980; Latkovic, 1989; Giuliano et al., 2002). Nevertheless, this approach has since been argued to be inaccurate due to wide variations in $\mathrm{M}$ cell ultrastructure and histochemistry (Gebert et al., 1999). Classification of a true M cell must also entail functional demonstration of antigen transcytosis (Gebert, 1997; Chodosh et 
al., 1998b). Until the present study, little evidence existed for either selective labeling or uptake of macromolecular tracers by purported $\mathrm{M}$ cells in the conjunctiva. In an earlier study in which the Guinea pig conjunctiva was exposed to latex microspheres, beads were phagocytosed not only by the 'supranodular' epithelium but also by cells of the perilimbal region and occasional goblet cells (Latkovic et al., 1984). This lack of cell-type specificity without demonstration of transcytosis, failed to reveal a role for $\mathrm{M}$ cells in this process. Additional studies of Guinea pig conjunctiva have similarly demonstrated non-selective uptake of the macromolecular tracer horseradish peroxidase (HRP) by both FAE and nonFAE (Stock et al., 1987). Again, the non-specific uptake of a soluble tracer such as HRP simply suggests that these epithelial cells are undergoing active pinocytosis, a process known to occur in most cells. It is important to note that the defining functional characteristic of an $\mathrm{M}$ cell is its ability to selectively bind and transcytose macromolecules. Such criteria were met by the studies described here.

The finding of functional $\mathrm{M}$ cells in the conjunctival mucosa warrants future studies on its implications for ocular immunity. In the gut, the mucosal immune response is potentiated by both selectively binding pathogens and nonselectively "sampling" soluble luminal antigens by $\mathrm{M}$ cells, which then translocate these antigens to underlying lymphocytes and antigen-presenting cells. This has prompted many studies aimed at using M-cell-targeted immunogens as the vehicle to elicit local mucosal immunity (Wu et al., 2001; Clark et al., 2002). Similar strategies, using MAL-I, may be used to investigate immune responses in 
the eye. Furthermore, because opportunistic bacterial and viral pathogens have been found to cause disease following $M$ cell-mediated translocation across the mucosal barrier (Clark et al., 2003; Helander et al., 2003; Fujimura et al., 2004), future studies should address whether ocular pathogens can similarly use the conjunctival $\mathrm{M}$ cell as a port of entry. 


\section{CHAPTER 4. HAEMOPHILUS INFLUENZAE UPTAKE IN VIVO}

\subsection{Abstract}

Antigen-sampling $\mathrm{M}$ cells have been identified in conjunctival tissue overlying lymphoid follicles in rabbits and Guinea pigs in previous studies by our lab. Guinea pig conjunctival M cells were found to display $\alpha(2-3)$ sialic acid on their surface, through selective labeling by Maackia amurensis leukoagglutinin I (MAL-I). Sialic acid was confirmed to be involved in lectin binding since neuraminidase pre-treatment of specimens abolished MAL-I binding. The M cells of the conjunctiva have been shown to transcytose small macromolecular markers, but it is unknown if they, like $\mathrm{M}$ cells at other mucosa-associated lymphoid tissue (MALT), can also translocate large microbes. To test the hypothesis that MAL-I positive M cells are able to translocate bacteria, the nontypeable Haemophilus influenzae strain OM12, which expresses the HMW1 adhesin for $\alpha(2-3)$ sialic acid, and reference $H$. influenzae strain Rd KW20, which lacks HMW1, were used for in vivo functional assays.

Bacteria, pre-labeled with fluorescein, were instilled into the conjunctival sac for up to $130 \mathrm{~min}$. Bacterial distribution in the Guinea pig conjunctiva was assessed using confocal laser scanning microscopy and electron microscopy. M cells were found to selectively bind and translocate bacteria, while nonfollicular epithelial cells in the palpebral region did not. The number of fluorescent bacteria found within $15.4 \mu \mathrm{m}$ of the epithelial surface was counted using 3dimensional reconstructions of follicle-associated epithelium (FAE) and non-FAE 
regions. After a 66 min in vivo exposure, $423 \pm 165$ bacteria per $\mathrm{mm}^{2}$ of $\mathrm{FAE}$ were counted within $15.4 \mu \mathrm{m}$ from the surface. No bacteria were found in nonFAE palpebral regions at the corresponding time. By $127 \mathrm{~min}$, the number of bacteria increased to $579 \pm 44$ per $\mathrm{mm}^{2}$ of FAE surface and they had moved $50 \%$ deeper into the follicle. At this time-point, control palpebral regions occasionally contained an isolated bacterium but overall had less than $3 \%$ of the number found in the FAE region. Co-administration with MAL-I reduced OM12 transport by $61 \%$. Similarly, Rd KW20 uptake was $71 \%$ less at $63 \mathrm{~min}$ and $58 \%$ less at $121 \mathrm{~min}$, indicating OM12 uptake is at least partially mediated by binding to $\alpha$ (23) sialic acid.

This study demonstrates that conjunctival $\mathrm{M}$ cells are a port of entry for large microbes, as documented for other mucosa-associated lymphoid tissue (MALT). Conjunctival M cells may play a role in initiating a mucosal immune response against commensal or transient ocular species, and potentially a role in uptake of pathogens.

\subsection{Introduction}

Antigen-sampling $M$ cells have been shown to exist within the epithelium overlying conjunctiva-associated lymphoid tissue (CALT) in the Guinea pig and rabbit (Liu et al., 2005; Meagher et al., 2005). The distinctive features of M cell morphology include unusual microvilli, large numbers of intracellular membranous vesicles, and a thin apical bridge of cytoplasm overlying intercellular pockets of lymphocytes and macrophages. Each of these 
characteristic features participates in the principal function of $\mathrm{M}$ cells which is the sampling and transcytosis of antigens across the epithelium to underlying antigen-presenting cells. Antigen sampling by $\mathrm{M}$ cells initiates the mucosal immune response, which promotes the production of anti-inflammatory secretory $\lg \mathrm{A}$.

In other mucosal tissues, such as the Peyer's patches, the function of M cells in initiating the adaptive immune responses has been exploited by opportunistic bacterial and viral pathogens as a means to breach the mucosal barrier (Brayden et al., 2005). Beneath the epithelial surface the pathogens avoid elimination by antigen-presenting cells and may induce local or systemic disease.

Despite morphological evidence for the existence of $M$ cells in the conjunctival epithelia, it was important to establish, using functional parameters, whether microbes access the sub-epithelial region through $\mathrm{M}$ cells. Such a process may precede the generation of anti-microbial IgA present in the tear film (Coyle et al., 1988; Cheng et al., 1996; McClellan et al., 1998) or function as a conduit for ocular pathogens. Because M cells of the Guinea pig conjunctiva express $\alpha(2-3)$ sialic acid on their surface, microbes which bind this carbohydrate epitope were considered as good candidates for internalization by $\mathrm{M}$ cells (Meagher et al., 2005). Pathogens and microbes known to bind a(2-3) sialic acid include reovirus (Connolly et al., 2001a), influenza virus (Gambaryan et al., 1997), Helicobacter pylori (Hirmo et al., 1998b), Mycoplasma pneumoniae 
(Roberts et al., 1989a), and some strains of nontypeable Haemophilus influenzae (NTHi) (St Geme, 1994).

In the studies presented in this chapter, the gram-negative bacterium, nontypeable Haemophilus influenzae (NTHi) strain OM12 was used to test Mcell-mediated internalization across the conjunctiva. NTHi strains are respiratory pathogens as well as commensal organisms which colonize the nasopharynx in up to $80 \%$ of humans (Foxwell et al., 1998). When NTHi overcomes host mucociliary defenses, it may spread throughout the respiratory tract and cause diseases such as otitis media, conjunctivitis, sinusitis, pneumonia, and exacerbations of chronic bronchitis. Often this occurs in the setting of viral upper respiratory tract infections or allergic disease where colonization spreads to anatomically contiguous regions (i.e. middle ear, sinuses, the conjunctiva, or the lungs). Adherence of the organism to respiratory epithelium is of key importance in the pathogenesis of disease (reviewed in Foxwell et al., 1998). NTHi adherence is mediated by both pilus and non-pilus adhesins. The major nonpilus adhesins are high molecular weight 1 and 2 (HMW1/HMW2) and Hia (Buscher et al., 2004). The NTHi strain OM12 used in the experiments to follow is the strain from which HMW1/2 were originally cloned and sequenced. OM12s produce HMW1/HMW2 proteins but not Hia. Although HMW1 and HMW2 share $71 \%$ identity and $80 \%$ similarity, HMW1 is known to have specificity for oropharyngeal cells while HMW2 mediates binding with greater affinity to genital tract epithelial cells (Buscher et al., 2004). 
Early clues that suggested HMW1 and lectins may share overlapping specificities for target tissues came from competition experiments. St. Geme (1994) demonstrated that HMW1-mediated binding to Chang epithelial cells was

decreased by $76 \%$ when preincubated with Maackia amurensis agglutinin (MAA), a mixture of MAL-I and MAL-II isolectins. This finding suggested that HMW1 binds to $a(2-3)$ linked sialic acid, which is a similar binding site for MAL-I. Based on our earlier demonstration that MAL-I binds selectively to M cells of the Guinea pig conjunctiva, we reasoned that $\mathrm{M}$ cells may bind and translocate OM12 in vivo. In the following study, NTHi was used to test the hypothesis that M cells translocate microbes across the conjunctival surface.

Most of the work presented in this chapter has been published: Petris, C. K., Golomb, M. and Phillips, T. E. (2007). "Bacterial transcytosis across conjunctival M cells." Investigative Ophthalmology and Visual Science 48(5): 2172-2177. Elsevier is the copyright holder of this work.

\subsection{Methods and Materials}

\section{Guinea pigs}

Thirteen outbred, male Guinea pigs (Harlan, Indianapolis, IN), 5 - 7 weeks of age, were used in this study. All experimental procedures used in this study conformed to the ARVO Statement for the Use of Animals in Ophthalmic and Vision Research and University of Missouri Animal Care and Use Committee guidelines. 


\section{$\underline{\text { Bacterial strains }}$}

Nontypeable $H$. influenzae strain OM12 (R2846) was first isolated from the inner ear of a patient with otitis media (Barenkamp, 1986). Rd KW20 (R652) is a reference $H$. influenzae strain which has been fully sequenced (Fleischmann et al., 1995). Rd strains are generally avirulent in human (Skoczynska et al., 2005) and animal models (Williams et al., 2001) and are susceptible to killing by human serum (Williams et al., 2001). Both strains came from the collection of Arnold L. Smith (Seattle Biomedical Research Institute, Seattle, WA).

\section{Growth and fluorescent labeling of bacteria}

Bacteria colonies were grown overnight on chocolate agar (Coleman et al., 2003) without bacitracin, and resuspended at $A_{600}=2.0$ in calcium, magnesiumfree phosphate buffered saline (CMF-PBS: $138 \mathrm{mM} \mathrm{NaCl}, 2.67 \mathrm{mM} \mathrm{KCl}, 1.47$ $\mathrm{mM} \mathrm{KH}{ }_{2} \mathrm{PO}_{4}, 8.06 \mathrm{mM} \mathrm{Na}_{2} \mathrm{HPO}_{4}-7 \mathrm{H}_{2} \mathrm{O}, \mathrm{pH}$ 7.4). Bacterial labeling was carried out by adding an equal volume of fluorescein isothiocyanate (FITC; Sigma, St. Louis, MO) in the same buffer to achieve a final concentration of $0.5 \mathrm{mg} / \mathrm{ml}$, and the suspension was gently rotated for 15 minutes at room temperature in the dark. The labeling reaction was stopped with the addition of one-tenth volume 10 $\mathrm{mg} / \mathrm{ml} \mathrm{BSA}$ in PBS (CMF-PBS plus $0.901 \mathrm{mM} \mathrm{CaCl}_{2}, 0.493 \mathrm{mM} \mathrm{MgCl}_{2}-2 \mathrm{H}_{2} \mathrm{O}, \mathrm{pH}$ 7.4). Bacteria were washed three times with phosphate-buffered saline containing $0.1 \%$ gelatin (PBS-G) (Smith et al., 1973) and resuspended in PBS-G at an $\mathrm{A}_{600}=1.0\left(0.8-1.6 \times 10^{9} / \mathrm{ml} \mathrm{CFU} / \mathrm{ml}\right.$ for OM12 and $1.5-2.1 \times 10^{9} / \mathrm{ml}$ 
$\mathrm{CFU} / \mathrm{ml}$ for Rd). After a brief lag, FITC-labeled bacteria grew at the same rate as unlabeled bacteria and more than $90 \%$ were viable as CFU (data not shown).

\section{Surgical procedure}

Guinea pigs were given intramuscular injections of ketamine $\mathrm{HCl}$ (40 $\mathrm{mg} / \mathrm{kg}$ ) and xylazine (5 mg/kg) to induce and maintain anesthesia. Surgical procedures were carried out behind barrier conditions. Prior to bacterial instillation, the Guinea pig's head was rested on one side with the nose propped up to slow drainage through the lacrimal puncta. The orientation of the OD (right eye) was facing upward and parallel to the ground to ensure equal distribution of instillations to the superior and inferior conjunctival sacs. First, the 120 min incubation was begun in the right eye with the instillation of FITC-labeled bacteria in PBS-G $\left(A_{600}=1.0\right)$ into the superior and inferior conjunctival sac $(15 \mu \mathrm{l}$ each $)$. Bacteria were re-administered to each of the superior and inferior conjunctival sacs in $10 \mu \mathrm{l}$ aliquots at 10,20 , and 30 minutes after the initial instillation. At 50 min after initial instillation, the Guinea pig's head was re-situated so that the left eye was now facing upwards. Next, the 60 min incubation was begun with similar instillations at 50, 60, 70 and 80 min into the eye. At 110 min following the first instillation, animals were euthanized with an intravenous injection of Beuthanasia $(100 \mathrm{mg} / \mathrm{kg})$ and both eyes quickly exenterated, starting with the right eye. After removal of the lens, the conjunctival sac was cut at the lateral canthi and the preparation was pinned onto a wax backing with mucosal surfaces facing upward. Whole mounts were rinsed thoroughly with PBS-CMF and then 
fixed for at least $2 \mathrm{hr}$ in $2 \%$ freshly depolymerized paraformaldehyde (PF) in HEPES wash buffer (HWB: $70 \mathrm{mM} \mathrm{NaCl}, 30 \mathrm{mM}$ HEPES, $2 \mathrm{mM} \mathrm{CaCl}_{2}$, pH 7.4). Variations in dissection length resulted in the average time between the initial instillation to the time the tissue was placed in fixative of $66.0 \pm 2.0$ min (mean \pm standard deviation) and $126.7 \pm 4.9 \mathrm{~min}$.

In blocking experiments, $15 \mu \mathrm{l}$ aliquots of $0.5 \mathrm{mg} / \mathrm{ml}$ biotinylated Maackia amurensis leukoagglutinin I (MAL-I; Vector Laboratories; Burlingame, CA) were administered to both the superior and inferior conjunctival sacs 15 minutes before beginning the same series of instillations described above, with the addition of $0.5 \mathrm{mg} / \mathrm{ml} \mathrm{MAL-I-biotin} \mathrm{to} \mathrm{each} \mathrm{aliquot} \mathrm{of} \mathrm{FITC-labeled} \mathrm{bacteria.} \mathrm{All}$ follicles used in the present study were isolated from the fornix region. The FAE tissue analyzed in this set of experiments was exclusively sampled from the inferior fornix and control tissue was harvested from the inferior palpebral region. There did not appear to be a difference between superior and inferior forniceal follicles, as in previous experiments, but the superior side was not systematically analyzed.

\section{Immunohistochemistry}

Tissue from the inferior forniceal and palpebral conjunctiva was blocked for at least 30 minutes with $0.1 \%$ BSA in HWB, stained with $20 \mu \mathrm{g} / \mathrm{ml}$ MAL-Ibiotin in $0.1 \%$ BSA in HWB for at least $1 \mathrm{hr}$, rinsed $3 \times$ (at least 15 min each rinse) in HWB, and incubated with $1 \mu \mathrm{g} / \mathrm{ml}$ streptavidin-Alexa 568 (Molecular Probes, Eugene, OR) and 3 M 4',6-diamidino-2-phenylindole (DAPI; Molecular 
Probes) in $0.1 \% \mathrm{BSA}$ in HWB for at least $1 \mathrm{hr}$. Tissues were stored in $2 \% \mathrm{PF}$ in HWB at $4^{\circ} \mathrm{C}$ until examination. For imaging, tissues were mounted between two coverslips in the presence of an anti-fade agent, $1 \% 1,4-$ diazabicyclo[2.2.2]octane (Aldrich Chemical, Milwaukee, WI) in $200 \mathrm{mM}$ Tris buffer ( $\mathrm{pH} 8.6)$.

\section{Confocal Microscopy}

Follicles from the inferior fornix were located using fluorescence microscopy to identify MAL-I-labeled M cells. For each experimental condition, ten different regions of FAE were selected from each of three different eyes. These regions were sampled by collecting one stack of images from the center of each randomly chosen follicle using a Zeiss LSM 510 META laser scanning confocal microscope (Carl Zeiss Microlmaging, Inc., Thornwood, NY). Each stack covered a cross-sectional area of $112 \mu \mathrm{m} \times 112 \mu \mathrm{m}$ and contained 36 optical sections which were collected at a $0.44 \mu \mathrm{m}$-step interval for a total depth of $15.4 \mu \mathrm{m}$. Stacks began at the MAL-I-stained apical surface of the epithelium. Control images were obtained in the same manner by collecting stacks for ten randomly chosen regions of inferior palpebral conjunctiva from the same 3 eyes from which FAE regions were sampled for each experimental condition. For control tissues, the apical surface was also determined by MAL-I staining since it labels the superficial mucin in goblet cells in the non-FAE regions. 
For demonstration purposes, several stacks of slightly overlapping regions were taken (as described above) and tiled to create a montage of larger regions containing whole follicles.

A 40x PlanApochromat water-immersion objective $(N A=1.2)$ was used in this study, and images were collected at a resolution of $1020 \times 1020$ which the Zeiss software (based on the Nyquist theorem) determined to be optimal for the objective. All images were collected with bidirectional scanning at a scan speed of 7 and frame averaging set to 4 . The $30 \mathrm{~mW} 488 \mathrm{~nm}$ laser was used at $1.92 \%$ power with a gain of 700 and offset of -0.2 . The $1 \mathrm{~mW} 534 \mathrm{~nm}$ laser was used at $100 \%$ power with a gain of 700 and offset of -0.1 . The green channel pinhole was set at 1.0 Airy units and the red channel set at 0.89 Airy units so that the two channels had matching of optical section thicknesses of $\sim 0.9 \mu \mathrm{m}$.

\section{Quantification of bacteria}

To aid bacterial quantification, an image processing routine (Fovea Pro 4.0 image processing software; Reindeer Graphics, Inc., Asheville, NC) was used to separate bacteria that were just touching or slightly overlapping and reduce stray pixel noise while retaining any signal greater than or equal to $5 \times 5$ pixels. With this routine, a binary image was created of the green channel by using a standard threshold of $20-255$ for all images. Then an opening operation, which is an erosion followed by dilation, was performed using the Euclidean distance map (EDM) morphological operation. The EDM opening was 
chosen since it is more isotropic, preserving shape information better than other morphological routines which reduce stray noise.

Bacteria were quantified in all images using a standardized method created specifically for this project. By comparing adjacent sections of a stack of images, bacteria which were found in two or more consecutive planes were counted. In the case that a cluster of bacteria or two contiguous bacteria were not resolved after the morphological operations described above, they were counted as one. Finally, the depth of each bacterium was estimated by recording the distance between the deepest plane in which the bacterium was detected and the first plane in the stack of images.

\section{$\underline{\text { Tissue Processing for Transmission Electron Microscopy }}$}

Conjunctival tissue for transmission electron microscopy (TEM) came from an animal inoculated with OM12, as described above, for 61 min prior to fixation in PFG for $2 \mathrm{hr}$. Tissues were post-fixed using an OTO (osmiumthiocarbohydrazide-osmium) method in an attempt to increase the contrast of the epithelium based on the method of Willingham and Rutherford (Willingham et al., 1984): $1 \%$ osmium in HWB, followed by $1 \%$ thiocarbohydrazide in water, then $1 \%$ osmium in water; all steps performed for $1 \mathrm{hr}$ each with extensive water rinses between steps. Tissues were then stained en bloc with $0.25 \%$ uranyl acetate in $25 \%$ ethanol, dehydrated, and embedded in EmBed 812 (Electron Microscopy Sciences, Fort Washington, PA). 


\section{Tissue Processing for Scanning Electron Microscopy}

Scanning electron microscopy (SEM) images were obtained from conjunctival tissue which was prepared by incubating a whole mount in $10 \mathrm{ml}$ of an ice-cold solution of $2.2 \times 10^{9} / \mathrm{ml}$ OM12 in PBS for $60 \mathrm{~min}$. Tissue was then rinsed in ice-cold PBS and fixed in ice-cold PFG $(2 \%$ paraformaldehyde $+2.5 \%$

glutaraldehyde in HWB) for $2 \mathrm{hr}$. FAE and non-FAE tissues were dissected from the whole mount and immunolabeled with $100 \mu \mathrm{g} / \mathrm{ml}$ MAL-I-biotin, followed by 10 nm gold conjugated goat anti-biotin and gold particle enhancement as described previously (Meagher et al., 2005). Tissues were osmicated, dehydrated and critical point dried before viewing using secondary-electron and backscatteredelectron (SE or BSE) imaging on a Hitachi S-4700 Field Emission Scanning Electron Microscope (FESEM) (Hitachi, LTD., Tokyo, Japan) (Meagher et al., 2005). SE and BSE signals were overlaid after collection using Adobe Photoshop (San Jose, CA).

\section{$\underline{\text { Statistics }}$}

Statistical data is reported as the mean \pm standard deviation for results referring to a single eye, and mean \pm standard error for comparing means from multiple animals in different treatment groups. Student's $t$-test was used to determine statistical significance, and statistics were calculated using StatView SE (Abacus Concepts, Berkeley, CA).

\subsection{Results}




\section{Observations of conjunctival morphology \& labeling}

Consistent with previous observations from our lab, the Guinea pig conjunctiva had numerous large follicles in the superior and inferior fornix region. When viewed with a stereoscope, these follicles appeared as regions of bulging domes of mucosa which were selectively labeled with MAL-I.

Using confocal fluorescent microscopy, MAL-I, secondarily labeled with Alexa-568, was found to label the apical surface of M cells on FAE domes and intracellular mucin stores in goblet cells in the non-FAE regions. Groups of M cells with elongated, polygonal shapes were often touching other $\mathrm{M}$ cells at the apex of their irregular projections while encircling other unlabeled cells or shared entire borders with other $M$ cells (Figure 4-1). M cells were easily distinguished from the more rounded or oval shape staining of goblet cells which were found in isolation from one another (Figure 4-1). Goblet cells were generally absent from the FAE region which is consistent with the need for an attenuated mucus layer over the antigen-sampling M cells (Meagher et al., 2005).

\section{Visualization of FITC-labeled Haemophilus influenzae}

Using confocal microscopy, FITC-labeled OM12 were routinely observed in the FAE (Figure 4-2); however, individual bacteria were not resolved using fluorescent stereomicroscopy. The outcome of the standardized image processing routine, described in the Methods and Materials, is demonstrated in Figure 4-2. This method enhanced the fluorescent signal from labeled bacteria, 
reduced stray noise, and enabled quantification of bacteria by separating bacteria which were barely touching or overlapping.

Using the tiling function on Zeiss LSM Image Browser software, multiple stacks could be automatically scanned with $10 \%$ overlap. The images are then concatenated, which is a process that integrates the slightly overlapping borders of the each image in the stack with the adjacent images, creating a single, seamless composite. Figure 4-3A shows a projection view of images which were originally scanned as 9 different stacks collected in a $3 \times 3$ array with 36 slices each, for a total of 324 images. Figure 4-3B is an orthogonal section through the reconstructed $z$-stack; this cross-sectional view along the $y$-axis allows one to appreciate location and depth of fluorescently labeled bacteria below the surface. Similar cross-sectional projection views were created to visualize relative numbers and depth of bacteria in the FAE and non-FAE exposed to different experimental conditions (Figure 4-4).

\section{Quantification of FITC-labeled Haemophilus influenzae}

In $z$-stacks of FAE tissue collected $66 \pm 1.5 \mathrm{~min}$ after in vivo instillation of OM12, an average of $423 \pm 165$ bacteria per $\mathrm{mm}^{2}$ of FAE surface were found in a 3-dimensional space measuring $112 \mu \mathrm{m} \times 112 \mu \mathrm{m}$ in the $x-y$ dimension and 15.4 $\mu \mathrm{m}$ deep (Table 4-1). A movie of a representative FAE region from the $66 \pm 1.5$ min experimental group was created for demonstration purposes, see supplemental multimedia file (movie_s1.avi). A depth of $15.4 \mu \mathrm{m}$ was chosen after preliminary screening of random follicles did not find bacteria below this 
depth. It is remarkable to note that no bacteria were found in ten similar randomly selected $z$-stacks of palpebral tissues after a $66 \pm 1.5 \mathrm{~min}$ in vivo exposure. While z-stacks from the bulbar region were not systematically analyzed, randomly sampled regions failed to detect any bacteria in this region.

Following a $125 \pm 4.7 \mathrm{~min}$ in vivo exposure to OM12 bacteria, the number of OM12 increased $37 \%$ to $579 \pm 44$ bacteria per $\mathrm{mm}^{2}$ of FAE surface (Table 41). Control tissue from palpebral regions occasionally contained an isolated bacterium but overall had less than $3 \%$ of the number found in the FAE region of the same experimental group. The control values may overestimate bacterial uptake in this region since it was not possible to distinguish bacteria caught in mucus-filled crevices at the epithelial surface or being transported via lymphatic vessels from the follicle region to draining lymph nodes.

There was wide variation in the number of OM12 bacteria found in each individual follicle after 66 min in vivo incubation with OM12. In a single eye, some follicles were found to have no bacteria and others as many as 1754 bacteria per $\mathrm{mm}^{2}$. These variations are likely to have resulted from differences in the rate the bacteria penetrated the tear film and gained access to the epithelial surface, rather than differences in the receptors between follicles, since both intra- and inter-animal variability was greatly reduced by $127 \mathrm{~min}$ (Table 4-1).

\section{MAL-I-blocking experiments}

For blocking experiments, biotinylated MAL-I, an $\alpha(2-3)$ sialic acid binding lectin, was used to pre-saturate binding sites. MAL-I was also simultaneously 
added to the eye in the OM12 aliquots. In these tissues, there was a significant decrease of $61 \%(p=0.0027)$ in bacterial uptake to an average of $229 \pm 143$ bacteria per $\mathrm{mm}^{2}$ of FAE surface at $124 \pm 4 \min$ (Table $\left.4-1\right)$.

\section{Bacterial Depth}

Bacteria moved progressively deeper into the follicle region with time (Figure 4-5). After a $66 \mathrm{~min}$ in vivo instillation, the average depth of OM12 was $4.12 \pm 0.5 \mu \mathrm{m}$ with none deeper than $10 \mu \mathrm{m}$. At $125 \mathrm{~min}$ after instillation, the average depth of bacteria had increased to $6.08 \pm 1.4 \mu \mathrm{m}$ and $5.5 \%$ of all bacteria could be found deeper than $10 \mu \mathrm{m}$.

\section{Uptake of non-sialic acid binding Haemophilus influenzae}

$H$. influenzae strain Rd KW20, which does not express the sialic acid binding HMW1 adhesin, was not as efficiently transported by M cells as was OM12 (Table 4-1). After $63 \pm 2.1$ min in vivo incubation with Rd KW20, $122 \pm$ 116 bacteria were found per $\mathrm{mm}^{2}$ of FAE surface which is $29 \%$ of the level of OM12 present at a comparable time-point. Similarly, after $121 \pm 2.1 \mathrm{~min}$ incubation, there was an average of $243 \pm 178 \mathrm{Rd} \mathrm{KW} 20$ per $\mathrm{mm}^{2}$ of FAE which is only $42 \%$ of the OM12 uptake (Table $4-1$ ).

\section{Observations of OM12 by SEM}

Examination of the conjunctival epithelial surface by SEM failed to find any bacteria associated with the FAE or non-FAE surface after 15-120 min of 
incubation in vivo. Only occasional clusters of extracellular bacteria trapped in small bits of remaining surface mucus were noted. In an attempt to slow bacterial translocation by $\mathrm{M}$ cells for visualization of bacteria on the conjunctival surface, conjunctival whole mounts were incubated with OM12 on ice. After 60 min, some bacteria were found associated with the apical surface of the epithelia, and others were occasionally seen trapped in mucus at the surface, as before. In all cases, these bacteria were bound to cells within the FAE that had M cell characteristics, including a sparse, irregular microvillar border of varying length that labeled with MAL-I (Figure 4-6).

\section{Observations of OM12 by TEM}

By TEM, cross-sections of FAE cells with M-cell morphology and intraepithelial lymphoid cells were found to contain OM12 bacteria (Figure 4-7). 


\subsection{Figures}

\begin{tabular}{|c|c|c|c|c|}
\hline Bacterial strain & $\begin{array}{l}\text { Incubation } \\
\text { conditions }\end{array}$ & $\begin{array}{c}\text { Palpebral } \\
\text { control }^{*}\end{array}$ & $\begin{array}{c}\text { Forniceal } \\
\mathrm{FAE}^{*}\end{array}$ & $\begin{array}{c}\text { Control vs. } \\
\text { FAE } \\
\text { Paired } t \text {-test } \\
p \text {-value } \\
\end{array}$ \\
\hline OM12 & $65 \mathrm{~min}$ & $0 \pm 0$ & $462 \pm 451$ & 0.0014 \\
\hline OM12 & $66 \mathrm{~min}$ & $0 \pm 0$ & $686 \pm 620$ & 0.0014 \\
\hline OM12 & $68 \mathrm{~min}$ & $0 \pm 0$ & $120 \pm 147$ & 0.0014 \\
\hline summary & $66 \pm 1.5$ & $0 \pm 0^{* *}$ & $423 \pm 165^{\star *}$ & \\
\hline OM12 & $121 \mathrm{~min}$ & $27 \pm 40$ & $566 \pm 386$ & 0.0017 \\
\hline OM12 & $123 \min$ & $8 \pm 25$ & $662 \pm 415$ & 0.0005 \\
\hline OM12 & $130 \mathrm{~min}$ & $16 \pm 34$ & $510 \pm 263$ & 0.0010 \\
\hline summary & $125 \pm 4.7$ & $17 \pm 5.5^{\star *}$ & $579 \pm 44^{* *}$ & \\
\hline OM12 & $120 \mathrm{~min}+$ MAL-I & & $175 \pm 149$ & \\
\hline OM12 & 123 min + MAL-I & & $391 \pm 510$ & \\
\hline OM12 & $128 \mathrm{~min}+\mathrm{MAL}-\mathrm{I}$ & & $120 \pm 126$ & \\
\hline summary & $124 \pm 4 \mathrm{~min}$ & & $229 \pm 143^{* *}$ & \\
\hline Rd KW20 & $61 \mathrm{~min}$ & & $8 \pm 25$ & \\
\hline Rd KW20 & $62 \mathrm{~min}$ & & $239 \pm 269$ & \\
\hline Rd KW20 & $65 \mathrm{~min}$ & & $120 \pm 272$ & \\
\hline summary & $63 \pm 2.1 \mathrm{~min}$ & & $122 \pm 116^{* *}$ & \\
\hline Rd KW20 & $119 \min$ & & $255 \pm 276$ & \\
\hline Rd KW20 & $122 \min$ & & $415 \pm 240$ & \\
\hline Rd KW20 & $123 \mathrm{~min}$ & & $60 \pm 93$ & \\
\hline summary & $121 \pm 2.1 \mathrm{~min}$ & & $243 \pm 178^{* *}$ & \\
\hline
\end{tabular}

Values are the mean \pm standard deviation for 10 follicles or control regions except for the 123 min Rd KW20 sample in which only 8 distinct follicles could be imaged.

${ }^{* *}$ Results for each treatment group are expressed as mean \pm standard error.

*bacteria per $\mathrm{mm}^{2}$ of FAE in 3-dimensional volumes measuring $112 \times 112 \times 15.4$ $\mu \mathrm{m}$ 


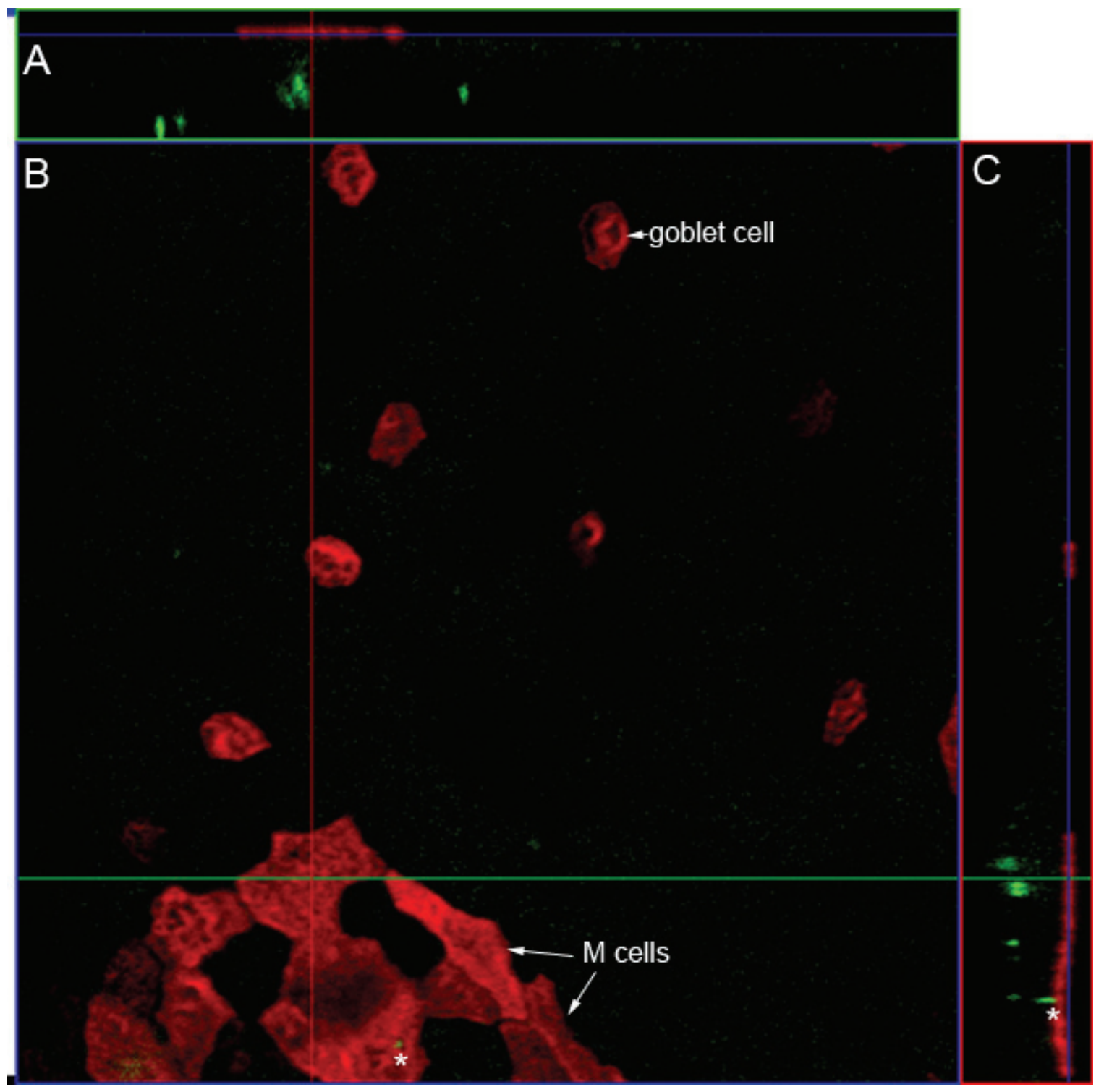

Figure 4-1. Visualization of bacteria using confocal laser scanning microscopy. Large box $(B)$ is a single slice taken at the apical surface of the conjunctival epithelium of the border of FAE and non-FAE tissue. Top rectangle $(A)$ represents an orthogonal cross-section taken at the green line which begins at the apical surface and penetrated $15.4 \mu \mathrm{m}$ into the tissue. Green bacteria are seen under M cells stained red with MAL-I. Right rectangle $(C)$ is a cross-section of the larger image taken along the red line. As in the $x$-axis orthogonal view, bacteria are seen underlying $M$ cells. Asterisks represent an OM12 bacterium (green) which is seen in both the FAE en face view and in orthogonal (cross-sectional) view since it is close to the surface. Some goblet cells which sometimes also stain with MAL-I are seen with their characteristic round apical profile in isolation from each other. 

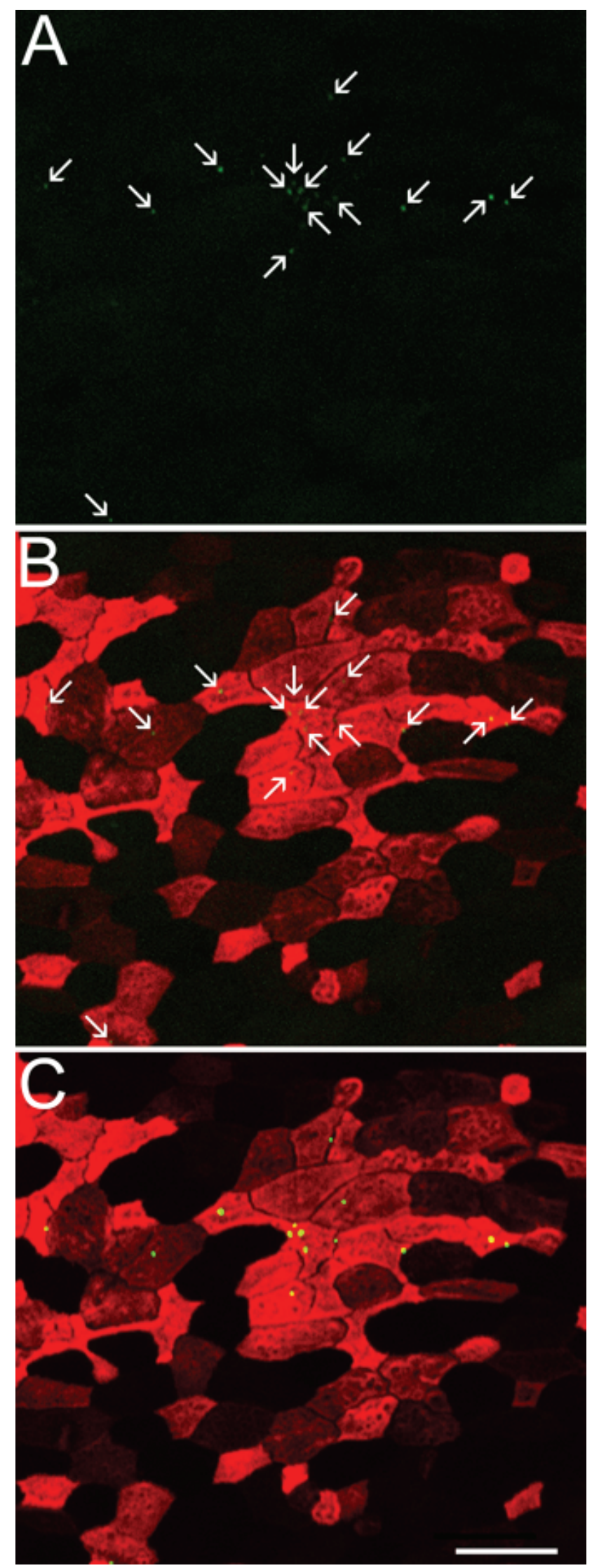

Figure 4-2. Three alternative displays of a single projected $z$ stack of an FAE region following in vivo incubation with FITClabeled OM12. This projection view was created from a stack of 36 optical sections of an FAE region following a $66 \mathrm{~min}$ in vivo exposure to $1.5 \times 10^{9}$ FITC-labeled OM12 bacteria. (A) The upper panel shows a 2-dimensional maximum projection of the green channel (OM12 bacteria) from one $z$-stack collected under standard conditions. FITClabeled bacteria are marked by arrows. No image processing steps have been performed on images shown in panels $A$ and $B$ other than the projection and cropping the image by $10 \%$ in the $y$-axis to allow the figure to fit the page. (B) In the middle image, the FITC-labeled bacteria in the green channel are shown superimposed on the MAL-I labeling in the red channel. Bacteria can be seen but are sometimes difficult to recognize against the intense MAL-I labeling of $M$ cell surfaces. (C) The lower image shows a projection of the same $z-$ stack after performing a standard EDM opening, image-processing step to reduce noise and intensify the green channel signal as described in the Methods. The bacteria are readily detected against the red MAL-I staining following this processing step and can be seen to be exclusively associated with MALI-labeled M cells. Scale bar: $20 \mu \mathrm{m}$. 


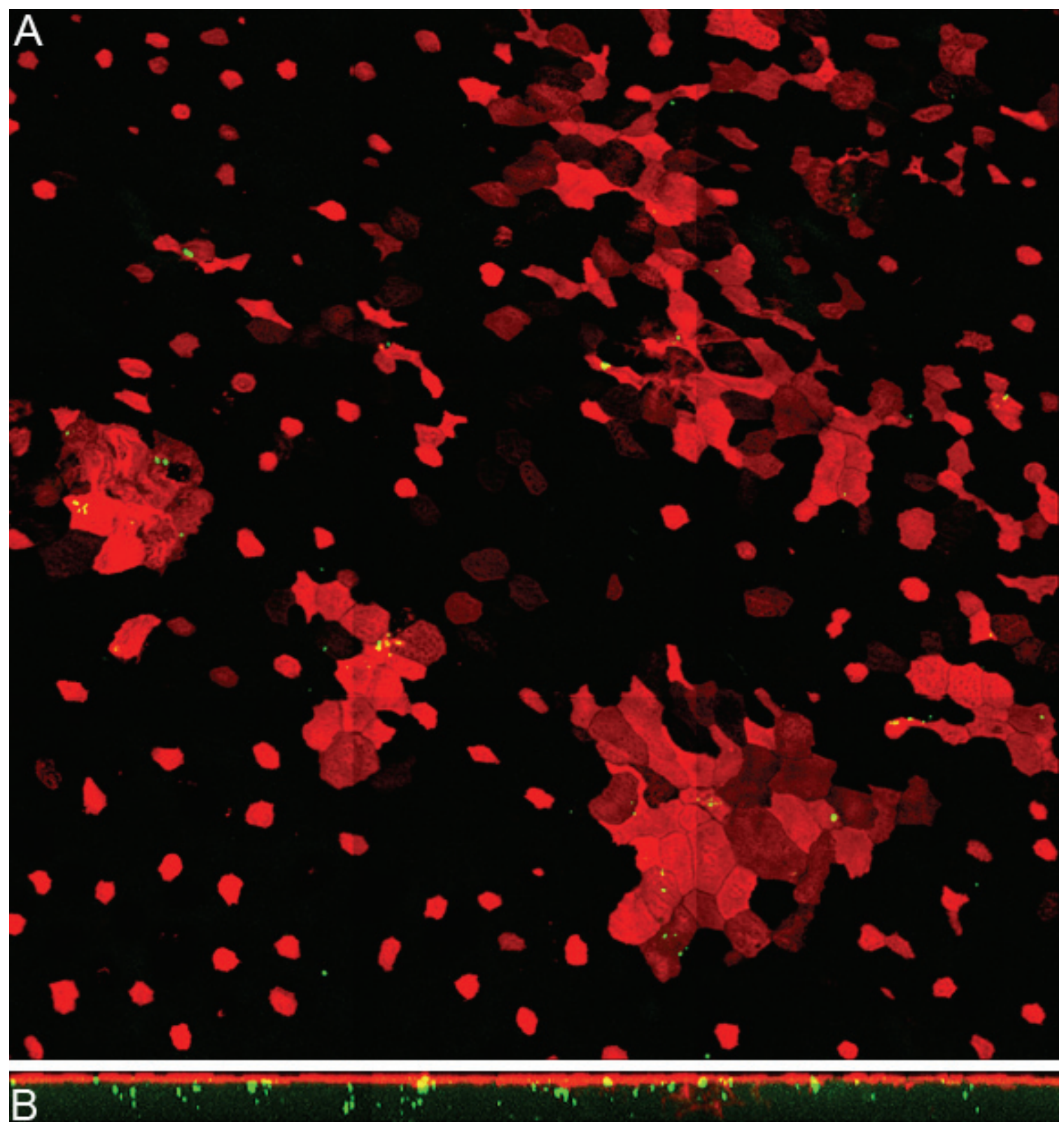

Figure 4-3. Projection views of $3 \times 3$ concatenated montage stacks. $X$-axis (A) and $z$-axis (B) views present. 
A

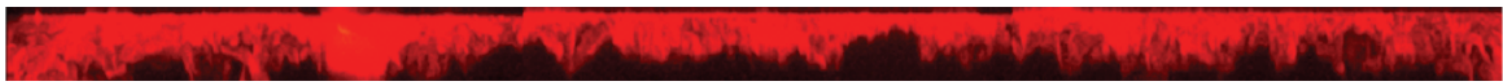

B

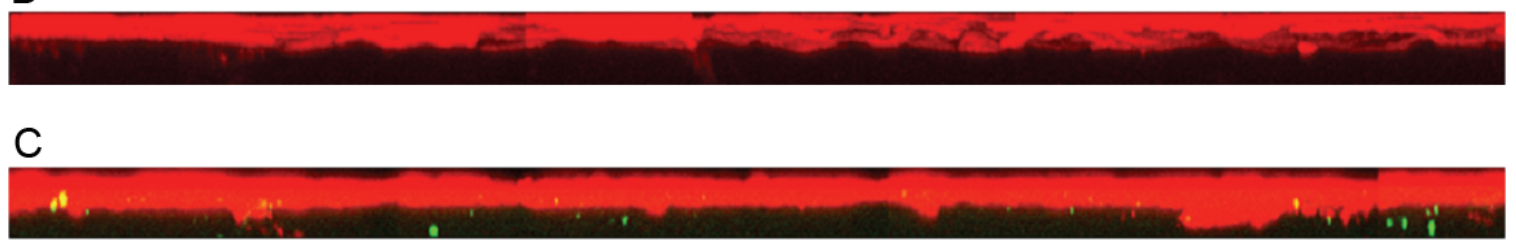

D

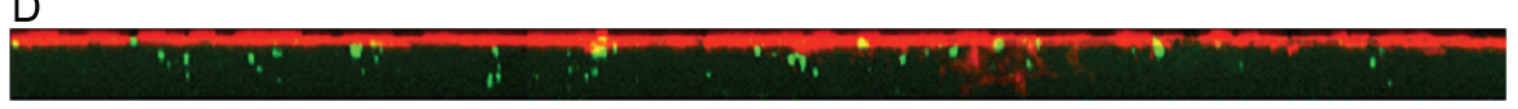

E

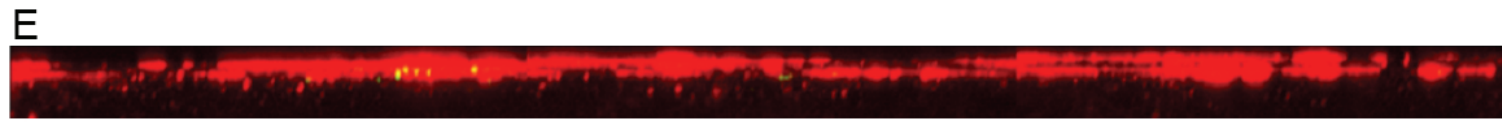

$\mathrm{F}$

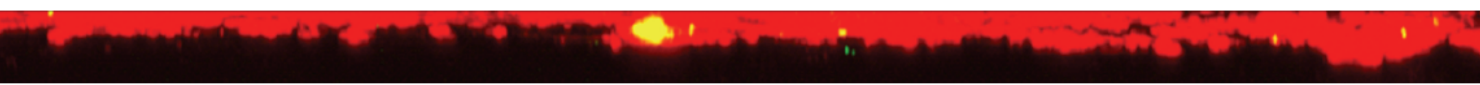

Figure 4-4. Cross-sectional (z-axis) projection views of FAE and non-FAE tissues. Non-FAE (palpebral) regions do not show evidence of fluorescent OM12 bacteria after 1 hour (A) or 2 hour (B) in vivo incubations. FAE regions did have evidence of bacteria in the corresponding 1 hour (C) and 2 hour (D) treatment groups. By two hours (D) bacteria appear more numerous and have moved deeper within the sampled region. In MAL-I pretreated conjunctiva, bacteria were less numerous and present at more superficial locations when compared to tissues not pre-treated with MAL-I at both 1 hour (E) and 2 hour (F). 


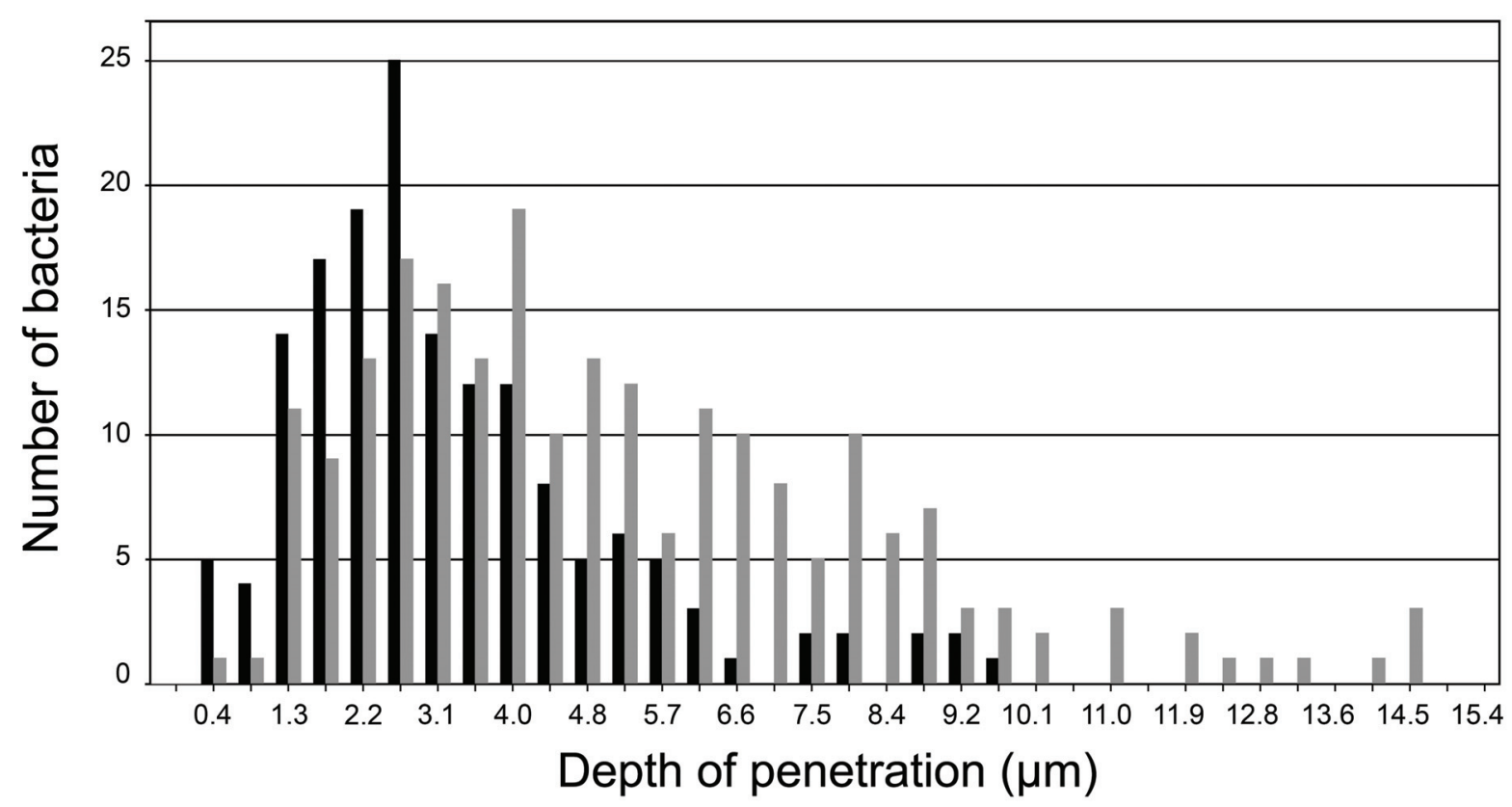

Figure 4-5. Bacterial counts at increasing depth within the FAE. Following instillation of $1.6 \times 10^{9}$ FITC-labeled OM12 into the inferior conjunctiva sac, 15.4 $\mu \mathrm{m}$ deep $z$-stacks of FAE tissue were collected using confocal microscopy. The depth of penetration of each bacterium was determined by measuring the lowest optical section in which each appeared after a 66 min (black bars) or $127 \mathrm{~min}$ (grey bars) in vivo incubation. Bacteria were found to move deeper into the follicle with increasing time. 


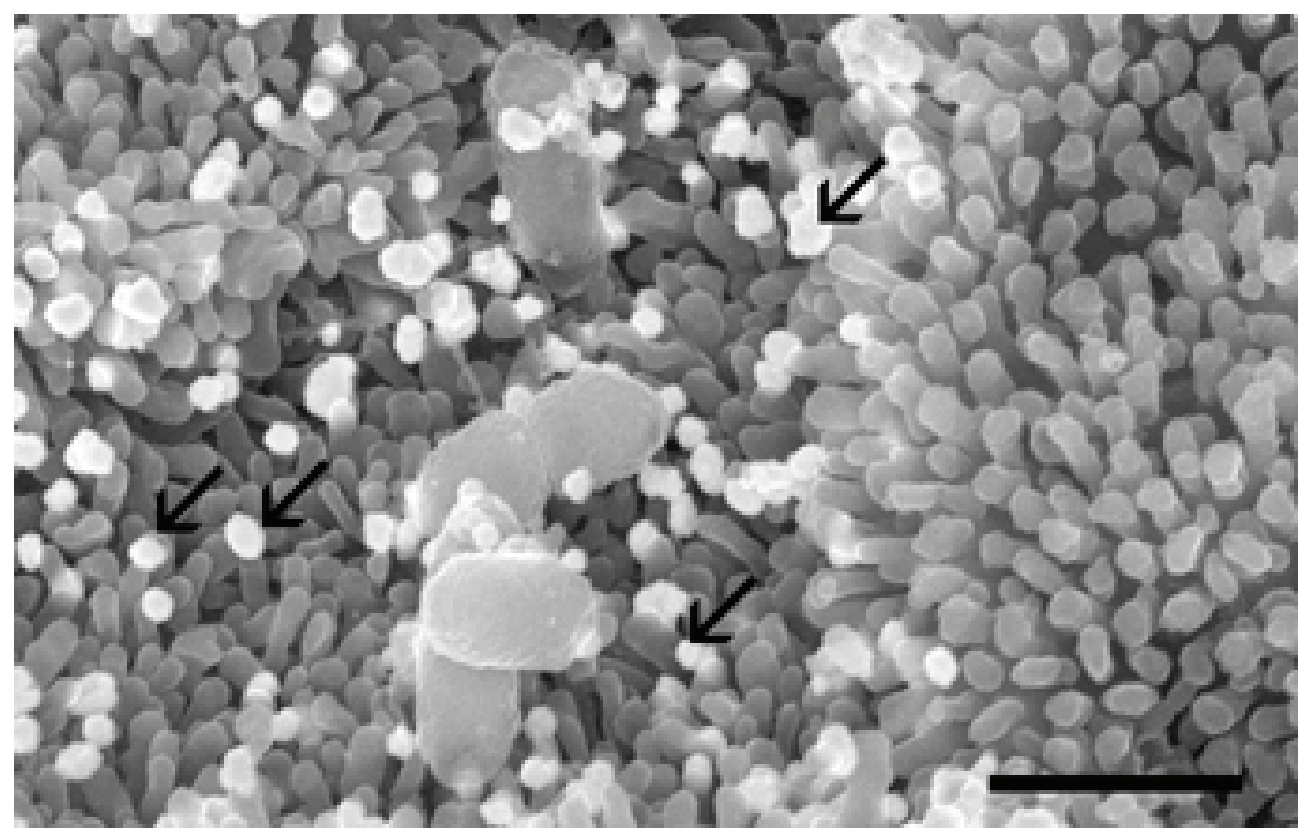

Figure 4-6. Preferential adherence of OM12 bacteria to the apical surface of conjunctival FAE cells expressing $\alpha(2-3)$ sialic acid on their surface. Conjunctival, whole-mount tissue was exposed to NTHi for $60 \mathrm{~min}$ on ice to reduce uptake and trap bacteria on their apical surface binding sites. After rinsing and aldehyde fixation, $M$ cell surfaces were labeled with biotinylated MALI. Gold conjugated antibodies against biotin and gold enhancement was used to generate large colloidal gold deposits (arrows) on the surface of $M$ cells. Bacteria were found exclusively on the apical surfaces of cells that were also labeled with MAL-I. Scale bar: $1 \mu \mathrm{m}$. 


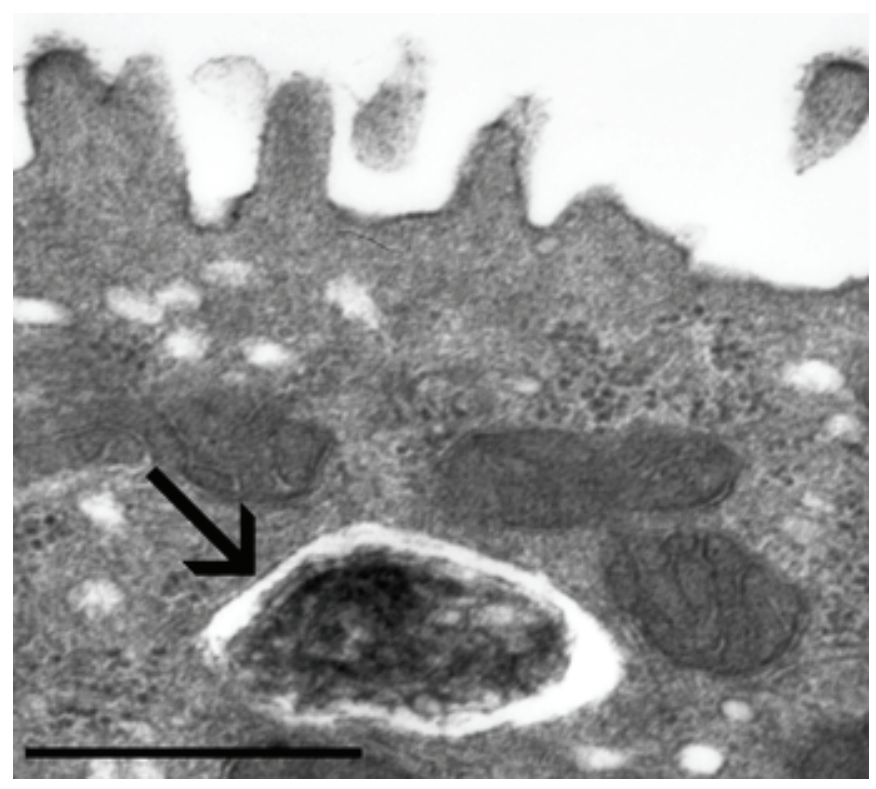

Figure 4-7. Conjunctival $M$ cell containing a vesicular bound bacterium (arrow) $61 \mathrm{~min}$ after instillation of OM12 into the inferior conjunctival sac. The $\mathrm{M}$ cell can be recognized by its sparse, pleomorphic microvilli. Scale bar: $0.5 \mu \mathrm{m}$. 


\subsection{Discussion}

The results demonstrate that the NTHi bacterium is transcytosed across the epithelium via $\mathrm{M}$ cells that are located above conjunctival lymphoid follicles and migrate deeper into the follicle with time. These findings provide functional evidence that conjunctival $\mathrm{M}$ cells, like their counterparts in other mucosal locations, are the site of entry for large microbes at the conjunctival surface, and may similarly function for the entry for bacterial and viral pathogens. Although nontypeable (nonencapsulated) $H$. influenzae are normally commensal bacteria of the human upper respiratory tract, these microbes can be responsible for several mucosal diseases including conjunctivitis, otitis media, sinusitis and bronchitis (Murphy et al., 1987). Although studies have not specifically demonstrated that $H$. influenzae is able to cause experimental conjunctivitis in the Guinea pig, this species has been used for studying NTHi-mediated otitis media. The rationale for choosing the Guinea pig as a model system to study how microbes may cross conjunctival $\mathrm{M}$ cells was based on the specific expression of $\alpha(2-3)$ sialic acid on their apical surface, together with the wellcharacterized propensity of certain NTHi strains to bind this carbohydrate. Although this study does not specifically investigate bacterial conjunctivitis in the Guinea pig, it nonetheless provides important evidence that conjunctival M cells are a port of entry for microbes, possibly including ocular pathogens.

Multiple studies have identified potentially pathogenic bacteria such as NTHi, Pseudomonas aeruginosa, and Staphylococcus aureus in the conjunctiva of normal individuals who show no overt signs of infection (Cagle et al., 1981; 
Sankaridurg et al., 1996; Brook, 2001). Furthermore, non-pathogenic bacteria such as Propionibacterium spp and Staphylococcus epidermidis frequently reside in the conjunctiva (Cagle et al., 1981; McClellan et al., 1998; Brook, 2001). The colonization of the conjunctival sac is suppressed by endogenous factors in the tear film, such as lysozyme, lactoferrin and lactoperoxidase, as well as IgA, which is a component of the adaptive immune response. IgA functions to inhibit colonization by binding to bacterial adhesins and preventing adhesion of bacteria to the mucosal surfaces. An additional mechanism by which IgA limits bacterial colonization may be through promoting bacterial agglutination. IgA antibodies against NTHi, S. epidermidis, $P$. aeruginosa, E. coli, and herpes simplex virus have all been found in the tears of asymptomatic human volunteers (Coyle et al., 1988; Cheng et al., 1996; McClellan et al., 1998). The present studies suggest that M-cell-mediated transcytosis may be a mechanism for initiating local mucosal immune responses against commensal or transient ocular bacterial species.

The first steps in NTHi pathogenesis include adherence and subsequent colonization and these bacteria have evolved multiple adhesins (Ecevit et al., 2004). The well-characterized adhesin HMW1 is a high molecular weight protein expressed on the surface of $51-80 \%$ of clinical isolates (St Geme et al., 1998; Ecevit et al., 2004), and mediates adhesion to epithelial cells via a(2-3) linked sialic acid (St Geme, 1994). Maackia amurensis agglutinin (MAA), which generally refers to an unfractionated mixture of MAL-I and MAL-II, has been shown to reduce OM12 binding to Chang epithelial cells by $74 \%$ (St Geme, 
1994). Our results demonstrated that MAL-I inhibited the uptake of OM12 by $61 \%$ and suggest that OM12 binding to Guinea pig conjunctival $M$ cells is partially mediated by HMW1. Nevertheless, it is likely, that OM12 expresses other adhesins that function in binding to $\mathrm{M}$ cells.

Our studies have identified that NTHi binds to and is translocated across $M$ cells. Since translocation is reduced by $61 \%$ when MAL-I is incubated simultaneously, it is likely that NTHi binding the $\alpha(2-3)$ sialic acid precedes internalization. Nevertheless, it is possible that $\mathrm{M}$ cells express a variety of receptors that are specific for many different gram-positive or gram-negative bacteria, such as germ-line encoded pattern recognition receptors. Recent studies have suggested a possible role for Toll-like receptors (TLRs) expressed on $M$ cells in the intestinal tract (Chabot et al., 2006; Tyrer et al., 2006). TLRs are a family of germ-line encoded pattern recognition receptors (PRRs) that recognize conserved motifs of bacterial and viral pathogens. Whether TLRs or other PRRs play a role in M-cell sampling in the conjunctiva is unknown.

The $\mathrm{M}$ cells of the Guinea pig conjunctiva is not the only mucosal surface which $M$ cells express $\alpha(2-3)$ linked sialic acid glycoconjugates. In the Peyer's patches of the rabbit, $\alpha(2-3)$ linked sialic acid containing glycoconjugates have been shown to mediate the attachment and translocation of reovirus by $\mathrm{M}$ cells. Furthermore, the sialic acid binding lectins, MAL-I and MAL-II, inhibit reovirus binding to these M cells (Helander et al., 2003). Despite the binding of MAL-II to the surface of all rabbit intestinal cells both within and outside the FAE, the authors suggested that while the sialic acid epitope is a membrane component 
common to all intestinal epithelial cells, the reduced glycocalyx on $\mathrm{M}$ cells allows interaction with larger ligands like reovirus. Although the glycocalyx on Guinea pig conjunctival epithelial cells is less extensive than in the intestinal tract, it still forms a dense coat extending $300 \mathrm{~nm}$ out from the microvilli and microplicae of the surface (Nichols et al., 1983). While less is known about the glycocalyx above the follicle-associated epithelium of the conjunctiva, the sparse and pleomorphic nature of $\mathrm{M}$ cell microvilli is consistent with a reduced, less uniform glycocalyx (Meagher et al., 2005). It is worth noting that $\mathrm{M}$ cells are the only epithelial cell type in the Guinea pig conjunctiva that strongly expresses $\alpha(2-3)$ linked sialic acid at the apical surface, and it may therefore be associated with a M-cell-specific glycoprotein or glycolipid receptor (Meagher et al., 2005).

Although the results above demonstrate that NTHi cross the conjunctiva via $\mathrm{M}$ cells, there may be many other Gram-negative bacteria capable of crossing conjunctival M cells. The Guinea pig conjunctiva has for many years been used as a functional test of bacterial invasiveness using the so-called "Sereny test." The Sereny test is routinely used for Shigella virulence assays in which Shigella flexneri are inoculated into the conjunctival sacs of Guinea pigs and the extent of the ensuing keratoconjunctivitis is evaluated (Sereny, 1957; Anderson et al., 2000). Since the apical membrane of polarized cells are impervious to S. flexneri (Mounier et al., 1992), our findings point to conjunctival $\mathrm{M}$ cells as a mechanism of entry and inflammation in a manner identical to their passage across the intestinal mucosa via M cells of the Peyer's patch (Jensen et al., 1998). Interestingly, two additional bacterial species that score positive in the Sereny 
test, Salmonella typhimurium (Belfort et al., 1985) and Yersinia enterocolitica (Heesemann et al., 1983), also cross the intestinal mucosal barrier via M cells (Sansonetti et al., 1999).

It is likely that the absence of mucosal lymphoid follicles and their associated $\mathrm{M}$ cells in the conjunctiva of the traditional experimental models, mice and rats, prevented the early recognition of this important cell type in ocular mucosa. Mice and rats may compensate for the absence of $\mathrm{M}$ cells by their extensive nasal-associated lymphoid tissue (NALT), and drainage from the nasolacrimal duct may take the place of CALT. The absence of CALT in mice and rats suggests that these animals may be poor models to study human ocular allergy or microbial uptake, since human CALT more closely resembles that of the rabbit and Guinea pig. CALT is now recognized as a normal part of the human conjunctiva (Knop et al., 2000), but M cells have yet to be characterized as part of the normal human CALT. Nonetheless, the presence of M cells in the Guinea pig and rabbit suggests they are probably present in human CALT as well. Future studies investigating of the afferent limb of CALT will be important for advances in the field of ocular immunology.

Whether clinically important human ocular pathogens such as herpes simplex virus use conjunctival $\mathrm{M}$ cells as a port of entry is currently unknown and will be the subject of future studies. If so, it may be possible to use $M$ celltargeted immunogens as vehicles to elicit local mucosal immune responses against microbial pathogens or ocular allergens. 


\section{CHAPTER 5. SUMMARY AND FUTURE DIRECTIONS}

\subsection{Summary}

This thesis tested the hypothesis that the conjunctiva contains an M cell defined by morphological specializations, distinctive apical surface glycoconjugates, and the ability to transcytose macromolecules and bacteria. Guinea pigs were used to search for the existence of ocular $M$ cells because the abundant lymphoid tissue in the conjunctival fornix represents the human conjunctiva better than other rodent models. Using scanning and transmission electron microscopy, clusters of unique cells were identified in the follicleassociated epithelium (FAE) of the conjunctiva which possessed ultrastructural and morphological characteristics that were strikingly reminiscent of $\mathrm{M}$ cells in other mucosal locations (Chapter 2). The next challenge was to find a selective marker for these putative $\mathrm{M}$ cells to enable their identification using fluorescence microscopy and in vivo labeling. Since M cells characteristically possess a unique glycocalyx with a different carbohydrate composition than surrounding cells, a panel of lectins was screened against the FAE and non-FAE for one that specifically labeled a subset of FAE cells. From this approach the sialyllactosespecific lectin MAL-I was identified. MAL-I was shown to specifically label the apical surface of only a subset of FAE cells and little, if any, of the surrounding non-FAE was labeled by this marker (Chapter 2).

Having established the existence of a conjunctival cell type with features that met the morphological definition of an $\mathrm{M}$ cell, the next series of experiments 
aimed to test whether this cell type also functioned like an $\mathrm{M}$ cell. A functional definition of an $\mathrm{M}$ cell includes the ability to selectively translocate materials across the epithelial barrier. MAL-I was an obvious probe for such experiments, since we had already identified this lectin as a specific marker of the putative $M$ cells in vitro. The conjunctival sac of anesthetized Guinea pigs was exposed to fluorescently-labeled MAL-I over a series of time points. Subsequent examination of the processed conjunctiva demonstrated specific binding of MAL-I to putative $\mathrm{M}$ cells, as seen previously when this lectin was applied to fixed tissue. Significantly, there was also a time-dependent translocation of MAL-I to immune cells beneath the epithelium. Taken together with morphological evidence, these functional data established the existence of ocular $\mathrm{M}$ cells that were capable of antigen sampling and transcytosis (Chapter 3 ).

The ability of conjunctival $\mathrm{M}$ cells to sample and translocate a bacterium was used as a further test of whether conjunctival M cells function similarly to those of the intestinal Peyer's patches. From a potentially large choice of candidate microbes to study, we narrowed our focus to the Gram-negative bacterium, nontypeable Haemophilus influenzae strain OM12, since it was previously shown to bind to $\alpha(2,3)$ linked sialic acid. In vivo studies demonstrated selective binding of NTHi to MAL-I-labeled M cells, and the translocation of this bacterium to underlying lymphoid tissue (Chapter 4). Significantly, this is the first demonstration of bacterial translocation via M cells in the conjunctiva. 


\subsection{Future Directions}

The existence of $\mathrm{M}$ cells in the oropharyngeal, respiratory, and gastrointestinal epithelia, indicates that these cells are a common and important epithelial cell type of the mucosa-associated lymphoid tissues. At these locations, M cells play key roles in immune defense pathways involving antigen sampling and transcytosis, and may provide passage to infiltrating pathogens. A mucosal surface that is constantly exposed to foreign antigens and potential pathogens is the conjunctiva. According to the World Health Organization, millions of current cases of ocular disease and blindness worldwide are attributable to a failure to safeguard against infection (WHO, 2007). Despite the importance of the conjunctiva in ocular health, very little was known at the beginning of the current studies about the cellular mechanisms regulating antigen sampling and transcytosis across this mucosal surface.

\section{Immunization}

The capacity of $\mathrm{M}$ cells to translocate protein antigens and inert particles with intact immunomodulatory properties from the lumen to underlying macrophages, dendritic cells, and lymphocytes can be exploited for mucosal vaccine delivery. There is much interest in developing mucosal vaccines that take advantage of the lectin-binding properties of the $\mathrm{M}$ cell surface to target vaccine delivery. Numerous studies using antigen-loaded liposomes, nanoparticles, and polystyrene microspheres covalently bound to lectins, have 
created M-cell-targeted mucosal vaccines candidates; however, strategies to overcome the many obstacles of orally administered vaccines (i.e. the acidic environment of the stomach and biliary and pancreatic secretions) are still being perfected. Mucosal vaccines given nasally have fewer obstacles and have, thus far, been more successful at producing protective mucosal immune responses than oral vaccines. Studies with MAL-I-conjugated particles or peptides are one potential avenue for investigating ocular mucosal immunization of the Guinea pig conjunctiva.

An additional reason to use lectins in mucosal vaccines is that some are known to have adjuvant properties. Adjuvants are immunostimulatory factors that are administered together with protein, which alone does not stimulate the innate immune system, provokes a strong immune response with specific antibody production. Future studies testing the adjuvant activity of MAL-I could compare immunoglobulin titers to an inert protein, i.e. ovalbumin, before and after vaccination with and without MAL-I used as an adjuvant.

Live vaccines have ideal features for effective mucosal delivery and immune stimulation due to targeted delivery to $\mathrm{M}$ cells and their potent immunostimulatory molecules. For example, in the case of influenzae, the live attenuated vaccine is able to induce a more rapid and potent immune response than inactivated vaccines and are more cross-protective against related strains of the same virus. Examples of currently available vaccines consisting of live, attenuated organisms include the Sabin oral polio vaccine, Vibrio cholerae, Salmonella typhi and others. Since we have demonstrated that $H$. influenzae 
crosses conjunctival M cells, and it is not known to be an ocular pathogen in the Guinea pig, this organism may be an ideal candidate to use to study immunization with a live organism in the Guinea pig conjunctiva.

\section{CALT and immunosuppressive drugs}

Immunomodulatory medications, including steroids and cyclosporine, are used to treat common ocular diseases such as dry eye. Long-term use of such drugs may have detrimental effects on the normal surveillance and protection of the ocular surface by CALT. Future studies should address the affects of these drugs on conjunctival lymphoid tissue. The Guinea pig CALT may be an ideal model in which to characterize changes in the number and size of lymphoid follicles after topical administration of immunosuppressive drugs.

\section{Identifying $M$ cell receptors}

An important future study is the identification of a unique conjunctival $\mathrm{M}$ cell surface receptor that is responsible for selective binding of MAL-I, NTHi, and potentially many other foreign antigens. The finding that co-incubation of MAL-I and NTHi resulted in a partial inhibition (61\%) of $\mathrm{NHTi}$ binding to $\mathrm{M}$ cells, suggested that both of these share a common surface attachment site. A likely candidate for such a site is $\alpha(2,3)$ linked sialic acid which is known to bind the HMW1 protein in NTHi. Other potential binding sites for NTHi binding, which have been recently investigated on $\mathrm{M}$ cells in other mucosae, include pattern recognition receptors (PRRs), such as toll-like receptors. Antibodies against 
PRRs could be used to screen for those that are uniquely expressed on MAL-I positive $\mathrm{M}$ cells of the conjunctiva. One draw-back to this approach for the current model may be the limited availability of Guinea pig specific antibodies.

An obvious hurdle in the identification of unique $\mathrm{M}$ cell receptors, through molecular and biochemical techniques, is the small number of these cells relative to the surrounding epithelial tissue. A potentially promising strategy specifically designed to isolate rare cell types is laser dissection microscopy, which dissects and captures specific cells from fixed specimens. Such a strategy could be used to isolate MAL-I positive M cells from surrounding MAL-I negative epithelial cells. Reverse-transcription PCR could be used to amplify the cDNAs within MAL-I positive M cells as well as MAL-I negative epithelial cells, which could be used to probe cDNA microarrays of the conjunctiva. This approach would identify many genes specific to $\mathrm{M}$ cells, and subsequent characterization of gene products would focus on those predicted to be surface receptors (e.g., an integral membrane protein with a signal peptide) with putative glycosylation sites to which MAL-I could potentially bind. Antibodies raised against these proteins could then be used to confirm whether they are specifically expressed on $\mathrm{M}$ cells and whether they are involved in the uptake of antigens such as MAL-I. 


\section{REFERENCES}

Allan, C. H., Mendrick, D. L. and Trier, J. S. (1993). "Rat intestinal M cells contain acidic endosomal-lysosomal compartments and express class II major histocompatibility complex determinants." Gastroenterology 104(3): 698708.

Allansmith, M. R., Greiner, J. V. and Baird, R. S. (1978). "Number of inflammatory cells in the normal conjunctiva." Am J Ophthalmol 86(2): 250-9.

Amerongen, H. M., Weltzin, R., Farnet, C. M., Michetti, P., Haseltine, W. A. and Neutra, M. R. (1991). "Transepithelial transport of HIV-1 by intestinal M cells: a mechanism for transmission of AIDS." J. Acquir. Immune. Defic. Syndr. 4(8): 760-765.

Anderson, R. J., Pasetti, M. F., Sztein, M. B., Levine, M. M. and Noriega, F. R. (2000). "DguaBA attenuated Shigella flexneri 2a strain CVD 1204 as a Shigella vaccine and as a live mucosal delivery system for fragment $C$ of tetanus toxin." Vaccine 18(21): 2193-202.

Arnold, R. R., Russell, J. E., Champion, W. J., Brewer, M. and Gauthier, J. J. (1982). "Bactericidal activity of human lactoferrin: differentiation from the stasis of iron deprivation." Infect Immun 35(3): 792-9.

Asti, R. N., Kurtdede, N., Altunay, H. and Ozen, A. (2000). "Electron microscopic studies on conjunctiva associated lymphoid tissue (CALT) in Angora goats." DTW - Deutsche Tierarztliche Wochenschrift 107(5): 196-198.

Axelrod, A. J. and Chandler, J. W. (1979). "Morphological Characteristics of Conjunctival Lymphoid Tissue in the Rabbit." Chapter 53 from Immunology and Immunopathology of the Eye. A.M. Silverstein and G.R. O'Connor, (eds.): Masson \& Cie, NY: 292-301.

Barenkamp, S. J. (1986). "Protection by serum antibodies in experimental nontypable Haemophilus influenzae otitis media." Infect Immun 52(2): 572-8.

Baskin, T. I., Miller, D. D., Vos, J. W., Wilson, J. E. and Hepler, P. K. (1996). "Cryofixing single cells and multicellular specimens enhances structure 
and immunocytochemistry for light microscopy." J Microsc 182(Pt 2): 14961.

Befus, A. D., Johnston, N., Leslie, G. A. and Bienenstock, J. (1980). "Gutassociated lymphoid tissue in the chicken. I. Morphology, ontogeny, and some functional characteristics of Peyer's patches." J Immunol 125(6): 2626-32.

Belfort, R., Jr., Toledo, M. R., Burnier, M., Smith, R. L., Silva, V. L. and Trabulsi, L. R. (1985). "Experimental guinea pig ocular infection by Salmonella typhimurium." Invest Ophthalmol Vis Sci 26(4): 591-4.

Bienenstock, J., Johnston, N. and Perey, D. Y. (1973). "Bronchial lymphoid tissue. I. Morphologic characteristics." Laboratory Investigation 28(6): 686692.

Bienenstock, J., McDermott, M., Befus, D. and O'Neill, M. (1978). "A common mucosal immunologic system involving the bronchus, breast and bowel." Adv Exp Med Biol 107: 53-9.

Bockman, D. E. (1983). "Functional histology of appendix." Arch Histol Jpn 46(3): 271-92.

Bockman, D. E. and Cooper, M. D. (1973). "Pinocytosis by epithelium associated with lymphoid follicles in the bursa of Fabricius, appendix, and Peyer's patches. An electron microscopic study." Am J Anat 136(4): 455-77.

Bockman, D. E. and Cooper, M. D. (1975). "Early lymphoepithelial relationships in human appendix. A combined light- and electron-microscopic study." Gastroenterology 68(5 Pt 1): 1160-8.

Bockman, D. E. and Stevens, W. (1977). "Gut-associated lymphoepithelial tissue: bidirectional transport of tracer by specialized epithelial cells associated with lymphoid follicles." J Reticuloendothel Soc 21(4): 245-54.

Brandtzaeg, P. and Bjerke, K. (1989). "Human Peyer's patches: lympho-epithelial relationships and characteristics of immunoglobulin-producing cells." Immunol Invest 18(1-4): 29-45. 
Brandtzaeg, P., Farstad, I. N. and Haraldsen, G. (1999). "Regional specialization in the mucosal immune system: primed cells do not always home along the same track." Immunol Today 20(6): 267-77.

Brayden, D. J., Jepson, M. A. and Baird, A. W. (2005). "Keynote review: intestinal Peyer's patch $\mathrm{M}$ cells and oral vaccine targeting." Drug Discov Today 10(17): 1145-57.

Bron, A. J., Mengher, L. S. and Davey, C. C. (1985). "The normal conjunctiva and its responses to inflammation." Trans Ophthalmol Soc U K 104 ( Pt 4): 424-35.

Brook, I. (2001). "Ocular infections due to anaerobic bacteria." Int Ophthalmol 24(5): 269-77.

Buscher, A. Z., Burmeister, K., Barenkamp, S. J. and St Geme, J. W., 3rd (2004). "Evolutionary and functional relationships among the nontypeable Haemophilus influenzae HMW family of adhesins." J Bacteriol 186(13): 4209-17.

Bye, W. A., Allan, C. H. and Trier, J. S. (1984). "Structure, distribution, and origin of M cells in Peyer's patches of mouse ileum." Gastroenterology 86 $(5 \mathrm{Pt}$ 1): $789-801$.

Cagle, G. D. and Abshire, R. L. (1981). "Quantitative ocular bacteriology: a method for the enumeration and identification of bacteria from the skinlash margin and conjunctiva." Invest Ophthalmol Vis Sci 20(6): 751-7.

Calder, V. L. and Lackie, P. M. (2004). "Basic science and pathophysiology of ocular allergy." Curr Allergy Asthma Rep 4(4): 326-31.

Carr, R. M., Lolachi, C. M., Albaran, R. G., Ridley, D. M., Montgomery, P. C. and O'Sullivan, N. L. (1996). "Nasal-associated lymphoid tissue is an inductive site for rat tear IgA antibody responses." Immunol Invest 25(5-6): 387-96.

Chabot, S., Wagner, J. S., Farrant, S. and Neutra, M. R. (2006). "TLRs regulate the gatekeeping functions of the intestinal follicle-associated epithelium." $\underline{\mathrm{J}}$ Immunol 176(7): 4275-83. 
Chandler, J. and Axelrod, A. (1980). Conjunctiva-associated lymphoid tissue: a probable component of the mucosa-associated lymphoid system. Immunologic Diseases of the Mucous Membrane: Pathology, Diagnosis, and Treatment. G. O'Connor. NY, Masson Publisher: 63-70.

Cheng, K. H., Spanjaard, L., Rutten, H., Dankert, J., Polak, B. C. and Kijlstra, A. (1996). "Immunoglobulin A antibodies against Pseudomonas aeruginosa in the tear fluid of contact lens wearers." Invest Ophthalmol Vis Sci 37(10): 2081-8.

Childers, N. K., Denys, F. R., McGee, N. F. and Michalek, S. M. (1990). "Ultrastructural study of liposome uptake by $\mathrm{M}$ cells of rat Peyer's patch: an oral vaccine system for delivery of purified antigen." Reg Immunol 3(1): 8-16.

Chipman, D. M. and Sharon, N. (1969). "Mechanism of lysozyme action." Science 165(892): 454-65.

Chodosh, J., Nordquist, R. E. and Kennedy, R. C. (1998a). "Anatomy of mammalian conjunctival lymphoepithelium." Adv Exp Med Biol 438: 55765.

Chodosh, J., Nordquist, R. E. and Kennedy, R. C. (1998b). "Comparative anatomy of mammalian conjunctival lymphoid tissue: a putative mucosal immune site." Dev Comp Immunol 22(5-6): 621-630.

Chu, R. M., Glock, R. D. and Ross, R. F. (1979). "Gut-associated lymphoid tissues of young swine with emphasis on dome epithelium of aggregated lymph nodules (Peyer's patches) of the small intestine." Am J Vet Res 40(12): 1720-8.

Clark, M. A., Blair, H., Liang, L., Brey, R. N., Brayden, D. and Hirst, B. H. (2002). "Targeting polymerised liposome vaccine carriers to intestinal M cells." Vaccine 20(1-2): 208-217.

Clark, M. A., Hirst, B. H. and Jepson, M. A. (1998). "M-cell surface beta1 integrin expression and invasin-mediated targeting of Yersinia pseudotuberculosis to mouse Peyer's patch M cells." Infect Immun 66(3): 1237-43. 
Clark, M. A. and Jepson, M. A. (2003). "Intestinal M cells and their role in bacterial infection." Int. J. Med. Microbiol. 293(1): 17-39.

Clark, M. A., Jepson, M. A., Simmons, N. L., Booth, T. A. and Hirst, B. H. (1993). "Differential expression of lectin-binding sites defines mouse intestinal Mcells." J Histochem Cytochem 41(11): 1679-87.

Clark, M. A., Jepson, M. A., Simmons, N. L. and Hirst, B. H. (1994a). "Differential surface characteristics of $M$ cells from mouse intestinal Peyer's and caecal patches." Histochem J 26(3): 271-280.

Clark, M. A., Jepson, M. A., Simmons, N. L. and Hirst, B. H. (1994b). "Preferential interaction of Salmonella typhimurium with mouse Peyer's patch M cells." Res Microbiol 145(7): 543-52.

Clark, M. A., Jepson, M. A., Simmons, N. L. and Hirst, B. H. (1995). "Selective binding and transcytosis of Ulex europaeus 1 lectin by mouse Peyer's patch M-cells in vivo." Cell Tissue Res 282(3): 455-61.

Coleman, H. N., Daines, D. A., Jarisch, J. and Smith, A. L. (2003). "Chemically defined media for growth of Haemophilus influenzae strains." $\underline{\mathrm{J} \text { Clin }}$ Microbiol 41(9): 4408-10.

Connolly, J. L., Barton, E. S. and Dermody, T. S. (2001a). "Reovirus binding to cell surface sialic acid potentiates virus-induced apoptosis." J. Virol. 75(9): 4029-4039.

Cooper, M. D., Perey, D. Y., McKneally, M. F., Gabrielsen, A. E., Sutherland, D. E. and Good, R. A. (1966). "A mammalian equivalent of the avian bursa of Fabricius." Lancet 1(7452): 1388-91.

Coutinho, H. B., King, G., Sewell, H. F., Tighe, P., Coutinho, V. B., Robalinho, T. I. and Carvalho, A. B. (1993). "Immunocytochemical study of Peyer's patches follicular-associated epithelium in the marsupial, Didelphis albiventris." Dev Comp Immunol 17(6): 537-48.

Coyle, P. K. and Sibony, P. A. (1988). "Viral antibodies in normal tears." Invest Ophthalmol Vis Sci 29(10): 1552-8. 
de Aizpurua, H. J. and Russell-Jones, G. J. (1988). "Oral vaccination. Identification of classes of proteins that provoke an immune response upon oral feeding." J Exp Med 167(2): 440-51.

Dua, H. S., Gomes, J. A., Jindal, V. K., Appa, S. N., Schwarting, R., Eagle, R. C., Jr., Donoso, L. A. and Laibson, P. R. (1994). "Mucosa specific lymphocytes in the human conjunctiva, corneoscleral limbus and lacrimal gland." Curr Eye Res 13(1): 87-93.

Dwyer, R. S., Darougar, S. and Monnickendam, M. A. (1983). "Unusual features in the conjunctiva and cornea of the normal guinea-pig: clinical and histological studies." Br J Ophthalmol 67(11): 737-41.

Ecevit, I. Z., McCrea, K. W., Pettigrew, M. M., Sen, A., Marrs, C. F. and Gilsdorf, J. R. (2004). "Prevalence of the hifBC, hmw1A, hmw2A, hmwC, and hia Genes in Haemophilus influenzae Isolates." J Clin Microbiol 42(7): 306572.

Ermak, T. H., B. H. R. and J., P. (1994). "Lymphocyte compartments in antigensampling regions of rabbit mucosal lymphoid organs." American Journal of Tropical Medicine \& Hygiene. 50(5 Suppl): 14-28.

Ermak, T. H., S. H. J. and J., P. (1990). "Phenotypically distinct subpopulations of $\mathrm{T}$ cells in domes and M-cell pockets of rabbit gut-associated lymphoid tissues." Immunology. 71(4): 530-537.

Farstad, I. N., Halstensen, T. S., Fausa, O. and Brandtzaeg, P. (1994). "Heterogeneity of M-cell-associated B and T cells in human Peyer's patches." Immunology 83(3): 457-64.

Finzi, G., Cornaggia, M., Capella, C., Fiocca, R., Bosi, F., Solcia, E. and Samloff, I. M. (1993). "Cathepsin E in follicle associated epithelium of intestine and tonsils: localization to $\mathrm{M}$ cells and possible role in antigen processing." Histochemistry. 99(3): 201-11.

Fix, A. and Arp, L. (1989). "Conjunctiva-associated lymphoid tissue (CALT) in normal and Bordetella avium-infected turkeys." Veterinary Pathology. 1989 May;26(3):222-30. 
Fleischmann, R. D., Adams, M. D., White, O., Clayton, R. A., Kirkness, E. F., Kerlavage, A. R., Bult, C. J., Tomb, J. F., Dougherty, B. A., Merrick, J. M. and et al. (1995). "Whole-genome random sequencing and assembly of Haemophilus influenzae Rd." Science 269(5223): 496-512.

Fleiszig, S. M. and Efron, N. (1992). "Microbial flora in eyes of current and former

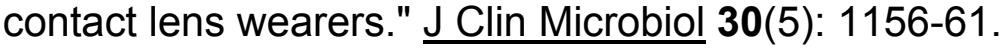

Ford, L. C., DeLange, R. J. and Petty, R. W. (1976). "Identification of a nonlysozymal bactericidal factor (beta lysin) in human tears and aqueous humor." Am J Ophthalmol 81(1): 30-3.

Fotopoulos, G., Harari, A., Michetti, P., Trono, D., Pantaleo, G. and Kraehenbuhl, J. P. (2002). "Transepithelial transport of HIV-1 by M cells is receptormediated." Proc Natl Acad Sci U S A 99(14): 9410-4.

Foxwell, A. R., Kyd, J. M. and Cripps, A. W. (1998). "Nontypeable Haemophilus influenzae: pathogenesis and prevention." Microbiol Mol Biol Rev 62(2): 294-308.

Frey, A., Giannasca, K. T., Weltzin, R., Giannasca, P. J., Reggio, H., Lencer, W. I. and Neutra, M. R. (1996). "Role of the glycocalyx in regulating access of microparticles to apical plasma membranes of intestinal epithelial cells: implications for microbial attachment and oral vaccine targeting." J Exp Med 184(3): 1045-59.

Frisch, E. B. and Phillips, T. E. (1990). "Lectin binding patterns to plasmalemmal glycoconjugates of goblet cells undergoing differentiation in vitro." J. Electron Microsc. Tech. 16(1): 25-36.

Fujimura, Y., Hosobe, M. and Kihara, T. (1992). "Ultrastructural study of M cells from colonic lymphoid nodules obtained by colonoscopic biopsy." Dig Dis Sci 37(7): 1089-98.

Fujimura, Y., Takeda, M., Ikai, H., Haruma, K., Akisada, T., Harada, T., Sakai, T. and Ohuchi, M. (2004). "The role of M cells of human nasopharyngeal lymphoid tissue in influenza virus sampling." Virchows Arch 444(1): 36-42.

Gambaryan, A. S., Tuzikov, A. B., Piskarev, V. E., Yamnikova, S. S., Lvov, D. K., Robertson, J. S., Bovin, N. V. and Matrosovich, M. N. (1997). 
"Specification of receptor-binding phenotypes of influenza virus isolates from different hosts using synthetic sialylglycopolymers: non-egg-adapted human $\mathrm{H} 1$ and $\mathrm{H} 3$ influenza $A$ and influenza $B$ viruses share a common high binding affinity for 6'-sialyl( $\mathrm{N}$-acetyllactosamine)." Virology 232(2): 345-350.

Gebert, A. (1995). "Identification of M-cells in the rabbit tonsil by vimentin immunohistochemistry and in vivo protein transport." Histochemistry \& Cell Biology 104(3): 211-220.

Gebert, A. (1996a). "M-cells in the rabbit tonsil exhibit distinctive glycoconjugates in their apical membranes." J. Histochem. Cytochem. 44(9): 1033-1042.

Gebert, A. (1997). "The role of M cells in the protection of mucosal membranes." Histochem. Cell Biol. 108(6): 455-470.

Gebert, A. and H., B. (1995a). "Ultrastructure and protein transport of M cells in the rabbit cecal patch." Anat Rec 241(4): 487-495.

Gebert, A. and Hach, G. (1992). "Vimentin antibodies stain membranous epithelial cells in the rabbit bronchus-associated lymphoid tissue (BALT)." Histochemistry 98(4): 271-273.

Gebert, A. and Hach, G. (1993). "Differential binding of lectins to M cells and enterocytes in the rabbit cecum." Gastroenterology 105(5): 1350-1361.

Gebert, A. and Pabst, R. (1999). "M cells at locations outside the gut." Semin Immunol 11(3): 165-170.

Gebert, A., Willfuhr, B. and Pabst, R. (1995b). "The rabbit M-cell marker vimentin is present in epithelial cells of the tonsil crypt." Acta Otolaryngol. 115(5): 697-700.

Giannasca, P. J., Boden, J. A. and Monath, T. P. (1997). "Targeted delivery of antigen to hamster nasal lymphoid tissue with M-cell-directed lectins." Infect. Immun. 65(10): 4288-4298.

Giannasca, P. J., Giannasca, K. T., Falk, P., Gordon, J. I. and Neutra, M. R. (1994a). "Regional differences in glycoconjugates of intestinal M cells in 
mice: potential targets for mucosal vaccines." Am. J. Physiol. 267(6 Pt 1): G1108-G1121.

Gillette, T. E., Chandler, J. W. and Greiner, J. V. (1982). "Langerhans cells of the ocular surface." Ophthalmology 89(6): 700-11.

Giuliano, E. A., Moore, C. P. and Phillips, T. E. (2002). "Morphological evidence of $\mathrm{M}$ cells in healthy canine conjunctiva-associated lymphoid tissue." Graefes Arch. Clin. Exp. Ophthalmol. 240(3): 220-226.

Grutzkau, A., Hanski, C., Hahn, H. and Riecken, E. O. (1990). "Involvement of M cells in the bacterial invasion of Peyer's patches: a common mechanism shared by Yersinia enterocolitica and other enteroinvasive bacteria." Gut 31(9): 1011-5.

Hall, J. M. and Pribnow, J. F. (1981). "Topical ocular immunization of rabbits." Invest Ophthalmol Vis Sci 21(5): 753-6.

Harokopakis, E., Childers, N. K., Michalek, S. M., Zhang, S. S. and Tomasi, M. (1995). "Conjugation of cholera toxin or its B subunit to liposomes for targeted delivery of antigens." $\mathrm{J}$ Immunol Methods 185(1): 31-42.

Haynes, R. J., Tighe, P. J., Scott, R. A. and Singh Dua, H. (1999). "Human conjunctiva contains high endothelial venules that express lymphocyte homing receptors." Exp Eye Res 69(4): 397-403.

Heesemann, J. and Laufs, R. (1983). "Construction of a mobilizable Yersinia enterocolitica virulence plasmid." J Bacteriol 155(2): 761-7.

Heggebo, R., Press, C. M., Gunnes, G., Lie, K. I., Tranulis, M. A., Ulvund, M., Groschup, M. H. and Landsverk, T. (2000). "Distribution of prion protein in the ileal Peyer's patch of scrapie-free lambs and lambs naturally and

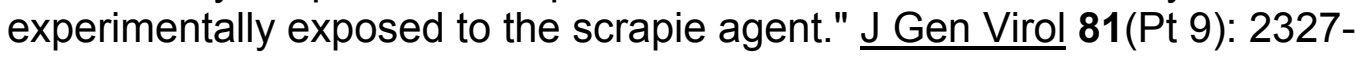
37.

Helander, A., Silvey, K. J., Mantis, N. J., Hutchings, A. B., Chandran, K., Lucas, W. T., Nibert, M. L. and Neutra, M. R. (2003). "The viral sigma1 protein and glycoconjugates containing alpha2-3-linked sialic acid are involved in type 1 reovirus adherence to M cell apical surfaces." J Virol 77(14): 79647977. 
Heppner, F. L., Christ, A. D., Klein, M. A., Prinz, M., Fried, M., Kraehenbuhl, J. P. and Aguzzi, A. (2001). "Transepithelial prion transport by M cells." Nat Med 7(9): 976-7.

Hingorani, M., Metz, D. and Lightman, S. L. (1997). "Characterisation of the normal conjunctival leukocyte population." Exp Eye Res 64(6): 905-12.

Hirmo, S., Artursson, E., Puu, G., Wadstrom, T. and Nilsson, B. (1998a). "Characterization of Helicobacter pylori interactions with sialylglycoconjugates using a resonant mirror biosensor." Anal Biochem 257(1): 63-66.

Holly, F. J. and Lemp, M. A. (1977). "Tear physiology and dry eyes." Surv Ophthalmol 22(2): 69-87.

Inman, L. R. and Cantey, J. R. (1983). "Specific adherence of Escherichia coli (strain RDEC-1) to membranous (M) cells of the Peyer's patch in Escherichia coli diarrhea in the rabbit." J Clin Invest 71(1): 1-8.

Iwasaki, A. and Kelsall, B. L. (1999). "Mucosal immunity and inflammation. I. Mucosal dendritic cells: their specialized role in initiating T cell responses." Am J Physiol 276(5 Pt 1): G1074-8.

Iwasaki, A. and Kelsall, B. L. (2001). "Unique functions of CD11b+, CD8 alpha+, and double-negative Peyer's patch dendritic cells." J Immunol 166(8): 4884-90.

Iwasaki, A., Welker, R., Mueller, S., Linehan, M., Nomoto, A. and Wimmer, E. (2002). "Immunofluorescence analysis of poliovirus receptor expression in Peyer's patches of humans, primates, and CD155 transgenic mice: implications for poliovirus infection." J Infect Dis 186(5): 585-92.

Jensen, O. L. and Gluud, B. S. (1985). "Bacterial growth in the conjunctival sac and the local defense of the outer eye." Acta Ophthalmol Suppl 173: 80-2.

Jensen, V. B., Harty, J. T. and Jones, B. D. (1998). "Interactions of the invasive pathogens Salmonella typhimurium, Listeria monocytogenes, and Shigella flexneri with M cells and murine Peyer's patches." Infect Immun 66(8): 3758-66. 
Jepson, M. A., , C. M. A., , S. N. L. and H., H. B. (1993a). "Epithelial M cells in the rabbit caecal lymphoid patch display distinctive surface characteristics." Histochemistry. 100(6): 441-7.

Jepson, M. A., Mason, C. M., Bennett, M. K., Simmons, N. L. and Hirst, B. H. (1992). "Co-expression of vimentin and cytokeratins in M cells of rabbit intestinal lymphoid follicle-associated epithelium." Histochem J 24(1): 339.

Jepson, M. A., Mason, C. M., Clark, M. A., Simmons, N. L. and Hirst, B. H. (1995). "Variations in lectin binding properties of intestinal M cells." Journal of Drug Targeting. 3(1): 75-77.

Jepson, M. A., Simmons, N. L., O'Hagan, D. T. and Hirst, B. H. (1993b). "Comparison of poly(DL-lactide-co-glycolide) and polystyrene microsphere targeting to intestinal M cells." J Drug Target 1(3): 245-249.

Jepson, M. A., Simmons, N. L., Savidge, T. C., James, P. S. and Hirst, B. H. (1993c). "Selective binding and transcytosis of latex microspheres by rabbit intestinal M cells." Cell Tissue Res. 271(3): 399-405.

Jepson, M. A., Simmons, NL, Hirst GL, Hirst BH (1993). "Identificaiton of M cells and their distribution in rabbit intestinal Peyer's patches and appendix." Cell Tissue Res 273: 127-136.

Jones, B. D., Ghori, N. and Falkow, S. (1994). "Salmonella typhimurium initiates murine infection by penetrating and destroying the specialized epithelial $\mathrm{M}$ cells of the Peyer's patches." J. Exp. Med. 180(1): 15-23.

Jones, L. T. (1973). "Anatomy of the tear system." Int Ophthalmol Clin 13(1): 322.

Kievits, F. and Kijlstra, A. (1985). "Inhibition of C3 deposition on solid-phase bound immune complexes by lactoferrin." Immunology 54(3): 449-56.

Kijlstra, A., Jeurissen, S. H. and Koning, K. M. (1983). "Lactoferrin levels in normal human tears." Br J Ophthalmol 67(3): 199-202. 
Knibbs, R. N., Goldstein, I. J., Ratcliffe, R. M. and Shibuya, N. (1991). "Characterization of the carbohydrate binding specificity of the leukoagglutinating lectin from Maackia amurensis. Comparison with other sialic acid-specific lectins." J. Biol. Chem. 266(1): 83-88.

Knop, E. and Knop, N. (1996). "MALT tissue of the conjuctiva and nasolacrimal system in the rabbit and human." Vis Res 36: S60.

Knop, E. and Knop, N. (2001). "Lacrimal drainage-associated lymphoid tissue (LDALT): a part of the human mucosal immune system." Invest Ophthalmol Vis Sci 42(3): 566-74.

Knop, E. and Knop, N. (2002a). "A functional unit for ocular surface immune defense formed by the lacrimal gland, conjunctiva and lacrimal drainage system." Adv. Exp. Med. Biol. 506(Pt B): 835-844.

Knop, E. and Knop, N. (2002b). "Human lacrimal drainage-associated lymphoid tissue (LDALT) belongs to the common mucosal immune system." Adv. Exp. Med. Biol. 506(Pt B): 861-866.

Knop, E. and Knop, N. (2007). "Anatomy and immunology of the ocular surface." Chem Immunol Allergy 92: 36-49.

Knop, N. and Knop, E. (2000). "Conjunctiva-associated lymphoid tissue in the human eye." Invest Ophthalmol Vis Sci 41(6): 1270-1279.

Korb, D. R., Craig, J., Doughty, M. J., Guillon, J., Smith, G. and Tomlinson, A. (2002). The tear film: structure, function, and clinical examination. Oxford ; Boston, Butterworth-Heinemann: BCLA.

Kracke, A., Hiller, A. S., Tschernig, T., Kasper, M., Kleemann, W. J., Troger, H. D. and Pabst, R. (1997). "Larynx-associated lymphoid tissue (LALT) in young children." Anat Rec 248(3): 413-20.

Kraehenbuhl, J. P. and Neutra, M. R. (2000). "Epithelial M cells: differentiation and function." Annu Rev Cell Dev Biol 16: 301-32. 
Landsverk, T. (1979). "The gastrointestinal mucosa in young milk-fed calves. A scanning electron and light microscopic investigation." Acta Vet Scand 20(4): 572-82.

Landsverk, T., Halleraker, M., Aleksandersen, M., McClure, S., Hein, W. and Nicander, L. (1991). "The intestinal habitat for organized lymphoid tissues in ruminants; comparative aspects of structure, function and development." Vet Immunol Immunopathol 28(1): 1-16.

Latkovic, S. (1979a). "The ultrastructure of the normal conjunctival epithelium of the guinea pig. III. The bulbar zone, the zone of the fornix and the supranodular zone." Acta Ophthalmol (Copenh) 57(2): 305-20.

Latkovic, S. (1979b). "The ultrastructure of the normal conjunctival epithelium of the guinea pig. IV. The palpebral and the perimarginal zones." Acta Ophthalmol (Copenh) 57(2): 321-35.

Latkovic, S. (1989). "Ultrastructure of M cells in the conjunctival epithelium of the guinea pig." Curr. Eye Res. 8(8): 751-755.

Latkovic, S. and Nilsson, S. (1984). "The phagocytic capability of the various zones of the guinea pig conjunctival epithelium: an electron microscopic study." Acta Ophthalmologica 62(3): 453-460.

Lelouard, H., Reggio, H., Roy, C., Sahuquet, A., Mangeat, P. and Montcourrier, P. (2001). "Glycocalyx on rabbit intestinal M cells displays carbohydrate epitopes from Muc2." Infection \& Immunity. 69(2): 1061-71.

Liebler, E. M., Paar, M. and Pohlenz, J. F. (1991). "M cells in the rectum of calves." Res Vet Sci 51(1): 107-14.

Liu, H., Meagher, C. K., Moore, C. P. and Phillips, T. E. (2005). "M cells in the follicle-associated epithelium of the rabbit conjunctiva preferentially bind and translocate latex beads." Invest Ophthalmol Vis Sci 46(11): 4217-23.

Lo, D., Tynan, W., Dickerson, J., Mendy, J., Chang, H. W., Scharf, M., Byrne, D., Brayden, D., Higgins, L., Evans, C. and O'Mahony, D. J. (2003). "Peptidoglycan recognition protein expression in mouse Peyer's Patch follicle associated epithelium suggests functional specialization." Cell Immunol 224(1): 8-16. 
Lowden, S. and Heath, T. (1995). "Lymphoid tissues of the ileum in young horses: distribution, structure, and epithelium." Anat Embryol (Berl) 192(2): 171-9.

Mantis, N. J., Cheung, M. C., Chintalacharuvu, K. R., Rey, J., Corthesy, B. and Neutra, M. R. (2002). "Selective adherence of IgA to murine Peyer's patch M cells: evidence for a novel IgA receptor." J Immunol 169(4): 1844-51.

Mantis, N. J., Frey, A. and Neutra, M. R. (2000). "Accessibility of glycolipid and oligosaccharide epitopes on rabbit villus and follicle-associated epithelium." American Journal of Physiology Gastrointestinal \& Liver Physiology. 278(6): G915-G923.

Marcial, M. A. and Madara, J. L. (1986). "Cryptosporidium: cellular localization, structural analysis of absorptive cell-parasite membrane-membrane interactions in guinea pigs, and suggestion of protozoan transport by $\mathrm{M}$ cells." Gastroenterology 90(3): 583-94.

McClellan, K. A. (1997). "Mucosal defense of the outer eye." Surv Ophthalmol 42(3): 233-46.

McClellan, K. A., Cripps, A. W., Clancy, R. L. and Billson, F. A. (1998). "The effect of successful contact lens wear on mucosal immunity of the eye." Ophthalmology 105(8): 1471-7.

McDermott, M. R. and Bienenstock, J. (1979). "Evidence for a common mucosal immunologic system. I. Migration of B immunoblasts into intestinal, respiratory, and genital tissues." J Immunol 122(5): 1892-8.

McDermott, M. R., Clark, D. A. and Bienenstock, J. (1980). "Evidence for a common mucosal immunologic system. II. Influence of the estrous cycle on B immunoblast migration into genital and intestinal tissues." $\underline{\mathrm{J} \text { Immunol }}$ 124(6): 2536-9.

Mclntosh, R. S., Cade, J. E., Al-Abed, M., Shanmuganathan, V., Gupta, R., Bhan, A., Tighe, P. J. and Dua, H. S. (2005). "The spectrum of antimicrobial peptide expression at the ocular surface." Invest Ophthalmol Vis Sci 46(4): 1379-85. 
McMaster, P. R., Aronson, S. B. and Bedford, M. J. (1967). "Mechanisms of the host response in the eye. IV. The anterior eye in germ-free animals." Arch Ophthalmol 77(3): 392-399.

Meagher, C. K., Liu, H., Moore, C. P. and Phillips, T. E. (2005). "Conjunctival M cells selectively bind and translocate Maackia amurensis leukoagglutinin." Exp Eye Res 80(4): 545-53.

Mestecky, J. (1987). "The common mucosal immune system and current strategies for induction of immune responses in external secretions." $\underline{\mathrm{J}}$ Clin Immunol 7(4): 265-76.

Mestecky, J., McGhee, J. R., Michalek, S. M., Arnold, R. R., Crago, S. S. and Babb, J. L. (1978). "Concept of the local and common mucosal immune response." Adv Exp Med Biol 107: 185-92.

Mishima, S. and Maurice, D. M. (1961). "The oily layer of the tear film and evaporation from the corneal surface." Exp Eye Res 1: 39-45.

Montgomery, P. C., Majumdar, A. S., Skandera, C. A. and Rockey, J. H. (1984). "The effect of immunization route and sequence of stimulation on the induction of IgA antibodies in tears." Curr Eye Res 3(6): 861-5.

Moore, C. P., Wilsman, N. J., Nordheim, E. V., Majors, L. J. and Collier, L. L. (1987). "Density and distribution of canine conjunctival goblet cells." Invest Ophthalmol Vis Sci 28(12): 1925-1932.

Morfitt, D. C. and Pohlenz, J. F. (1989). "Porcine colonic lymphoglandular complex: distribution, structure, and epithelium." Am J Anat 184(1): 41-51.

Morin, M. J., Warner, A. and Fields, B. N. (1994). "A pathway for entry of retroviruses into the host through $M$ cells of the respiratory tract." $\underline{J}$ Exp Med 180(4): 1523-7.

Mounier, J., Vasselon, T., Hellio, R., Lesourd, M. and Sansonetti, P. J. (1992). "Shigella flexneri enters human colonic Caco-2 epithelial cells through the basolateral pole." Infect Immun 60(1): 237-48. 
Murphy, T. F. and Apicella, M. A. (1987). "Nontypable Haemophilus influenzae: a review of clinical aspects, surface antigens, and the human immune response to infection." Rev Infect Dis 9(1): 1-15.

Nair, P. N. and Schroeder, H. E. (1986). "Duct-associated lymphoid tissue (DALT) of minor salivary glands and mucosal immunity." Immunology 57(2): 171-80.

Neutra, M. R., Frey, A. and Kraehenbuhl, J. P. (1996a). "Epithelial M cells: gateways for mucosal infection and immunization." Cell 86(3): 345-8.

Neutra, M. R., Giannasca, P. J., Gianasca, K. T. and Kraehenbuhl, J. P. (1995). "M cells and microbial pathogens." Infections of the gastrointestinal tract. M. J. Blaser, P. D. Smith, J. I. Ravdin, H. B. Greenberg and R. L. Guerrant. New York, Raven Press: 163-178.

Neutra, M. R., Mantis, N. J. and Kraehenbuhl, J. P. (2001). "Collaboration of epithelial cells with organized mucosal lymphoid tissues." Nat Immunol 2(11): 1004-9.

Neutra, M. R., Phillips, T. L., Mayer, E. L. and Fishkind, D. J. (1987). "Transport of membrane-bound macromolecules by $\mathrm{M}$ cells in follicle-associated epithelium of rabbit Peyer's patch." Cell Tissue Res. 247(3): 537-546.

Neutra, M. R., Pringault, E. and Kraehenbuhl, J. P. (1996b). "Antigen sampling across epithelial barriers and induction of mucosal immune responses." Annu. Rev. Immunol. 14: 275-300.

Nichols, B., Chiappino, M. and Dawson, C. (1985). "Demonstration of the mucous layer of the tear film by electron microscopy." Investigative Ophthalmology \& Visual Science. 1985 Apr;26(4):464-73.

Nichols, B., Dawson, C. and Togni, B. (1983). "Surface features of the conjunctiva and cornea." Investigative Ophthalmology \& Visual Science. 1983 May;24(5):570-6.

Nichols, B. A. (1996). "Conjunctiva." Microsc Res Tech 33(4): 296-319. 
Nichols, R. L., Murray, E. S. and Nisson, P. E. (1978). "Use of enteric vaccines in protection against chlamydial infections of the genital tract and the eye of guinea pigs." $\mathrm{J}$ Infect Dis 138(6): 742-6.

Ofek, I. and Sharon, N. (1988). "Lectinophagocytosis: a molecular mechanism of recognition between cell surface sugars and lectins in the phagocytosis of bacteria." Infect. Immun. 56(3): 539-547.

Osterlind, G. (1944). "An investigation into the presence of lymphatic tissue in the human conjunctiva, and its biological and clinical importance." Acta Ophthalmol. 23: 1-79.

Ouzilou, L., Caliot, E., Pelletier, I., Prevost, M. C., Pringault, E. and ColbereGarapin, F. (2002). "Poliovirus transcytosis through M-like cells." J Gen Virol 83(Pt 9): 2177-82.

Owen, R. L. (1977). "Sequential uptake of horseradish peroxidase by lymphoid follicle epithelium of Peyer's patches in the normal unobstructed mouse intestine: an ultrastructural study." Gastroenterology 72(3): 440-51.

Owen, R. L., Apple, R. T. and Bhalla, D. K. (1986a). "Morphometric and cytochemical analysis of lysosomes in rat Peyer's patch follicle epithelium: their reduction in volume fraction and acid phosphatase content in $\mathrm{M}$ cells compared to adjacent enterocytes." Anat Rec 216(4): 521-7.

Owen, R. L. and Bhalla, D. K. (1983). "Cytochemical analysis of alkaline phosphatase and esterase activities and of lectin-binding and anionic sites in rat and mouse Peyer's patch M cells." Am J Anat 168(2): 199-212.

Owen, R. L. and Ermak, T. H. (1990). "Structural specializations for antigen uptake and processing in the digestive tract." Springer Semin Immunopathol 12(2-3): 139-52.

Owen, R. L. and Jones, A. L. (1974a). "Epithelial cell specialization within human Peyer's patches: an ultrastructural study of intestinal lymphoid follicles." Gastroenterology 66(2): 189-203.

Owen, R. L. and Jones, A. L. (1974b). "Specialized lymphoid follicle epithelial cells in the human and nonhuman primate: A possible antigen uptake site." Scanning Electron Microscopy. III: 697-704. 
Owen, R. L., Nemanic, P. C. and Stevens, D. P. (1979). "Ultrastructural observations on giardiasis in a murine model. I. Intestinal distribution, attachment, and relationship to the immune system of Giardia muris." Gastroenterology 76(4): 757-69.

Owen, R. L., Nemanic, P. (1978). "Antigen Processing Structures of the Mammalian Intestinal Tract: An SEM Study of Lymphoepithelial Organs." Scanning Electron Microscopy. II: 367-378.

Owen, R. L., Pierce, N. F., Apple, R. T. and Cray, W. C., Jr. (1986b). "M cell transport of Vibrio cholerae from the intestinal lumen into Peyer's patches: a mechanism for antigen sampling and for microbial transepithelial

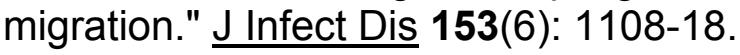

Pappo, J. (1989). "Generation and characterization of monoclonal antibodies recognizing follicle epithelial $\mathrm{M}$ cells in rabbit gut-associated lymphoid tissues." Cell Immunol 120(1): 31-41.

Pappo, J. and Ermak, T. H. (1989). "Uptake and translocation of fluorescent latex particles by rabbit Peyer's patch follicle epithelium: a quantitative model for M cell uptake." Clin Exp Immunol 76(1): 144-148.

Park, H. S., Francis, K. P., Yu, J. and Cleary, P. P. (2003). "Membranous cells in nasal-associated lymphoid tissue: a portal of entry for the respiratory mucosal pathogen group A streptococcus." J Immunol 171(5): 2532-7.

Pascopella, L., Raupach, B., Ghori, N., Monack, D., Falkow, S. and Small, P. L. (1995). "Host restriction phenotypes of Salmonella typhi and Salmonella gallinarum." Infect Immun 63(11): 4329-35.

Peppard, J. V., Mann, R. V. and Montgomery, P. C. (1988). "Antibody production in rats following ocular-topical or gastrointestinal immunization: kinetics of local and systemic antibody production." Curr Eye Res 7(5): 471-81.

Perkins, R. E., Kundsin, R. B., Pratt, M. V., Abrahamsen, I. and Leibowitz, H. M. (1975). "Bacteriology of normal and infected conjunctiva." $\underline{J}$ Clin Microbiol 1(2): 147-9.

Petris, C. K., Golomb, M. and Phillips, T. E. (2007). "Bacterial transcytosis across conjunctival M cells." Invest Ophthalmol Vis Sci 48(5): 2172-2177. 
Phillips, A. D., Navabpour, S., Hicks, S., Dougan, G., Wallis, T. and Frankel, G. (2000). "Enterohaemorrhagic Escherichia coli O157:H7 target Peyer's patches in humans and cause attaching/effacing lesions in both human and bovine intestine." Gut 47(3): 377-81.

Prinz, M., Huber, G., Macpherson, A. J., Heppner, F. L., Glatzel, M., Eugster, H. P., Wagner, N. and Aguzzi, A. (2003). "Oral prion infection requires normal numbers of Peyer's patches but not of enteric lymphocytes." Am. J. Pathol. 162(4): 1103-1111.

Roberts, D. D., Olson, L. D., Barile, M. F., Ginsburg, V. and Krivan, H. C. (1989a). "Sialic acid-dependent adhesion of Mycoplasma pneumoniae to purified glycoproteins." J. Biol. Chem. 264(16): 9289-9293.

Roberts, D. D., Olson, L. D., Barile, M. F., Ginsburg, V. and Krivan, H. C. (1989b). "Sialic acid-dependent adhesion of Mycoplasma pneumoniae to purified glycoproteins." J Biol Chem 264(16): 9289-9293.

Roy, M. J. (1987). "Precocious development of lectin (Ulex europaeus agglutinin I) receptors in dome epithelium of gut-associated lymphoid tissues." Cell Tissue Res. 248(3): 483-489.

Roy, M. J. and Varvayanis, M. (1987). "Development of dome epithelium in gutassociated lymphoid tissues: association of IgA with M cells." Cell Tissue Res 248(3): 645-51.

Russell, M. W. and Kilian, M. (2005). Biological activites of IgA. Mucosal immunology. J. Mestecky, J. Bienenstock, M. E. Lammet al. Boston, Elsevier Academic Press. 3rd.

Sack, R. A., Conradi, L., Krumholz, D., Beaton, A., Sathe, S. and Morris, C. (2005). "Membrane array characterization of 80 chemokines, cytokines, and growth factors in open- and closed-eye tears: angiogenin and other defense system constituents." Invest Ophthalmol Vis Sci 46(4): 1228-38.

Sacks, E. H., Wieczorek, R., Jakobiec, F. A. and Knowles, D. M., 2nd (1986).

"Lymphocytic subpopulations in the normal human conjunctiva. A monoclonal antibody study." Ophthalmology 93(10): 1276-83. 
Sankaridurg, P. R., Willcox, M. D., Sharma, S., Gopinathan, U., Janakiraman, D., Hickson, S., Vuppala, N., Sweeney, D. F., Rao, G. N. and Holden, B. A. (1996). "Haemophilus influenzae adherent to contact lenses associated with production of acute ocular inflammation." $\mathrm{J}$ Clin Microbiol 34(10): 2426-31.

Sansonetti, P. J., Arondel, J., Cantey, J. R., Prevost, M. C. and Huerre, M. (1996). "Infection of rabbit Peyer's patches by Shigella flexneri: effect of adhesive or invasive bacterial phenotypes on follicle-associated epithelium." Infect Immun 64(7): 2752-64.

Sansonetti, P. J. and Phalipon, A. (1999). "M cells as ports of entry for enteroinvasive pathogens: mechanisms of interaction, consequences for the disease process." Semin Immunol 11(3): 193-203.

Sereny, B. (1957). "Experimental keratoconjunctivitis shigellosa." Acta Microbiol Acad Sci Hung 4: 367-376.

Setzer, P. Y., Nichols, B. A. and Dawson, C. R. (1987). "Unusual structure of rat conjunctival epithelium. Light and electron microscopy." Invest Ophthalmol Vis Sci 28(3): 531-7.

Shalaby, W. S. (1995). "Development of oral vaccines to stimulate mucosal and systemic immunity: barriers and novel strategies." Clin Immunol Immunopathol 74(2): 127-34.

Sharma, R., van Damme, E. J., Peumans, W. J., Sarsfield, P. and Schumacher, U. (1996). "Lectin binding reveals divergent carbohydrate expression in human and mouse Peyer's patches." Histochem Cell Biol 105(6): 459-65.

Sharon, N. (1987). "Bacterial lectins, cell-cell recognition and infectious disease." FEBS Lett 217(2): 145-57.

Shau, H., Kim, A. and Golub, S. H. (1992). "Modulation of natural killer and lymphokine-activated killer cell cytotoxicity by lactoferrin." J Leukoc Biol 51(4): 343-9.

Shimosato, T., Tohno, M., Kitazawa, H., Katoh, S., Watanabe, K., Kawai, Y., Aso, H., Yamaguchi, T. and Saito, T. (2005). "Toll-like receptor 9 is 
expressed on follicle-associated epithelia containing $M$ cells in swine Peyer's patches." Immunol Lett 98(1): 83-9.

Shmakov, A. N., Bode, J., Kilshaw, P. J. and Ghosh, S. (2000). "Diverse patterns of expression of the 67-kD laminin receptor in human small intestinal mucosa: potential binding sites for prion proteins?" J Pathol 191(3): 31822.

Sicinski, P., Rowinski, J., Warchol, J. B., Jarzabek, Z., Gut, W., Szczygiel, B., Bielecki, K. and Koch, G. (1990). "Poliovirus type 1 enters the human host through intestinal M cells." Gastroenterology 98(1): 56-8.

Sigurethardottir, O. G., Valheim, M. and Press, C. M. (2004). "Establishment of Mycobacterium avium subsp. paratuberculosis infection in the intestine of ruminants." Adv Drug Deliv Rev 56(6): 819-34.

Silvey, K. J., Hutchings, A. B., Vajdy, M., Petzke, M. M. and Neutra, M. R. (2001). "Role of immunoglobulin A in protection against reovirus entry into Murine Peyer's patches." J Virol 75(22): 10870-9.

Skoczynska, A., Kadlubowski, M., Empel, J. and Hryniewicz, W. (2005). "Characteristics of Haemophilus influenzae type $b$ responsible for

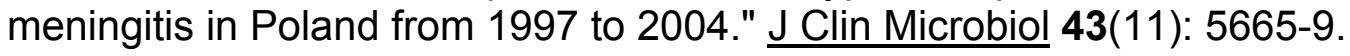

Smith, A. L., Smith, D. H., Averill, D. R. J., Marino, J. and Moxon, E. R. (1973). "Production of Haemophilus influenzae b meningitis in infant rats by intraperitoneal injection." Infect Immun 8: 270-290.

Smith, M. W., James, P. S., Tivey, D. R. and Brown, D. (1988). "Automated histochemical analysis of cell populations in the intact follicle-associated epithelium of the mouse Peyer's patch." Histochem J 20(8): 443-8.

Spit, B. J., Hendriksen, E. G., Bruijntjes, J. P. and Kuper, C. F. (1989a). "Nasal lymphoid tissue in the rat." Cell Tissue Res. 255(1): 193-198.

Spit, B. J., Hendriksen, E. G., Bruijntjes, J. P. and Kuper, C. F. (1989b). "Nasal lymphoid tissue in the rat." Cell Tissue Res 255(1): 193-198. 
St Geme, J. W., 3rd (1994). "The HMW1 adhesin of nontypeable Haemophilus influenzae recognizes sialylated glycoprotein receptors on cultured human epithelial cells." Infect Immun 62(9): 3881-9.

St Geme, J. W., 3rd, Kumar, V. V., Cutter, D. and Barenkamp, S. J. (1998). "Prevalence and distribution of the hmw and hia genes and the HMW and Hia adhesins among genetically diverse strains of nontypeable Haemophilus influenzae." Infect Immun 66(1): 364-8.

Steuhl, K. P. (1989). Ultrastructure of the conjunctival epithelium. Dev Ophthalmol. W. Straub. 19: 1-104.

Stock, E. L., Hill, R. A., Boyle-Vavra, S. and Roth, S. I. (1989). "Eosinophils and mast cell homogeneity of the guinea pig eyelid skin, conjunctiva, and ileum." Am J Anat 186(4): 359-68.

Stock, E. L., Sobut, R. A. and Roth, S. I. (1987). "The uptake of horseradish peroxidase by the conjunctival epithelium of the guinea-pig." Exp. Eye. Res. 45(2): 327-337.

Sullivan, D. A. (1999). Ocular mucosal immunity. Mucosal Immunology. P. L. Orgra. San Diego, Academic Press: 1241-1282.

Sullivan, D. A. and Allansmith, M. R. (1984). "Source of IgA in tears of rats." Immunology 53(4): 791-9.

Takskusaki, I. (1969). "Fine structure of the human palpebral conjunctiva with special reference to the pathological changes in vernal conjunctivitis." Arch Histol Jpn 30: 247-282.

Taylor, H. R., Pierce, N. F., Schacter, J., Pu, Z., Silverstein, A. M. and Prendergast, R. A. (1985). "Secretory immune cellular traffic between the gut and the eye." Advances in immunology and immunopathology of the eye. G. R. O'Connor and J. W. Chandler. New York, N.Y., Masson Pub.: 208-211.

Thiel, H. J. and Schumacher, U. (1994). "[Normal flora of the human conjunctiva: examination of 135 persons of various ages]." Klin Monatsbl Augenheilkd 205(6): 348-57. 
Tohno, M., Shimosato, T., Kitazawa, H., Katoh, S., lliev, I. D., Kimura, T., Kawai, Y., Watanabe, K., Aso, H., Yamaguchi, T. and Saito, T. (2005). "Toll-like receptor 2 is expressed on the intestinal M cells in swine." Biochem Biophys Res Commun 330(2): 547-54.

Torres-Medina, A. (1981). "Morphologic characteristics of the epithelial surface of aggregated lymphoid follicles (Peyer's patches) in the small intestine of newborn gnotobiotic calves and pigs." Am J Vet Res 42(2): 232-6.

Tyrer, P., Foxwell, A. R., Cripps, A. W., Apicella, M. A. and Kyd, J. M. (2006). "Microbial pattern recognition receptors mediate M-cell uptake of a gramnegative bacterium." Infect Immun 74(1): 625-31.

Tyrer, P. C., Ruth Foxwell, A., Kyd, J. M., Otczyk, D. C. and Cripps, A. W. (2007). "Receptor mediated targeting of M-cells." Vaccine 25(16): 3204-9.

Varadhachary, A., Wolf, J. S., Petrak, K., O'Malley, B. W., Jr., Spadaro, M., Curcio, C., Forni, G. and Pericle, F. (2004). "Oral lactoferrin inhibits growth of established tumors and potentiates conventional chemotherapy." Int J Cancer 111(3): 398-403.

Von Moll, L. K. and R., C. J. (1997). "Peyer's patch adherence of enteropathogenic Escherichia coli strains in rabbits." Infection \& Immunity 65(9): 3788-3793.

Walker, R. I., Schmauder-Chock, E. A., Parker, J. L. and Burr, D. (1988). "Selective association and transport of Campylobacter jejuni through $\mathrm{M}$ cells of rabbit Peyer's patches." Can J Microbiol 34(10): 1142-7.

Wassef, J. S., Keren, D. F. and Mailloux, J. L. (1989). "Role of M cells in initial antigen uptake and in ulcer formation in the rabbit intestinal loop model of shigellosis." Infect Immun 57(3): 858-63.

Weisz-Carrington, P., Roux, M. E., McWilliams, M., JM, P. H.-Q. and Lamm, M. E. (1979). "Organ and isotype distribution of plasma cells producing specific antibody after oral immunization: evidence for a generalized secretory immune system." J Immunol 123(4): 1705-8.

Weltzin, R., Lucia-Jandris, P., Michetti, P., Fields, B. N., Kraehenbuhl, J. P. and Neutra, M. R. (1989). "Binding and transepithelial transport of 
immunoglobulins by intestinal $\mathrm{M}$ cells: demonstration using monoclonal IgA antibodies against enteric viral proteins." J Cell Biol 108(5): 1673-85.

Williams, B. J., Morlin, G., Valentine, N. and Smith, A. L. (2001). "Serum resistance in an invasive, nontypeable Haemophilus influenzae strain." Infect Immun 69(2): 695-705.

Willingham, M. C. and Rutherford, A. V. (1984). "The use of osmiumthiocarbohydrazide-osmium (OTO) and ferrocyanide-reduced osmium methods to enhance membrane contrast and preservation in cultured cells." J Histochem Cytochem 32(4): 455-60.

Wolf, J. L., Rubin, D. H., Finberg, R., Kauffman, R. S., Sharpe, A. H., Trier, J. S. and Fields, B. N. (1981). "Intestinal M cells: a pathway for entry of reovirus into the host." Science 212(4493): 471-472.

Wotherspoon, A., Hardman-Lea, S. and Isaacson, P. (1994). "Mucosaassociated lymphoid tissue (MALT) in the human conjunctiva." J Pathol 174(1): 33-37.

Wu, Y., Wang, X., Csencsits, K. L., Haddad, A., Walters, N. and Pascual, D. W. (2001). "M cell-targeted DNA vaccination." Proc. Natl. Acad. Sci. USA 98(16): 9318-9323.

Yamamoto, K., Konami, Y. and Irimura, T. (1997). "Sialic acid-binding motif of Maackia amurensis lectins." J. Biochem. (Tokyo) 121(4): 756-761.

Yamanaka, T., Straumfors, A., Morton, H., Fausa, O., Brandtzaeg, P. and Farstad, I. (2001). "M cell pockets of human Peyer's patches are specialized extensions of germinal centers." Eur J Immunol 31(1): 107-17.

Zierhut, M., Elson, C. O., Forrester, J. V., Kijlstra, A., Kraehenbuhl, J. P. and Sullivan, D. A. (1998). "Mucosal immunology and the eye." Immunol Today 19(4): 148-150. 


\section{VITA}

Carisa Kay Meagher was born on June $24^{\text {th }}, 1979$ at Eglin Air Force Base near Fort Walton Beach, Florida. Carisa and her younger sister Anna were born to David and Colette Meagher. Carisa's adventurous sprit is due in part to her early years of travel with her family both domestically and abroad when her father worked for the Honeywell and later Boeing. Carisa graduated second in her class from Wentzville High School in 1998 and became an MU freshman in the fall of the same year majoring in biology/pre-med. She earned her B.S. in 2002 graduating with honors. Carisa became interested in the research of Tom Phillips as an undergraduate student in his histology class, and in 2002 joined his lab as Ph.D. student in the Biology graduate program. Carisa married Michael Petris, a faculty member in the Biochemistry department in September 2005 in her home town of Lake St. Louis, Missouri. In the same year, Carisa began a medical degree at $\mathrm{MU}$ where she is currently entering her $3^{\text {rd }}$ year rotations. Her long-term goals are to combine cell biological research with her chosen field of medicine. 